\title{
Frequency Domain Transfer Function Identification Using the Computer Program Si'SFIT
}

D. I. Trudnowski

December 1992

Prepared for

the Bonneville Power Administration under a Related Services Agreement with the U.S. Department of Energy

Contract DE-AC06-76RLO 1830

Pacific Northwest Laboratory Operated for the U.S. Department of Energy by Battelle Memorial Institute 


\title{
DISCLAIMER
}

This report was prepared as an account of work sponsored by an agency of the United States Goverrment. Neither the United States Government nor any agency thereof, nor Battelle Memorial Institute, nor any of their employees, makes any warranty, expressed or implied, or assumes any legal liability or responsibility for the accuracy, completeness, or usefulness of any information, apparatus, product, or process disclosed, or represents that its use would not infringe privately owned rights. Reference herein to any specific commercial product, process, or service by trade name, trademark, manufacturer, or otherwise does not necessarily constitute or imply its endorsement, recommendation, or favoring by the United States Government or any agency thereof, or Battelle Memorial Institute. The views and opinions of authors expressed herein do not necessarily state or reflect those of the United States Government or any agency thereof.

\author{
PACIFIC NORTHWEST LABCRATORY \\ operated by \\ BATTELLE MEMORIAL INSTITUTE \\ for the \\ UNITED STATES DEPARTMENT OF ENERGY \\ under Contract DE-ACO6-76RLO 1830
}

Printed in the United States of America

Available to DOE and DOE contractors from the

Office of Scientific and Technical Information, P.O. Box 62, Oak Ridge, TN 37831;

prices available from (615) 576-8401. FTS 626-8401.

Available to the public from the National Technical Information Service,

U.S. Department of Commerce, 5285 Port Royal Rd., Springfield, VA 22161. 


\title{
Frequency Domain
}

\section{Transfer Function Identification}

\section{Using the Computer Program SYSFIT}

\author{
D. J. Trudnowski
}

December 1992

\begin{abstract}
Prepared for
the Bonneville Power Administration under a Related Services Agreement with the U.S. Department of Energy Contract DE-AC06-76RLO 1830
\end{abstract}

Pacific Northwest Laboratory Richland, Washington 99352 


\section{Summary}

Pacific Northwest Laboratory (PNL) conducted this study for the Bonneville Power Administration (BPA). The purposes of the study were to investigate the characteristics of fitting linear dynamic models to a system's frequency response using optimization search techniques and to develop general "rules-of-thumb" for conducting such analyses.

Problems often encountered in engineering and science require the mathematical modeling of a physical system's dynamic characteristics. There are two basic approaches to dynamically modeling a system: 1) model the system using theoretical derivations, or 2) use a curve-fitting technique to optimally fit a linear model to specified system response data. With the second option, one can fit a model to the time-domain or the frequency-domain response of the system. The objective of this study was to investigate the characteristics of fitting linear models to system frequency-response data under controlled conditions using algorithms available in the BPA computer program called SYSFIT. The conditions studied include fitting algorithms and options; parent system configurations; underlying noise characteristics; and different Fourier transformation techniques. Many general "rules of thumb" for fitting under these conditions were drawn from the testing results.

Because the primary application of SYSFIT for BPA involves studying oower system dynamics, this investigation was geared toward simulating the effects that might be en.ountered in studying electromechanical oscillations in power systems. Electromechanical oscillations typically occur in the $0.1-\mathrm{Hz}$ to $2.0-\mathrm{Hz}$ range. For this reason, the example systems used to investigate the characteristics of frequency domain-fitting consist of multiple modes between $0.1 \mathrm{~Hz}$ and $2.0 \mathrm{~Hz}$. Although the intended focus of this work is power system oscillations, the studies are sufficiently generic that the results can be applied to many types of oscillatory systems with closely-spaced modes (including flexible mechanical structures and manipulators).

In general, there are two possible ways of solving the optimization problem. One is to use a leastsquares optimization function and to write the system in such a form that the problem becomes one of linear least-squares. The solution can then be obtained using a standard least-squares technique. The other method involves using a search method to obtain the optimal model. This method allows considerably more freedom in forming the optimization function and model, but it requires an initial guess of the system parameters. SYSFIT employs this second approach.

Detailed investigations were conducted into three main areas: 1) fitting to exact frequency response data of a linear system; 2) fitting to the discrete Fourier transformation (DFT) of noisy data; and 3) fitting to multi-path systems. The first area consisted of investigating the effects of alternative optimization cost function options; using different optimization search methods; incorrect model order; missing response data; closely-spaced poles; and closely-spaced pole-zero pairs. Within the second area, different noise colorations and levels were studied. In the third area, methods were investigated for improving fitting results by incorporating more than one system path.

The following is a list of guidelines and properties developed from the study for fitting a transfer function to the frequency response of a system using optimization search methods. 
- In forming the optimization cost function: 1) represent the system gain using log-magnitude data; 2) if phase data is used, equally penalize gain and phase contributions to the initial cost function; and 3) the initial cost function should approximately be 100 .

- Use of both gain and phase data in the optimization cost function can improve fitting results under many conditions, such as 1) closely-spaced poles, 2) missing low- or high-frequency data, and 3) nonminimum phase characteristics.

- Of the search options available in SYSFIT, use the DFP method first as it often converges with the least number of iterations.

- In estimating the model order, it is better to over-estimate which often results in near pole/zero cancellations for the extra terms.

- In fitting to systems with closely-spaced poles, expect the identified closely-spaced terms to have relatively larger errors.

- In fitting to the DFT of impulse response data, be aware of the following: 1) if a windowing scheme is used with the DFT (such as hanning), false damping will be introduced into the system poles, an alternative is to use the folding DFT discussed in the report; 2) if too long of a data record is used, noise can begin to dominate the response and cause poor fitting; 3 ) if too short of a data record is used, the resolution of the DFT data is too poor Sor accurate fits; 4) in general, noise levels with a SNR of $20 \mathrm{db}$ or greater allow for accurate fitting to dominate system poles; and 5) highly-colored noise can cause significant errors in the bandwidth of the noise.

- Successful convergence to the proper solution is highly dependent on the initial model. 


\section{Contents}

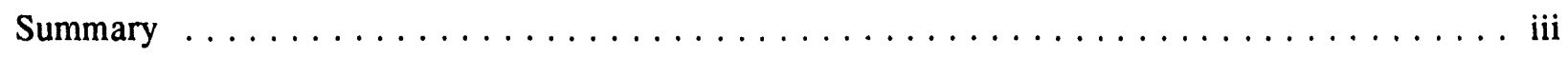

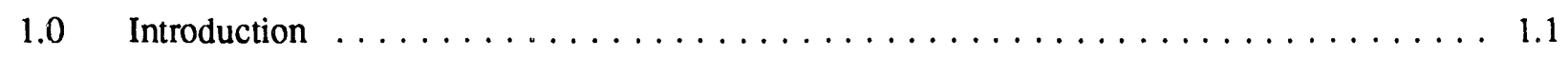

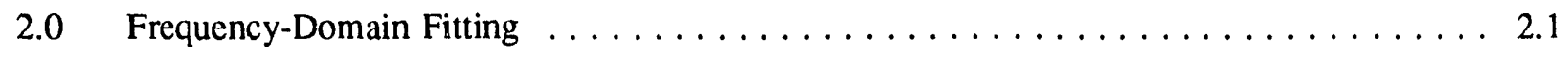

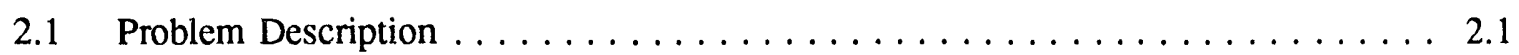

$2.2 \quad$ Literature Review $\ldots \ldots \ldots \ldots \ldots \ldots \ldots \ldots \ldots \ldots \ldots \ldots \ldots \ldots \ldots \ldots \ldots \ldots$

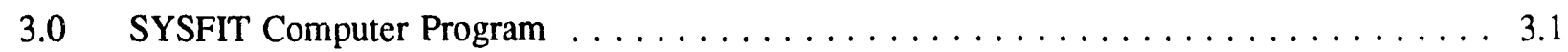

3.1 Program Description $\ldots \ldots \ldots \ldots \ldots \ldots \ldots \ldots \ldots \ldots \ldots \ldots \ldots \ldots \ldots \ldots \ldots \ldots$

3.2 Porting SYSFIT to a SUN Platform $\ldots \ldots \ldots \ldots \ldots \ldots \ldots \ldots \ldots \ldots \ldots \ldots$

4.0 Example Systems and MATLAB Interfaces $\ldots \ldots \ldots \ldots \ldots \ldots \ldots \ldots \ldots \ldots \ldots \ldots \ldots \ldots \ldots .1$

4.1 Interfacing with MATLAB $\ldots \ldots \ldots \ldots \ldots \ldots \ldots \ldots \ldots \ldots \ldots \ldots \ldots \ldots \ldots \ldots \ldots$

4.2 Example Systems $\ldots \ldots \ldots \ldots \ldots \ldots \ldots \ldots \ldots \ldots \ldots \ldots \ldots .1$

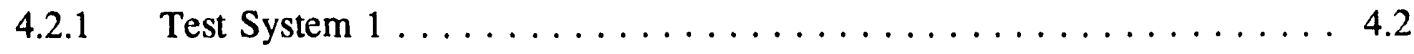

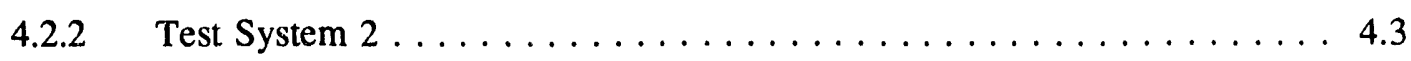

$4.2 .3 \quad$ Test System $3 \ldots \ldots \ldots \ldots \ldots \ldots \ldots \ldots \ldots \ldots \ldots \ldots \ldots \ldots$

4.3 Discrete Fourier Transformation Methods $\ldots \ldots \ldots \ldots \ldots \ldots \ldots \ldots .7$

4.4 Noise Models $\ldots \ldots \ldots \ldots \ldots \ldots \ldots \ldots \ldots \ldots \ldots \ldots \ldots . .4$

$5.0 \quad$ Properties of Frequency-Domain Fitting $\ldots \ldots \ldots \ldots \ldots \ldots \ldots \ldots \ldots \ldots \ldots \ldots \ldots \ldots \ldots$

5.1 Fitting to Exact Frequency Response Data $\ldots \ldots \ldots \ldots \ldots \ldots \ldots \ldots \ldots \ldots \ldots$

5.1 Different Optimization Routines $\ldots \ldots \ldots \ldots \ldots \ldots \ldots \ldots \ldots .1$

5.1.2 Alternative Cost Function Options $\ldots \ldots \ldots \ldots \ldots \ldots \ldots \ldots .2$

$5.1 .3 \quad$ Incorrect Model Order $\ldots \ldots \ldots \ldots \ldots \ldots \ldots \ldots \ldots \ldots$

5.1.4 Inaccurate or Missing Low- or High-Frequency Data $\ldots \ldots \ldots \ldots .12$ 


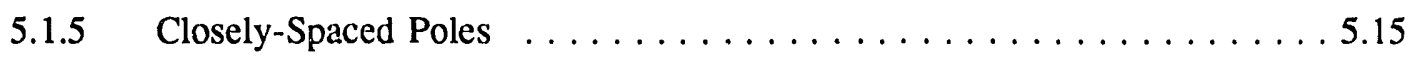

5.1.6 Closely-Spaced Pole-Zero Pairs $\ldots \ldots \ldots \ldots \ldots \ldots \ldots \ldots \ldots \ldots .19$

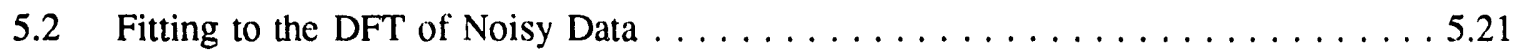

$5.2 .1 \quad$ Effects of Record Length $\ldots \ldots \ldots \ldots \ldots \ldots \ldots \ldots \ldots \ldots .22$

5.2.2 Effects of Noise Level and Coloration . . . . . . . . . . . . . . 5.25

5.3 Fitting to Multi-Path Systems $\ldots \ldots \ldots \ldots \ldots \ldots \ldots \ldots \ldots \ldots \ldots \ldots \ldots \ldots \ldots \ldots \ldots \ldots \ldots .28$

6.0 Conclusions and Recommendations $\ldots \ldots \ldots \ldots \ldots \ldots \ldots \ldots \ldots \ldots \ldots \ldots$

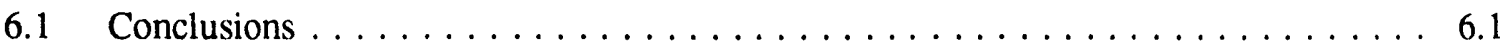

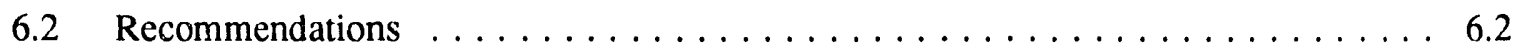

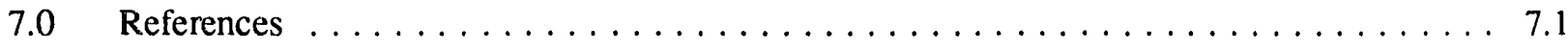

Appendix - SYSFIT Input Files for Examples $\ldots \ldots \ldots \ldots \ldots \ldots \ldots \ldots \ldots \ldots \ldots \ldots \ldots \ldots \ldots$

Table 4.2. Initial model for test system 1 . 


\section{Figures}

$4.1 \quad$ Frequency response of test system $1 \ldots \ldots \ldots \ldots \ldots \ldots \ldots$

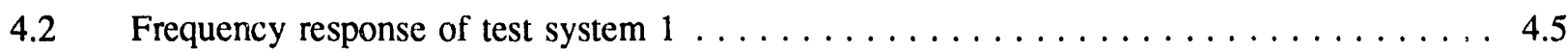

$4.3 \quad$ Frequency response of test system $2 \ldots \ldots \ldots \ldots \ldots \ldots$

$4.4 \quad$ Frequency response of test system $2 \ldots \ldots \ldots \ldots \ldots \ldots$

$4.5 \quad$ Frequency response of test system $3 \ldots \ldots \ldots \ldots \ldots \ldots$

$4.6 \quad$ Frequency response of test system $3 \ldots \ldots \ldots \ldots \ldots \ldots \ldots \ldots$

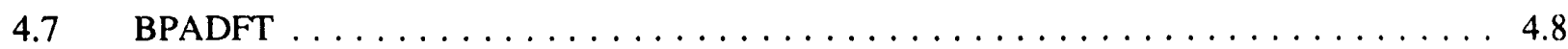

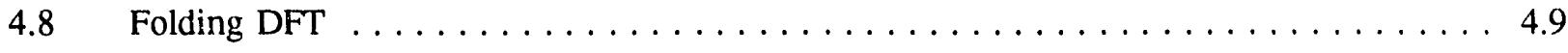

4.9 Comparing BPADFT and folding DFT $\ldots \ldots \ldots \ldots \ldots \ldots$

$4.10 \quad$ Frequency response of $1 / f$ and $1 / f^{2}$ filters $\ldots \ldots \ldots \ldots \ldots \ldots \ldots$

4.11 Frequency response of coloring filter $\ldots \ldots \ldots \ldots \ldots \ldots \ldots \ldots \ldots$

4.12 Frequency response of white and $1 / f$ noise $\ldots \ldots \ldots \ldots \ldots \ldots \ldots \ldots \ldots$

4.13 Frequency response of white and $1 / f^{2}$ noise $\ldots \ldots \ldots \ldots \ldots \ldots \ldots \ldots \ldots \ldots$

4.14 Frequency response of colored noise $\ldots \ldots \ldots \ldots \ldots \ldots \ldots \ldots \ldots$

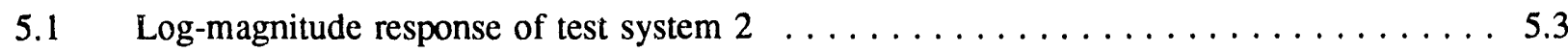

$5.2 \quad$ Magnitude-squared response for test system $2 \ldots \ldots \ldots \ldots \ldots$

5.3 Squared-magnitude fit versus actual response for Example $2 \ldots \ldots \ldots . \ldots$

$5.4 \quad$ Gain of initial and actual models for Example $4 \ldots \ldots \ldots \ldots \ldots$

$5.5 \quad$ Phase of initial and actual models for Example $4 \ldots \ldots \ldots \ldots \ldots$

$5.6 \quad$ Gain of identified model for Example $4 \ldots \ldots \ldots \ldots \ldots \ldots$

$5.7 \quad$ Phase of identified model for Example $4 \ldots \ldots \ldots \ldots \ldots \ldots$

$5.8 \quad$ Pole plot for final fit for Example $4 \ldots \ldots \ldots \ldots \ldots \ldots \ldots$ 
5.9 Gain of initial model compared to actual for Example $5 \ldots \ldots \ldots \ldots \ldots$

5.10 Phase of initial model compared to actual for Example $5 \ldots \ldots \ldots \ldots \ldots$

5.11 Identified modei gain compared to actual for Example $5 \ldots \ldots \ldots \ldots \ldots \ldots \ldots$

5.12 Identified model phase compared to actual for Example $5 \ldots \ldots \ldots \ldots \ldots 11$

5.13 Poles and zeros of identified model for Example $5 \ldots \ldots \ldots \ldots \ldots \ldots \ldots$

5.14 Identified model with first 10 data points missing in Example $6 \ldots \ldots .13$

5.15 Actual poles and identified poles with first 10 data

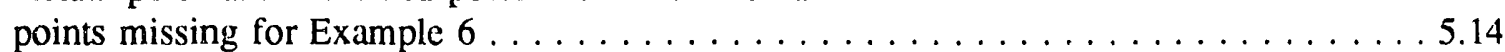

5.16 Identified model with first 40 data points missing for Example $6 \ldots \ldots \ldots \ldots$

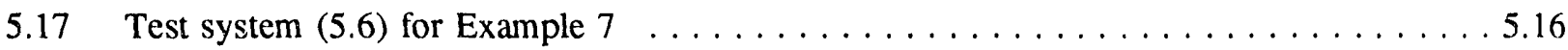

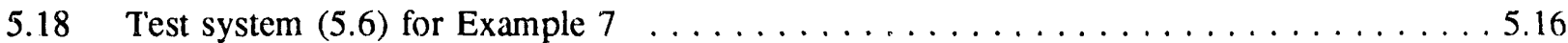

5.19 Identified model for $p=0.75$ for Example $7 \ldots \ldots \ldots \ldots \ldots \ldots \ldots \ldots$

5.20 Actual poles and identified poles for Example $7 \ldots \ldots \ldots \ldots \ldots$

5.21 Response of test system $(5.8)$ for Example $9 \ldots \ldots \ldots \ldots \ldots \ldots \ldots$

5.22 Actual poles and zeros for $p=0.75$ for Example $9 \ldots \ldots \ldots \ldots \ldots \ldots$

5.23 Identified poles and zeros for Example $9 \ldots \ldots \ldots \ldots \ldots \ldots \ldots \ldots \ldots \ldots \ldots \ldots \ldots .21$

5.24 Test system impulse response with noise for Example $10 \ldots \ldots \ldots \ldots \ldots \ldots$

5.25 Identified model for a 2048-point DFT for Example $10 \ldots \ldots \ldots \ldots \ldots \ldots$

5.26 Identified model for a 1536 -point DFT for Example $10 \ldots \ldots \ldots \ldots \ldots \ldots$

5.27 Identified model for a 1024-point DFT for Example $10 \ldots \ldots \ldots \ldots .24$

5.28 Identified model for $21-\mathrm{db}$ and $11-\mathrm{db}$ SNR for Example $12 \ldots \ldots \ldots \ldots \ldots \ldots$

5.29 Identified models under different noise colorations for Example $13 \ldots \ldots . \ldots . \ldots 5$

5.30 Identified model with colored noise for Example $14 \ldots \ldots \ldots \ldots \ldots \ldots \ldots$

5.31 Identified model for a fit to path 2 only for Example $15 \ldots \ldots \ldots \ldots . \ldots \ldots$

viii 


\section{Tables}

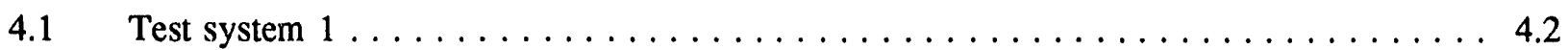

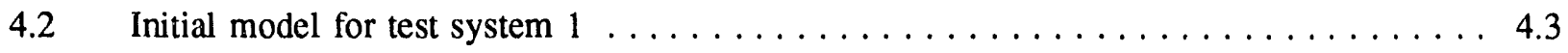

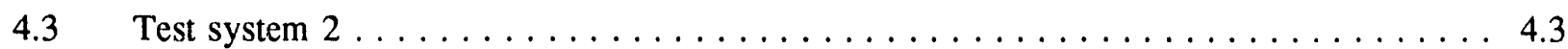

$4.4 \quad$ Initial model for test system $2 \ldots \ldots \ldots \ldots \ldots \ldots \ldots \ldots \ldots \ldots \ldots \ldots$

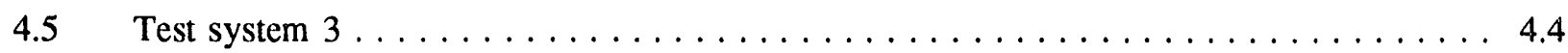

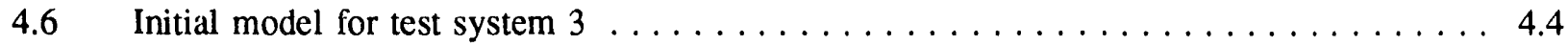

5.1 Comparison of optimization search routines for Example 1 (100 iterations) $\ldots \ldots \ldots .2$

$5.2 \quad$ Comparison of fit cases for Example $3 \ldots \ldots \ldots \ldots \ldots$

5.3 Parameter erors for $p=0.99$ identified model for Example $7 \ldots \ldots \ldots . \ldots$

5.4 Errors of identied poles for Example $8 \ldots \ldots \ldots \ldots \ldots \ldots \ldots \ldots \ldots$

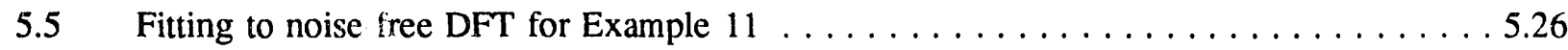

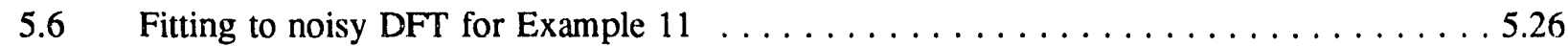

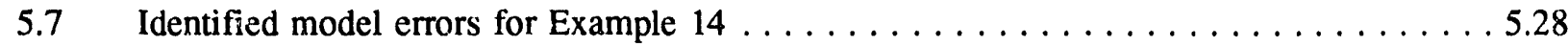




\subsection{Introduction}

Problems often encountered in engineering and science require the mathematical modeling of a physical system's dynamic characteristics. There are two basic approaches to dynamically modeling a system: 1) model the system using theoretical derivations, or 2) use a curve-fitting technique to optimally fit a linear model to specified system response data. With the second option, one can fit a model to the time-domain or the frequency-domain response of the system. The frequency response of systems with dynamic content dominated by oscillatory effects contains rich information pertaining to the characteristics of the system. Therefore, such data is often used to identify models.

Such oscillatory dynamic effects occur in large synchronous-generator-based power systems in the form of electromechanical oscillations. These oscillations arise when energy is exchanged between generators, or sets of generators, through transmission lines. In theory, a power system has $m-1$ modes of oscillation, where $m$ is the number of generators; modern systems have hundreds of generators. In reality, any one signal will be dominated by a few modes. To study and characterize these oscillatory dynamics, the Bonneville Power Administration (BPA) has developed computer codes to analyze systern frequency response for fitting a linear model. To make full integrated use of these codes as well as other analysis techniques, BPA has commissioned Pacific North Laboratory (PNL) ${ }^{(a)}$ to further develop the codes and techniques into a software tool termed the Power System Identification (PSI) Toolbox.

The first phase of PSI Toolbox development involves investigating the characteristics of the analysis techniques by evaluating existing software and developing guidelines for best use. Subsequent phases will include extending current software; developing new analysis algorithms; and reorganizing the software into a modular collection of computer programs.

The primary focus of this report is on the first phase. The characteristics of fitting linear models to the frequency response of oscillatory systems were investigated. The investigation was conducted by performing fits to the response of known linear models under controlled conditions. The conditions studied include fitting algorithms; parent system configurations; underlying noise characteristics; and different Fourier transformation methods. Many general "rules of thumb" for fitting under these conditions were drawn from the testing results. Special effort was made tc investigate the effects that might be encountered in studying electromechanical oscillations in power systems. These oscillations typically occur in the $0.1-\mathrm{Hz}$ to $2.0-\mathrm{Hz}$ range, so example systems used in the investigations consisted of multiple modes in this frequency range. Although the intended focus of this work is power system oscillations, the studies are generic enough that the results apply to many types of oscillatory systems with closely-spaced modes (including flexible mechanical structures and manipulators).

In Section 2, the fitting problem is introduced, and a review of the relevant literature is presented. The BPA analysis codes used to conduct the tests are discussed in Section 3. In Section 4, test systems and noise models are described. The main results on performing tests are presented in Section 5, and conclusions and recommendations are discussed in Section 6.

(a) Pacific Northwest Laboratory is operated by Battelle Memorial Institute for the U.S. Department of Energy under Contract DE-AC06-76RLO 1830. 


\subsection{Frequency-Domain Fitting}

\subsection{Problem Description}

Consider a general time-invariant dynamic system represented in the Laplace domain as $G(s)$. Let $U(s)$ and $Y(s)$ be the Laplace-domain input and output to $G$, such that,

$$
Y(s)=G(s) U(s)
$$

If the input is a sinusoid of the form

$$
u(t)=A \cos (\omega t)
$$

where $u(t)$ is the time-domain version of $U(s)$, then the steady-state time-domain output is

$$
y_{s s}(t)=A|(\sigma j \omega)| \cos (\omega t+\angle G(j \omega))
$$

where $G(j \omega)$ is $G(s)$ with $s=j \omega$ and $j=\sqrt{-1}$.

The question asked here is, Given $G(j \omega)$ at frequencies $\omega_{k}, k=1,2, \ldots, N$, can one represent $G$ with a linear model with known parameters? For convenience, let the linear model be represented in the Laplace domain as $G_{M}(s, \underline{x})$, where $\underline{x}$ is a vector of parameters that represent the model. The goal then becomes determining the values of $\underline{x}$ that make $G_{M}$ the best representation of $G$. As will become evident in the literature review, this problem can be posed mathematically in several ways. The literature reviewed here is concerned primarily with formulating and solving this problem.

\subsection{Literature Review}

A transfer function may be fitted to the frequency response of a system iusing either of two methods: graphical methods and fitting methods. Early work on graphical methods includes Chen and Philip (1963) and Ausman (1964). These methods apply well only to simple systems, and they suffer from poor accuracy. Fitting methods basically use some type of optimization or curve-fitting to adjust the parameters of the model so that its frequency response optimally fits the actual system response. The literature of fitting techniques is extensive and is the main subject of the review presented here.

One of the first widely referenced papers on fitting a model to frequency response data is that of Levy (1959). The model is assumed to be a ratio of polynomials in the form

$$
G_{M}(s)=\frac{b_{m} s^{m}+b_{m-1} s^{m-1}+\ldots+b_{0}}{s^{n}+a_{n-1} s^{n-1}+a_{n-2} s^{n-2}+\ldots+a_{0}}
$$

where the $a_{i}$ and $b_{i}$ parameters make up the unknown vector $\underline{x}$. The fit is performed by minimizing the weighted sum of squared errors between the measured data and the model frequency response. The weights are chosen so that they force the resulting solution to be the solution to a linear set of 
equations of order $m+n$. The weighting is later remr d by Sanathanan and Koemer (1963) by making the solution iterative. Time-domain constraints (such as a specified steady-state value) are added to the method in Payne (1970). The basic method of Levy (1959) is expanded in Jong and Shanmugam (1977) to fit a minimum-phase model to the magnitude frequency response data of a system.

Other early work in fitting transfer functions to frequency response data is described in Steiglitz. (1970) and Seidel (1975). Seidel describes a computer program that fits a linear stable model to the measured gain and phase of a system. The system is restricted to the single input, single output (SISO), and the model is assumed to be a cascade series of first- and/or second-order blocks (i.e., blocks multiplied together in the Laplace domain). A conjugate gradient search method (Pierre 1969) is used to find the $\underline{x}$ that minimizes

$$
J(\underline{x})=\frac{1}{2} \sum_{k=1}^{N}\left|G\left(j \omega_{k}\right)-G_{M}\left(j \omega_{k} \underline{x}\right)\right|^{2}\left(\omega_{k+1}-\omega_{k-1}\right)
$$

As with all gradient-based search techniques, an initial $\underline{x}$ must be specified. Seidel (1975) notes that parameter scaling, which makes $J(\underline{x})$ equally sensitive to all elements of $\underline{x}$, improves the convergence properties of the search problem. The scaling law employed (Seidel 1975) scales each parameter by its own magnitude at each step of the search.

Steiglitz (1970) also proposes a gradient-based search method, but in the discrete-time domain. Tae Fletcher and Powell gradient search method (Pierre 1969) is used to identify the parameters of a digital filter. The filter is forced to be minimum phase by always reflecting the identified poles and zeros into the unit circle.

The BPA program SYSFIT was first introduced in the literature in Hauer (1977 and 1982) and later discussed in Hauer (1989). SYSFIT allows the system to be multi-input, multi-output (MIMO). The model is assumed to be an interconnection of first-order and second-order blocks; several interconnection configurations are allowed (e.g., cascade and feedback). Also, some elements of $\underline{x}$ can be fixed or locked together by the user. Several different gradient search methods, optimization functions, and constraint options are provided. All search methods require an initial estimate of model parameters. The SYSFIT program is described in more detail in Section 3 of this report.

Tilly (1984) evaluates three different SISO system identification computer programs. The first program is called Transfer Function (TF); the second is called Transfer (TRANSF). Both were developed at Lawrence Livermore National Laboratory. With TF, the model is assumed to be a ratio of polynomials as in Equation (2.4), and an over-determined set of equations is then obtained by expanding Equation (2.4) for each sampled frequency with $G(j \omega)$ substituted for $G_{M}(j \omega)$ ). The overdetermined equation set is solved for the unknown coefficients using a leasi-squares approach. The assumed model for TRANSF is a summation of second-order biocks (in the Laplace domain), and the optimization function penalizes the sum of the squared difrerences between the model and the system data. TRANSF performs a linear least-squares fit to the data by linearizing the model and cost function. This fitting and linearization is iterated until the cost function converges to a minimum. The search technique seems very similar to the standard Newton-Raphson search method. The third program discussed in Tilly (1984) is NAVFIT. The assumed model for NAVFIT is a ratio of 
polynomials with a pure time delay. To minimize a cost function and find the optimal parameter set, NAVFIT uses Rosenbrock's Multivariable Search Method, a nonlinear programming method. Tilly (1984) concludes that NAVFIT and TRANSF perform better than TF when a reasonable initial condition is provided; the only advantage of TF is that it requires no initial condition.

The over-determined least-squares method employed by TF is expanded in Lin and Wu (1982) to include a MIMO system. Also, the problem of choosing the model order is addressed; in previous work it is assumed that the order is known. The model order is chosen by performing fits for progressively higher-order models until the residual error between the model and system data no longer decreases. The method is expanded in Braun and Ram (1987) by examining the rank of the over-determined matrix in choosing the model order.

In Richardson and Formenti (1982), it is recognized that the over-determined least-squares method is very numerically sensitive. The numerical instability is addressed by re-writing the model as

$$
G(s)=\frac{\hat{b}_{m} \phi_{m}(s)+\hat{b}_{m-1} \phi_{m-1}(s)+\ldots+\hat{b}_{0} \phi_{0}(s)}{\hat{a}_{n} \theta_{n}(s)+\hat{a}_{n-1} \theta_{n-1}(s)+\ldots+\hat{a}_{0} \theta_{0}(s)}
$$

where the polynomials $\phi_{i}(s), i=0,1, \ldots, m$ are a general set of orthogonal polynomials, as are the $\theta_{i}(s)$ polynomials.

Adcock (1987) describes the model-fitting algorithm used in a Hewlett-Packard (HP) 3562A Analyzer. The model is a proper SISO transfer function in ratio-of-polynomial form as in Equation (2.4). The coefficients are obtained by minimizing the least-squares difference between the model and the system similar to Levy (1959). To enhance the numerical robustness of the least-squares problem, the numerator and denominator polynomials are assumed to be a weighted series of Chebyshev polynomials, as opposed to the traditional power series. The weights are then obtained from the least-squares fit. Calculating the model coefficients from the Chebyshev weights is then straightforward. Adcock also proposes weighting the measurement data to emphasize possible pole and zero locations. A disadvantage of the method in Adcock (1987) is that the variance of any underlying noise must be known.

An extension of the method described in Adcock (1987) is used in Balas and Doyle (1990) to identify models for flexible structures. The method is extended to identify MIMO transfer functions.

In Mau and Wang (1959), a technique for fitting a linear system to frequency response data from vibration test data is developed. Structural dams often have oscillatory modes in the $0-\mathrm{Hz}$ to $10-\mathrm{Hz}$ range, and vibration tests are conducted to determine the dam's response. The model is assumed to be a superposition of second-order modal terms. The parameters of each modal term are individually identified by minimizing an optimization function involving the squared-error of the modal term and the true system response in the frequency range of the mode. For a given modal term, the optimization function is minimized only in the neighborhood of that term. This allows the modal terms to be identified individually. The parameters are identified using a gradient search technique. 
Mau and Wang (1989) propose using a "single-mode sweep" (SMS) method to identify initial estimates of the parameters. The SMS method is conducted using the following steps:

1) scan the frequency magnitude response to find a possible resonance peak; 2) use the five measurement points nearest to the peak to estimate damping, frequency, and participation of that mode (this is done using some simple linear approximations); 3) repeat steps 1 and 2 for each resonance peak.

An Akaike information criterion (termed AIC) from Akaike (1974) is used in Mau and Wang (1989) to determine the order of model. According to the criterion, the optimum number of modal terms should make the AIC function a minimum.

Least-squares methods of identifying models for helicopter dynamics are discussed in detail in Black and Murray-Smith (1989). The frequency-domain methods are compared with time and theoretical methods of deriving a linear model for a helicopter operating about a set point. It is demonstrated that the frequency-domain approach provides the most accurate model.

Over-determined least-squares parameter estimation is also addressed in Berchin and Soderstrand (1989). An iterative method is proposed. With each iteration, the least-squares estimation is modified to remove any bias resulting from measurement error. A total least-squares algorithm is employed to solve each step.

Kumaresan (1990) proposes a method of identilying a SISO model using a discrete-time transfer function. The method is derived by noting that the frequency response of a system in the $z$-transform domain is an infinite series involving the backward shift operator. Kumaresan derives the method, but no comparisons are made with conventional methods.

In all the fitting techniques, the optimization cost function is of critical importance. This issue is addressed in Sidman et al. (1991). It is argued that the cost function should use log-magnitude data, and that logarithmic spacing between data points should be employed. Inclusion of the phase information allows non-minimum-phase transfer functions to be identified. At points where the measured gain is small, the proposed cost function provides more information because it penalizes the $\log$ of the magnitude.

In Moser and Caughey (1991), problems and solutions experienced using a frequency-domainfitting algorithm on a large flexible structure are discussed. The model formulation consists of a number of second-order transfer functions connected in parallel, and the model may be MIMO. The model is fitted to the response data using two search algorithms: steepest descent and Newton-Raphson (Pierre 1969). Iterations are altered between the two search techniques.

Gu and Misra (1992) consider identifying a model by minimizing the infinity norm of the difference between the model and actual system response. All the other methods described up to now have addressed minimizing a two-norm function. Specific effects of bounded noise are investigated. 


\subsection{SYSFIT Computer Program}

SYSFIT is a FORTRAN-based computer program for fitting a model to measured frequencyresponse data. It was developed at BPA for various power system applications. SYSFIT and related routines are discussed in Hauer $(1974,1977,1982,1989)$ and Hauer and Taylor (1990). This section presents brief descriptions of the program and how it is ported to a SUN platform.

The primary technique for fitting a transfer function to response data in SYSFIT is a gradient-based search method. An initial model is provided by the user, and the program adjusts the parameters to minimize the difference between the model's response and the measured data. SYSFIT uses a generalpurpose gradient projection program called MORPAK II (Hauer 1974) together with application code specific to modal fitting and linear analysis.

\subsection{Program Description}

SYSFIT provides considerable flexibility in forming the system model. The model is constructed by interconnecting several individual blocks. Blocks may take on one of seven different forms, but are always of two types: special blocks for such functions as pure time delay, and second- order (or less) linear transfer function blocks. Each block of the second type has five parameters. These parameters may be fixed by the user or identified by the program. For example, block type 0 is of the form

$$
\frac{x(5) s^{2}-2 x(1) s+x(2)^{2}}{s^{2}-2 x(3) s+x(4)^{2}}
$$

Each $x(i)$ is either fixed by the user or identified during the fitting. One or more blocks are interconnected to form a path. If $P(s)$ is a given path and $P_{i}(s)$ is a block transfer function to be added to the path, then the possible connections are

$$
\begin{aligned}
& \text { cascade -- } P(s)=P(s) P_{i}(s) \\
& \text { parallel -- } P(s)=P(s)+P_{i}(s) \\
& \text { feedback -- } P(s)=\frac{P(s)}{1+P(s) P_{i}(s)} \\
& \text { reciprocal -- } P(s)=\frac{P_{i}(s)}{P(s)}
\end{aligned}
$$

Also, given paths can be interconnected to form new paths. The paths are used to describe a transfer function from a given input to a given output. Multiple paths are used to describe a MIMO model.

The model parameters in SYSFIT are obtained by fitting the model to measured data using a nonlinear gradient-based search technique. SYSFIT allows the user to choose from the following 
search methods: steepest descent; PARTAN; conjugate gradient; David Fletcher Powell (DFP); and self-scaling variable metric. These methods are described in Hauer (1974) and Pierre (1969).

A two-norm cost function is used with the search methods; the user is allowed a number of choices for the elements of the cost function. Let $G\left(j \omega_{k}\right)$ be the ineasured frequency response and $G_{M}\left(j \omega_{k}, \underline{x}\right)$ be the model response for frequency samples $k=1,2, \ldots, N$. The optimization cost function is the following quadratic positive-definite function

$$
J(\underline{x})=\sum_{m=1}^{4} W_{m} E_{m}(\underline{x})
$$

where

$$
E_{m}(x)=\frac{1}{N} \sum_{k=1}^{N} w_{m}(k)\left(e_{m}(k, x)\right\rangle^{2}
$$

and

$$
\begin{aligned}
& e_{1}(k, \underline{x})=\left|G_{M}\left(j \omega_{k}, x\right)\right|-\left|G\left(j \omega_{k}\right)\right| \\
& \text { or } \\
& e_{1}(k, \underline{x})=2 \log \left(\left|G_{M}\left(j \omega_{k}, \underline{x}\right)\right|\right)-2 \log \left(\left|G\left(j \omega_{k}\right)\right|\right) \\
& e_{1}(k, x)=\frac{\left|G_{M}\left(j \omega_{k}, x\right)\right|}{\left|G\left(j \omega_{k}\right)\right|} \\
& \text { or } \\
& e_{1}(k, \underline{x})=\frac{\left|G_{M}\left(j \omega_{k}, \underline{x}\right)\right|}{\left|G\left(j \omega_{k}\right)\right|} \cdots 1 \\
& e_{2}(k, \underline{x})=\angle G_{M}\left(j \omega_{k}, \underline{x}\right)-\angle G\left(j \omega_{k}\right) \\
& e_{3}(k, \underline{x})=\left(\left|G_{M}\left(j \omega_{k}, \underline{x}\right)\right|-\left|G_{M}\left(j \omega_{k-1}, \underline{x}\right)\right|\right)-\left(\left|G\left(j \omega_{k}\right)\right|-\left|G\left(j \omega_{k-1}\right)\right|\right) \\
& e_{4}(k, \underline{x})=\left(\angle G_{M}\left(j \omega_{k}, \underline{x}\right)-\angle G_{M}\left(j \omega_{k-1}, \underline{x}\right)\right)-\left(\angle G\left(j \omega_{k}\right)-\angle G\left(j \omega_{k-1}\right)\right)
\end{aligned}
$$

$E_{l}$ penalizes the magnitude response of the system in either absolute magnitude or log-magnitude form as chosen by the user. Phase differences are penalized with $E_{2} . E_{3}$ and $E_{4}$ are used to penalize "slope" differences. The $W_{m}$ 's are termed the cost weights and are always greater than or equal to 0 , and the 
$w_{m}(k)$ 's are the measurement weights; both are chosen by the user. To perform multi-path fits, the cost functions of the individual paths are added.

Because SYSFIT uses a gradient-based search method to fit the model parameters, an initial guess for the model parameters must be supplied to the program. With each step of the search, the model parameters are adjusted until an optimal set is obtained. The search termination options include 1) passage of convergence tests based on Kuhn-Tucker conditions (Hauer 1974); 2) reaching of the maximum uumber of iterations; and 3) ending of decreases in the optimization cost function.

SYSFIT has many other options in solving the fitting problem. Unfortunately, at this time, there is no single comprehensive manual for SYSFIT. The reader who wishes to use the program is encouraged to consult Hauer (1977), Hauer and Taylor (1990), and the code itself.

\subsection{Porting SYSFIT to a SUN Platform}

The version of SYSFIT delivered from BPA is a VAX-VMS version of the program. This version has been ported to a SUN Sparc 2 workstation operating under an UNIX system. The SUN version 1.4 FORTRAN compiler was used to compile and link the programs on the Sparc 2. This porting required a number of minor modifications, which are listed here in summary form.

\section{Modifications include}

changing file names in INCLUDE statements to lower-case letters because UNIX differentiates between upper- and lower-case letters

- adding parentheses to PARAMETER statements as required by the SUN compiler

changing the default input/output (I/O) unit numbers from 5 and 6 to 2 and 3 - SUN reserves 5 and 6 .

- modifying common files LUNITS.CMN and PPLOT.CMN to remove redundancies in COMMON and DATA statements

- changing OPEN statements in M2BPA.FOR to use SUN I/O options.

The VMS version of SYSFIT is linked with an object library called PHASE1/LIB. Because a VMS object library cannot be ported, this library was not included in linking the SUN version of SYSFIT. The file PZPRNT also was not included in the linking because it was not sent to PNL. Despite these exclusions, SYSFIT successfully compiles and links with the above modifications.

Several test runs were conducted to compare the differences between the SUN and VMS versions of SYSFIT. Differences occurred only at the tenth or higher decimal place. These small differences are likely the result of the different interpretations of floating-point operations on the two platforms. 


\subsection{Example Systems and MATLAB Interfaces}

To effectively evaluate the characteristics of fitting models to frequency-response data, fits to the data are performed under specified controlled conditions. Developing these conditions requires several test systems and synthetic noise files. The purpose of this section is to describe the test systems, noise files, and the pre- and post-processing for the examples. This section includes descriptions of

. interfacing with MATLAB for pre- and post-processing

example systems with special characteristics

synthetic noise models

techniques for taking the discrete Fourier transform (DFT) of impulse response data.

\subsection{Interfacing with MATLAB}

Much of the pre- and post-processing for conducting SYSFIT runs is done using the software package MATLAB and its associated Control System Toolbox (developed by The Mathworks, Inc.). This includes the development of test systems. Details on interfacing SYSFIT files with MATLAB are described here.

MATLAB (an acronym for matrix laboratory) is a multipurpose interactive program that allows a user to easily access several advanced numerical and matrix analysis methods. When used with the Control System Toolbox, it can solve many advanced analysis problems related to linear systems. A few of the functions include time-domain simulation; frequency-domain analysis; conversion between model formulations (e.g., state-space to ratio of zeros and poles); and root locus analysis. MATLAB allows the user to write custom functions using $m$-files.

Interfacing. MATLAB with SYSFIT is done using a combination of FORTRAN programs and $\mathrm{m}$ files. To savi a da a set for processing by SYSFIT, the user saves the data in MATLAB as a straight ASCII file. This ASCII file is then converted to a readable SYSFIT file using the FORTRAN program CONVERT2SYS. To import the results from a SYSFIT execution, the output model is extracted from the SYSFIT output file by running the FORTRAN program SYS2MAT, which creates an ASCII file that can be loaded into MATLAB. This file is then converted to MATLAB variables by running the m-file SYS2MAT.M.

\subsection{Example Systems}

Variations of three linear test systems were used to demonstrate examples of fitting models to frequency response data. Each system has specified characteristics. In addition, an "initial model" is presented for each system. This initial model was used as the initial guess when performing the SYSFIT runs that will be described in Section 5. The initial models were developed using an "eyeball" technique similar to what one might use as an initial try when performing actual fits. One 
studies the frequency response and uses general graphical rules as described in Nilsson (1983) to estimate transfer function terms.

\subsubsection{Test System 1}

Test system 1 is represented by the parameters in Table 4.1 . Throughout this report, " \pm " is used to represent complex conjugate pairs. Using the notation in Table 4.1 , the transfer function for this test system can be written as

$$
G(s)=\sum_{i=1}^{n} \frac{\operatorname{Residue}(i)}{s-\operatorname{Pole}(i)}
$$

or as

$$
G(s)=\frac{\operatorname{Gain} \prod_{i=1}^{m}(s-\operatorname{Zero}(i))}{\prod_{i=1}^{n}(s-\operatorname{Pole}(i))}
$$

where $n$ is the number of poles and $m$ is the number of zeros. A second version of this system (called version 2) is obtained by changing the zero at $s=-0.3 \pm j 0.9(2 \pi)$ to $s=-0.6 \pm j 0.9(2 \pi)$ and the zero at $s=-0.6 \pm j 1.5(2 \pi)$ to $s=-0.1 \pm j 1.5(2 \pi)$.

This system is characterized by two dominant modes at 0.35 and $0.45 \mathrm{~Hz}$, and two weaker, more lightly damped modes at 0.8 and $1.0 \mathrm{~Hz}$. After $1.6 \mathrm{~Hz}$, the frequency response of the system tends to roll off because of the real mode at $1.6 \mathrm{~Hz}$. The difference between the two versions is in the damping of the zeros. Although these differences seem small, they have a significant effect on the DFT of the impulse response of the systems.

The initial model for test system 1 is given in Table 4.2. Figures 4.1 and 4.2 show the frequency response of test system 1 and the initial model.

Table 4.1. Test system 1 .

\begin{tabular}{||l|l|l|l||}
\hline \multicolumn{1}{|c|}{ Poles } & \multicolumn{1}{|c|}{ Residues } & \multicolumn{1}{c|}{ Zeros } & \multicolumn{1}{c|}{ Gain } \\
\hline$-1.60(2 \pi)$ & 44.062 & $-0.80 \pm j 0.55(2 \pi)$ & $9.6 \pi$ \\
$-0.50 \pm j 0.35(2 \pi)$ & $57.46 \angle \mp 74.47^{\circ}$ & $-0.15 \pm j 0.65(2 \pi)$ & \\
$-0.25 \pm j 0.45(2 \pi)$ & $25.07 \angle \pm 137.87^{\circ}$ & $-0.30 \pm j 0.90(2 \pi)$ & \\
$-0.10 \pm j 0.80(2 \pi)$ & $3.00 \angle \mp 109.55^{\circ}$ & $-0.60 \pm j 1.50(2 \pi)$ & \\
$-0.05 \pm j 1.0(2 \pi)$ & $3.425 \angle \mp 143.10^{\circ}$ & & \\
\hline
\end{tabular}


Table 4.2. Initial model for test system 1 .

\begin{tabular}{||l|l||l|l||}
\hline \multicolumn{1}{|c|}{ Poles } & \multicolumn{1}{|c|}{ Residues } & \multicolumn{1}{|c|}{ Zeros } & \multicolumn{1}{c|}{ Gain } \\
\hline$-2.50(2 \pi)$ & 24.93 & $-0.4021(2 \pi)$ & 28.0 \\
$-0.20 \pm j 0.3485(2 \pi)$ & $61.56 \angle \mp 17.65^{\circ}$ & $-0.3979(2 \pi)$ & \\
$-0.25 \pm j 0.45(2 \pi)$ & $49.77 \angle \pm 172.1^{\circ}$ & $-0.10 \pm j 0.65(2 \pi)$ & \\
$-0.05 \pm j 0.80(2 \pi)$ & $4.711 \angle \mp 152.3^{\circ}$ & $-0.10 \pm j 0.90(2 \pi)$ & \\
$-0.05 \pm j 1.0(2 \pi)$ & $3.942 \angle \mp 158.2^{\circ}$ & $-0.05 \pm j 1.5(2 \pi)$ & \\
\hline
\end{tabular}

\subsubsection{Test System 2}

Test system 2 and its initial model are represented in Tables 4.3 and 4.4, and in Figures 4.3 and 4.4. The system is a simplified version of test system 1 .

Table 4.3. Test system 2 .

\begin{tabular}{||l|l|l|l||}
\hline \multicolumn{1}{|c|}{ Poles } & \multicolumn{1}{|c|}{ Residues } & \multicolumn{1}{|c|}{ Zeros } & \multicolumn{1}{c|}{ Gain } \\
\hline$-1.60(2 \pi)$ & 37.48 & $-0.15 \pm j 0.65(2 \pi)$ & $9.6 \pi$ \\
$-0.10 \pm j 0.80(2 \pi)$ & $10.34 \angle \pm 61.89^{\circ}$ & $-0.10 \pm j 1.5(2 \pi)$ & \\
$-0.05 \pm j 1.0(2 \pi)$ & $16.09 \angle \mp 122.0^{\circ}$ & & \\
\hline
\end{tabular}

Table 4.4. Initial model for test system 2 .

\begin{tabular}{||l|l||l|l||}
\hline \multicolumn{1}{|c|}{ Poles } & \multicolumn{1}{|c|}{ Residues } & \multicolumn{1}{|c|}{ Zeros } & \multicolumn{1}{c|}{ Gain } \\
\hline$-1.20(2 \pi)$ & 42.58 & $-0.20 \pm j 0.60(2 \pi)$ & 37.0 \\
$-0.20 \pm j 0.7493(2 \pi)$ & $6.889 \angle \pm 58.07^{\circ}$ & $-0.10 \pm j 1.5(2 \pi)$ & \\
$-0.10 \pm j 1.2(2 \pi)$ & $9.108 \angle \mp 134.9^{\circ}$ & & \\
\hline
\end{tabular}

\subsubsection{Test System 3}

Tables 4.5 and 4.6 and Figures 4.5 and 4.6 represent test system 3. Note that this model is similar to that for test system 1, except that the lower modes have been shifted to $0.2 \mathrm{~Hz}$ and $0.3 \mathrm{~Hz}$. Also, a complex zero pair has been added near $0.24 \mathrm{~Hz}$. 
Table 4.5. Test system 3 .

\begin{tabular}{||l|l||l|l||}
\hline \multicolumn{1}{|c|}{ Poles } & \multicolumn{1}{|c|}{ Residues } & \multicolumn{1}{|c|}{ Zeros } & \multicolumn{1}{c|}{ Gain } \\
\hline$-1.60(2 \pi)$ & 3.782 & $-0.75 \pm j 0.24(2 \pi)$ & 3.00 \\
$-0.30 \pm j 0.20(2 \pi)$ & $3.948 \angle \mp 31.99^{\circ}$ & $-0.65 \pm j 0.65(2 \pi)$ & \\
$-0.20 \pm j 0.30(2 \pi)$ & $3.818 \angle \mp 142.8^{\circ}$ & $-0.60 \pm j 0.90(2 \pi)$ & \\
$-0.10 \pm j 0.80(2 \pi)$ & $0.4661 \angle \mp 121.3^{\circ}$ & $-0.10 \pm j 1.50(2 \pi)$ & \\
$-0.05 \pm j 1.0(2 \pi)$ & $0.4582 \angle \pm 143.10^{\circ}$ & & \\
\hline
\end{tabular}

Table 4.6. Initial model for test system 3 .

\begin{tabular}{||l|l|l|l||}
\hline \multicolumn{1}{|c|}{ Poles } & \multicolumn{1}{|c|}{ Residues } & \multicolumn{1}{|c|}{ Zeros } & \multicolumn{1}{|c|}{ Gain } \\
\hline$-2.00(2 \pi)$ & 0.9336 & $-0.30(2 \pi)$ & 3.00 \\
$-0.03 \pm j 0.27(2 \pi)$ & $2.883 \angle \mp 8.875^{\circ}$ & $-0.30(2 \pi)$ & \\
$-0.03 \pm j 0.33(2 \pi)$ & $2.528 \angle \mp 177.4^{\circ}$ & $-0.20 \pm j 0.55(2 \pi)$ & \\
$-0.10 \pm j 0.80(2 \pi)$ & $0.1819 \angle \mp 150.6^{\circ}$ & $-0.20 \pm j 0.90(2 \pi)$ & \\
$-0.10 \pm j 1.0(2 \pi)$ & $0.1372 \angle \mp 163.4^{\circ}$ & $-0.10 \pm j 1.50(2 \pi)$ & \\
\hline
\end{tabular}

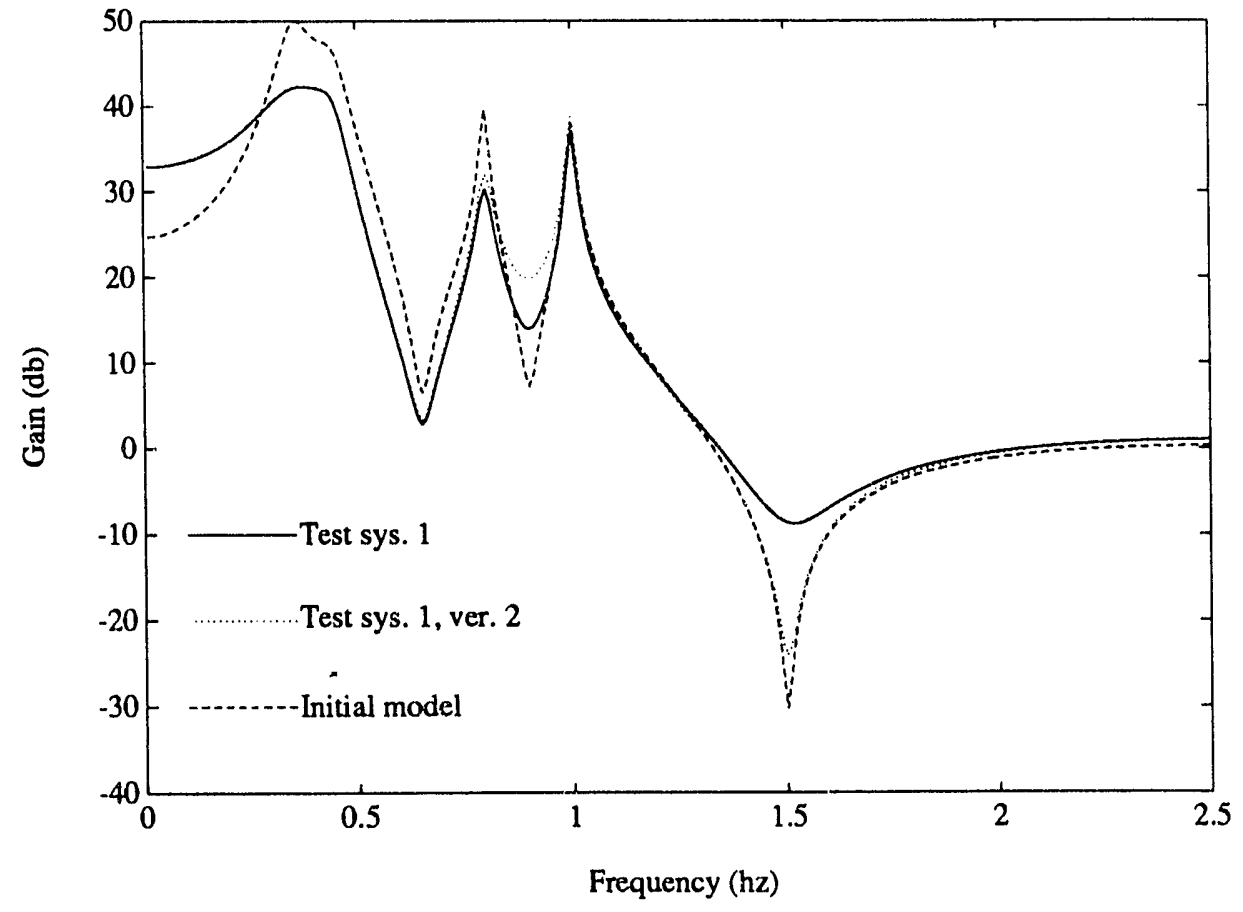

Figure 4.1. Frequency response of test system 1. 


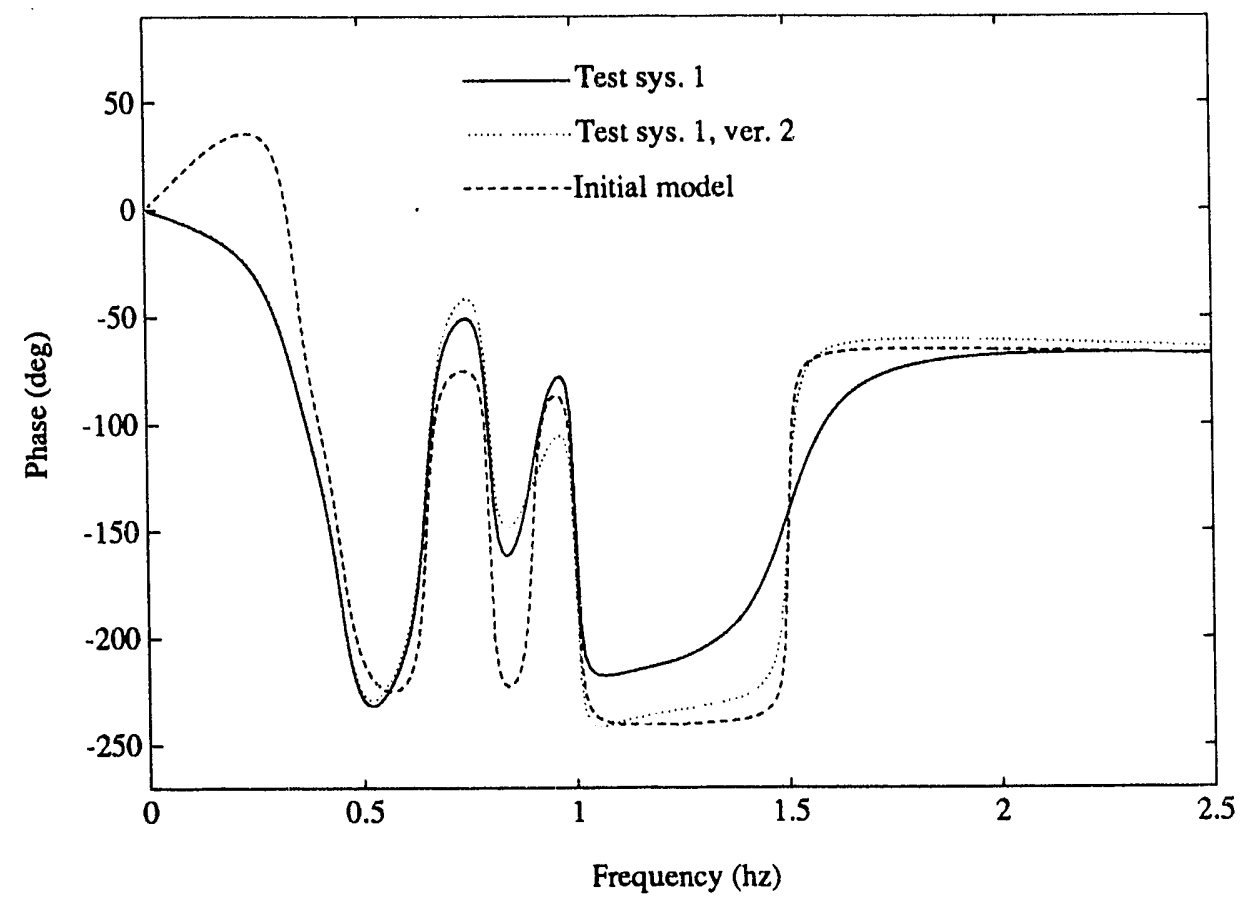

Figure 4.2. Frequency response of test system 1.

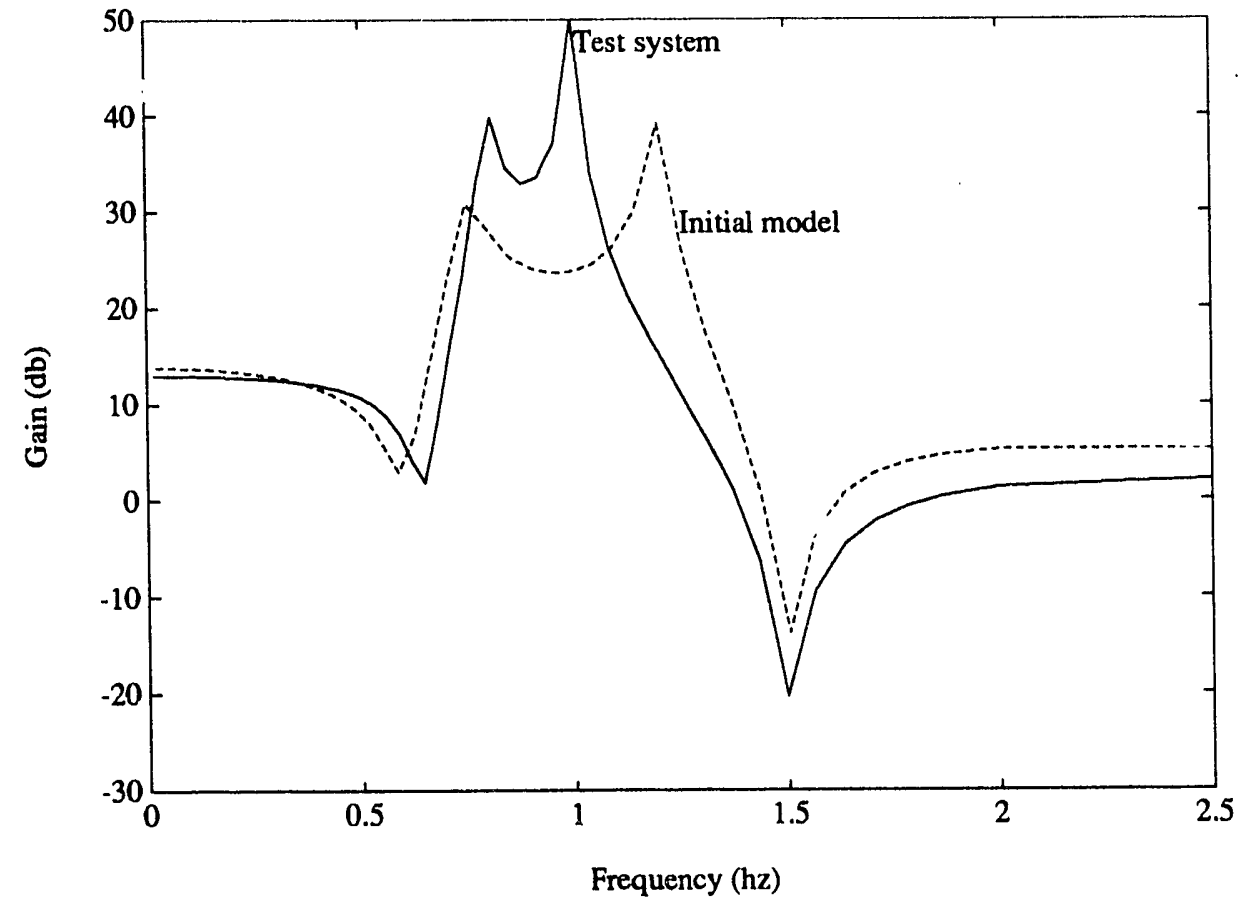

Figure 4.3. Frequency response of test system 2. 


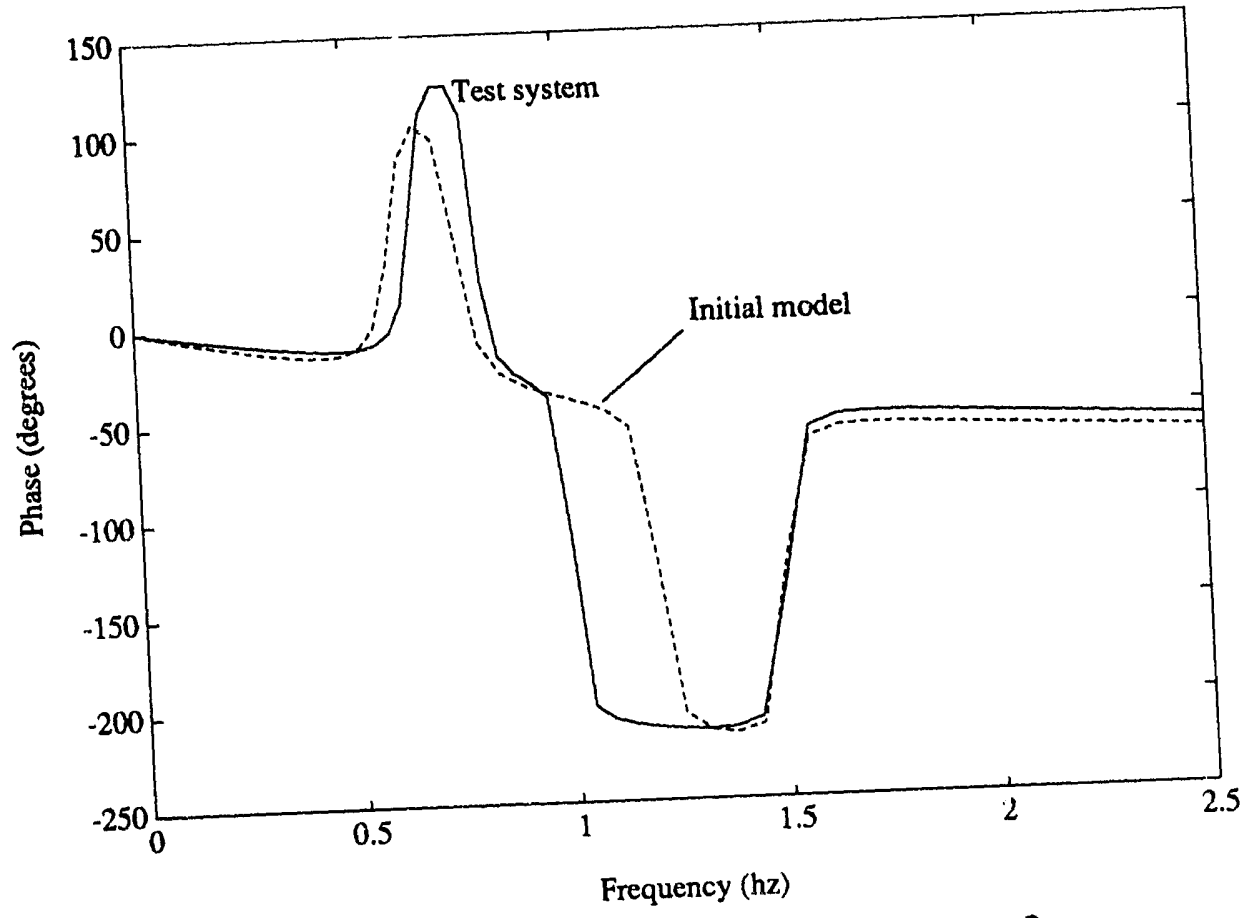

Figure 4.4. Frequency response of test system 2.

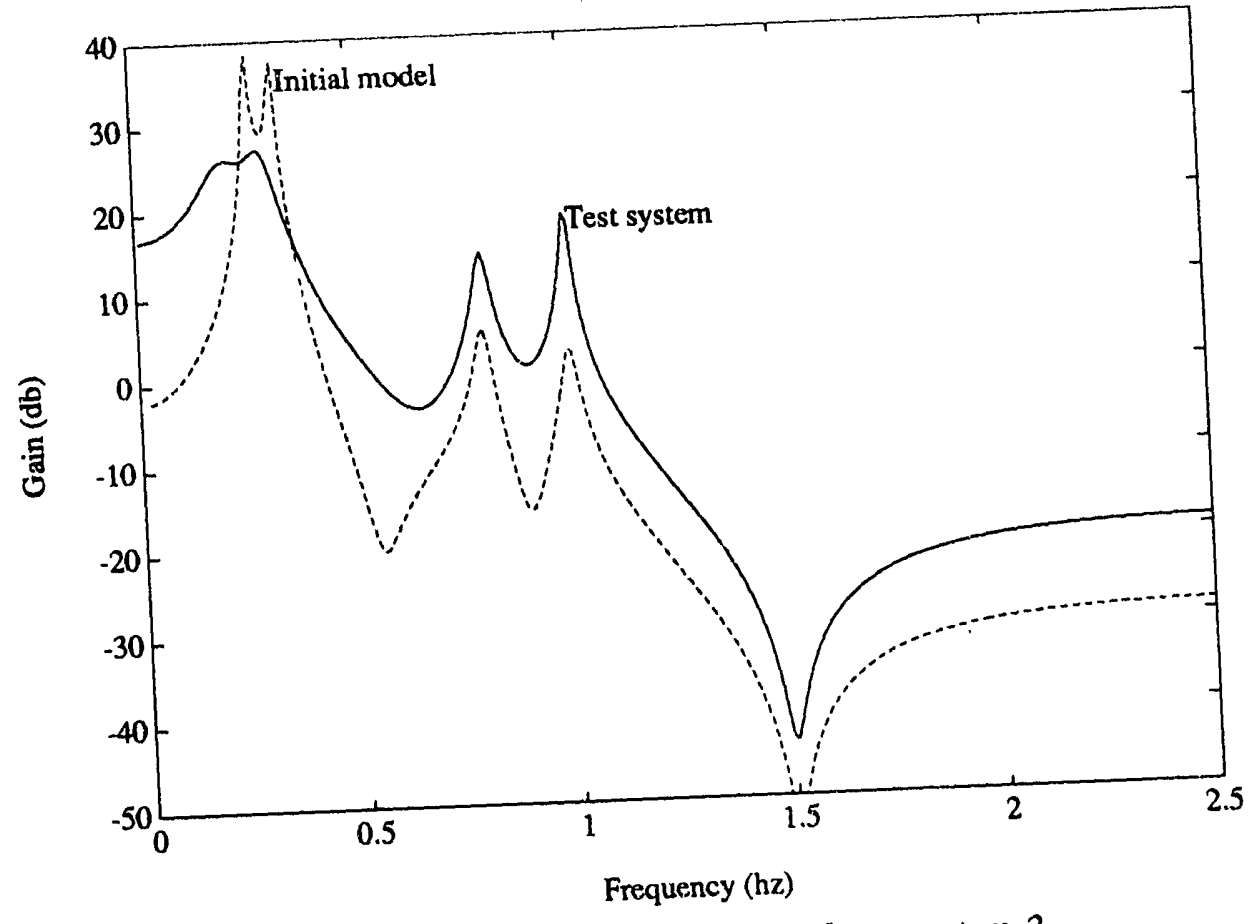

Figure 4.5. Frequency response of test system 3. 


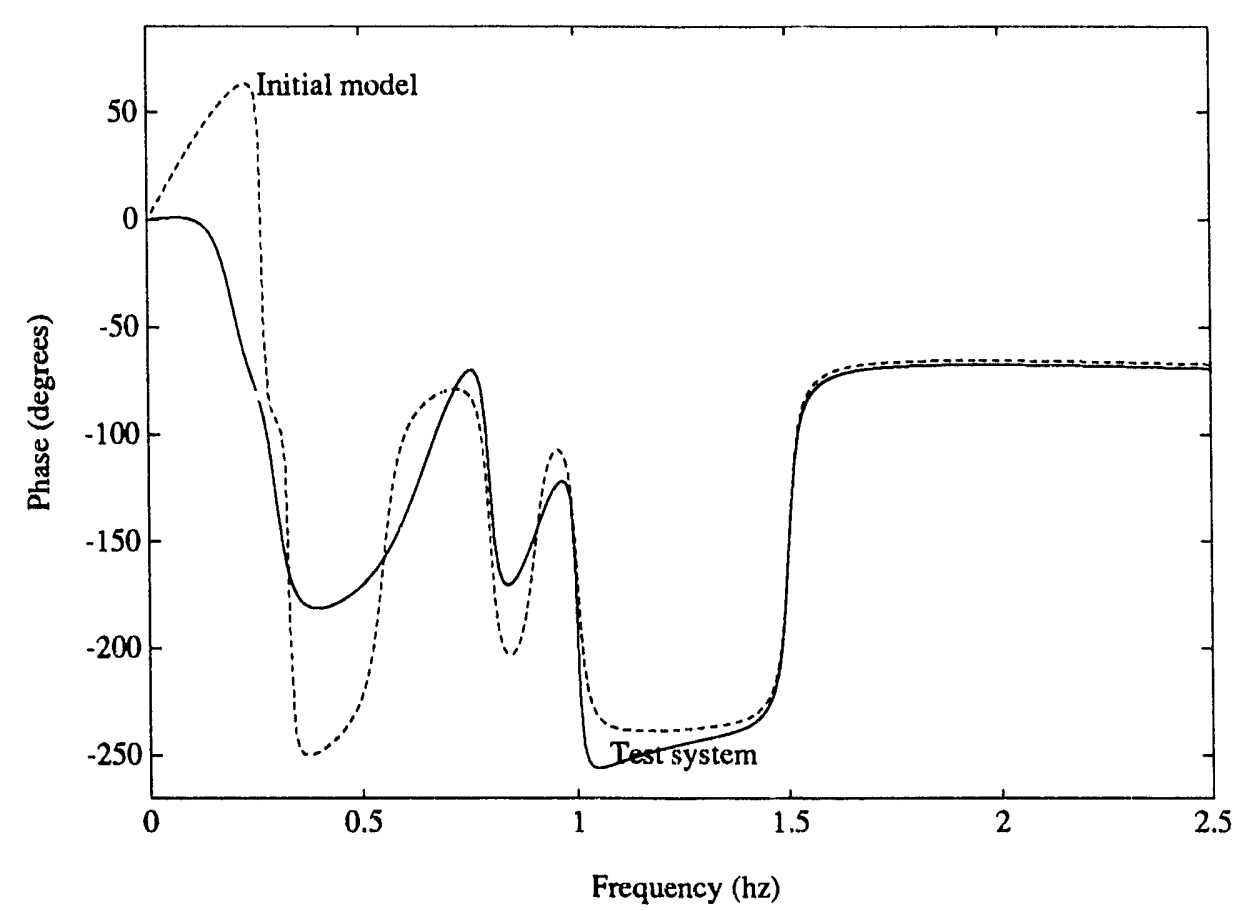

Figure 4.6. Frequency response of test system 3.

\subsection{Discrete Fourier Transformation Methods}

To fit a model to the frequency response of a system, one must first obtain the response data. How this is done is highly dependent upon the system. A common method used in measuring frequency response of a power system is to excite the system with an impulse signal. Then, a discrete Fourier transformation (DFT) is conducted on the sampled time-domain response. A key question is, How should the DFT be performed? In this section, two methods are discussed and compared; the effects of fitting response data to these two methods are presented in Section 5.

Because of the Nyquist sampling theorem, a basic assumption for the standard DFT is that the finite time-domain record repeats every $N$ samples, where $N$ is the total number of samples (Oppenheim and Schafer 1975). A large discontinuity between the first and last time samples causes the well-known problem of leakage. Therefore, "tricks" are often used to make the first and last samples continuous. The most common trick is to use a window that forces the end samples to smoothly converge to zero.

A standard method used by BPA for analyzing the DFT of a system impulse response is to precondition the data with zero padding and a squared Hanning window with the impulse occurring in the middle of the window (Hauer 1989). Figure 4.7 depicts this method for test system 1. This type of analysis is termed here $B P A D F T$ for convenience. The zero padding provides interpolation in the frequency domain, and the Hanning window reduces leakage at the expense of resolution (e.g., wider main-lobes). 


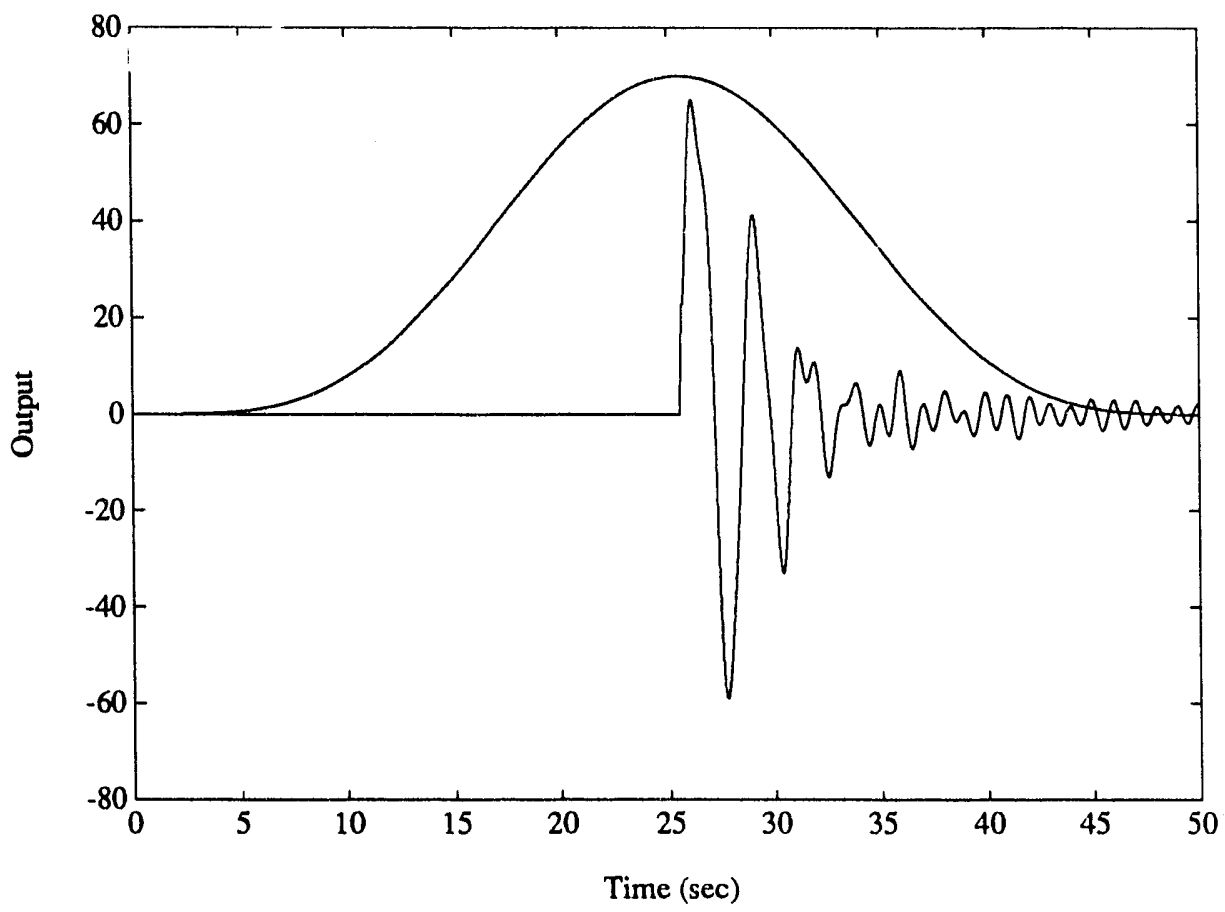

Figure 4.7. BPADFT.

An alternative to zero-padding and windowing is to pad the first half of the impulse response signal with the second half of the time response. Figure 4.8 demonstrates this for the impulse of test system 1. This provides continuity at the beginning and end of the time response and places the discontinuity at the impulse location of the pulse (which already has a discontinuity because of the pulse). The DFT in this form is termed the folding DFT, again for convenience.

In Figure 4.9, the BPADFT and folding DFT are compared with the actual frequency response of test system 1. With each method, 1024 data points are used. Close inspection of the peaks shows that the folding DFT more closely matches the system response. Although the differences seem small, the effects on identifying accurate damping coefficients are significant. This is demonstrated in Section 5.

\subsection{Noise Models}

To study noise effects on frequency-domain fitting, several synthetic noise files were constructed. Four noise models, each with its own coloration, include 1) white noise; 2) $1 / f$ noise; 3) $1 / f^{2}$ noise; and 4) sharply colored noise. White noise has a flat power spectrum over the frequency range of interest. The synthetic white noise signals were generated using the stationary Gaussian noise generator in MATLAB. 


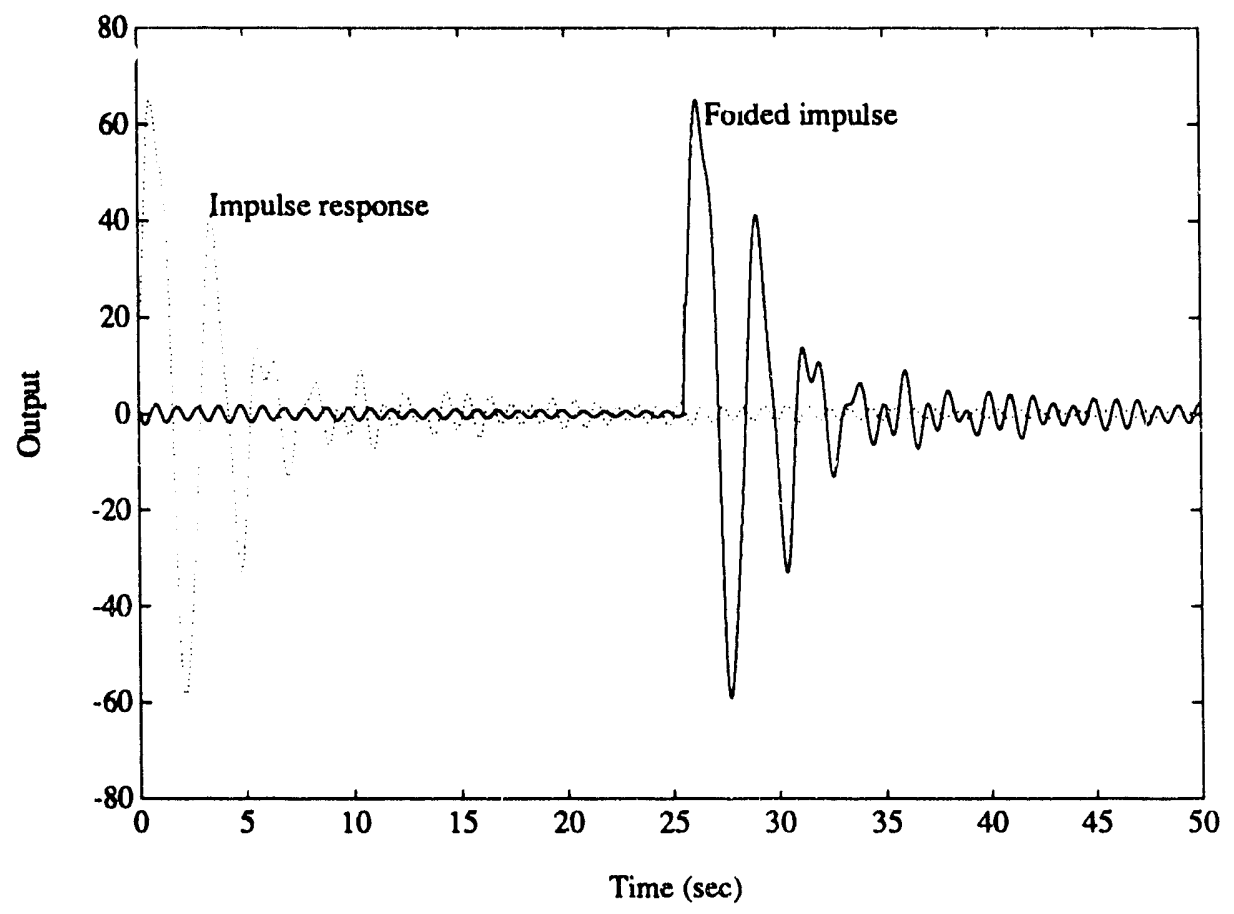

Figure 4.8. Folding DFT.

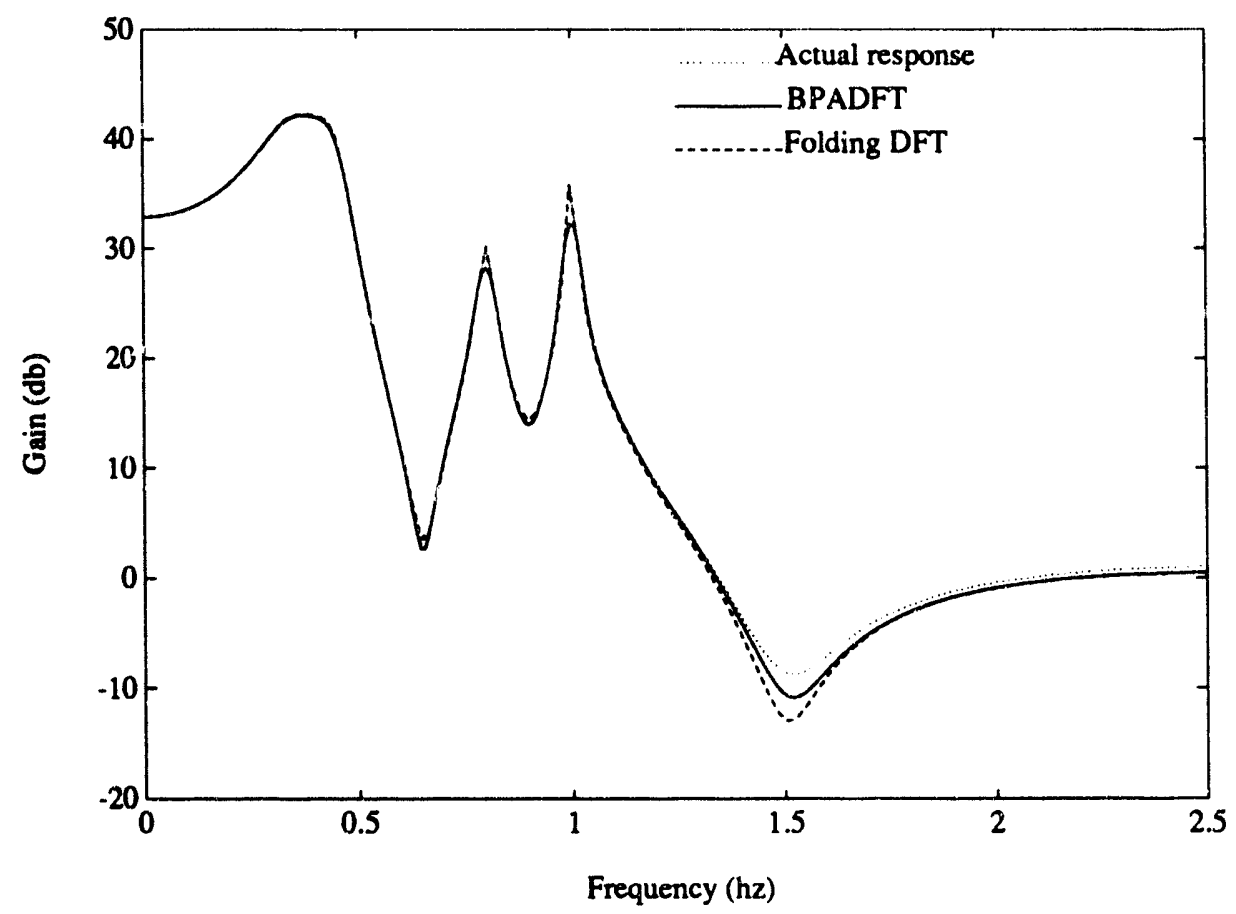

Figure 4.9. Comparing BPADFT and folding DFT. 
The power spectrum for $1 / f$ noise rolls off at a rate of $1 / f$ where $f$ is the frequency in the range of interest. For the models investigated here, the frequency range of interest is 0.1 to $2.0 \mathrm{~Hz}$. For this range, $1 / f$ noise is obtained by passing white noise through the nonlinear filter

$$
G_{1 / f}(s)=\frac{(2 \pi 0.1)^{1 / 2}}{s^{1 / 2}+(2 \pi 0.1)^{1 / 2}}
$$

Likewise, $1 / f^{2}$ noise has a power spectrum that rolls off at a rate of $1 / f^{2}$ for the range of interest. This noise is generated by passing white noise through the filter

$$
G_{1 / r^{s}}(s)=\frac{2 \pi 0.1}{s+2 \pi 0.1}
$$

Figure 4.10 shows the frequency response of Equations (4.3) and (4.4). Note that the $1 / f$ noise rolls off at $10 \mathrm{db} /$ decade, and the $1 / f^{2}$ rolls off at $20 \mathrm{db} /$ decade over the frequency range of interest. White and $1 / f$ noise have unique characteristics in that their power spectrum decreases linearly with frequency. If audible noise with this characteristic is recorded and played back at a different speed, it will sound the same. These types of noises are called scaling moises (West 1990). For this reason, and others discussed in West (1990), 1/f noise is often called fractal noise.

Colored noise is generated by passing white noise through a sharply tuned filter. For the examples discussed later in this report, the coloring filter consists of a tenth-order Chebyshev band-pass filter with corners at $0.4 \mathrm{~Hz}$ and $0.7 \mathrm{~Hz}$. Figure 4.11 shows the frequency response of this filter.

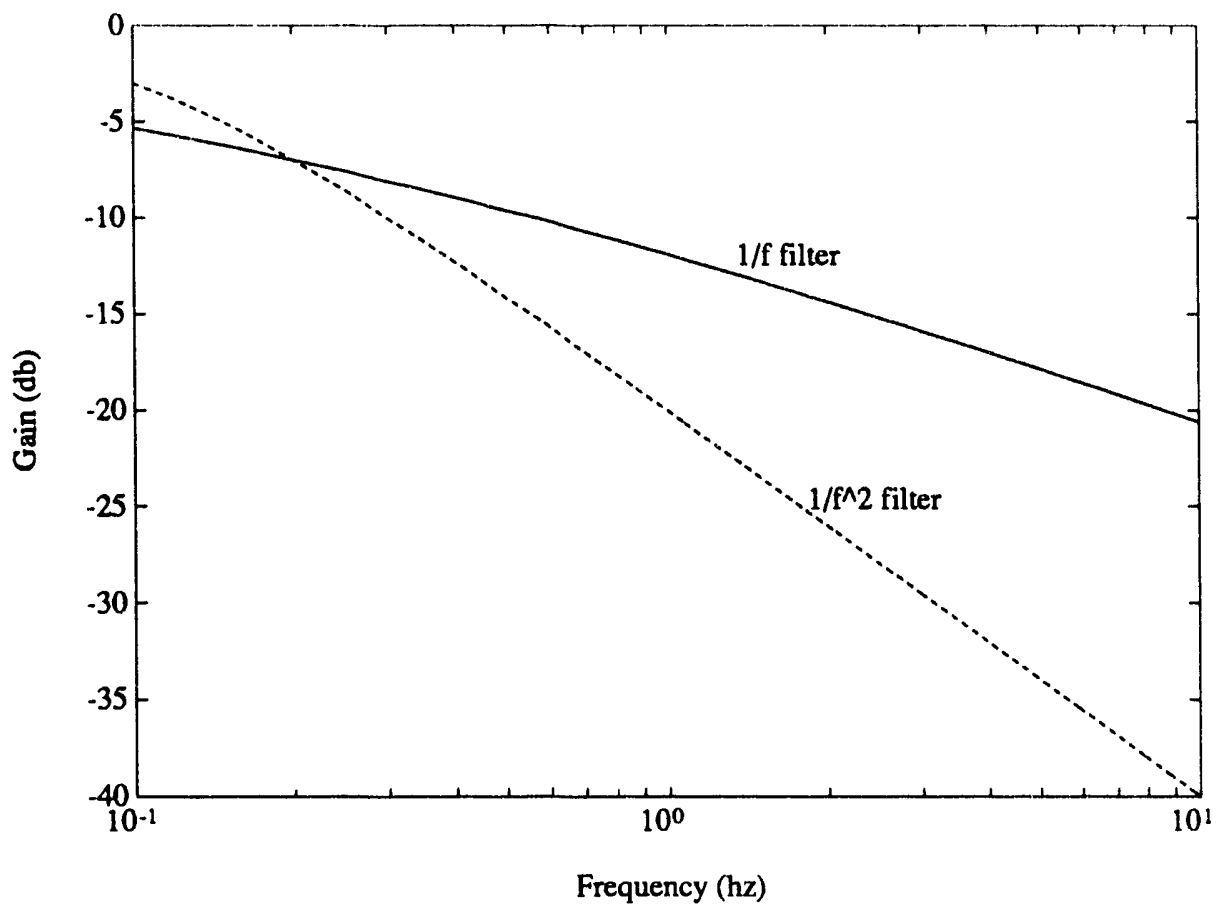

Figure 4.10. Frequency response of $1 / f$ and $1 / f^{2}$ filters. 


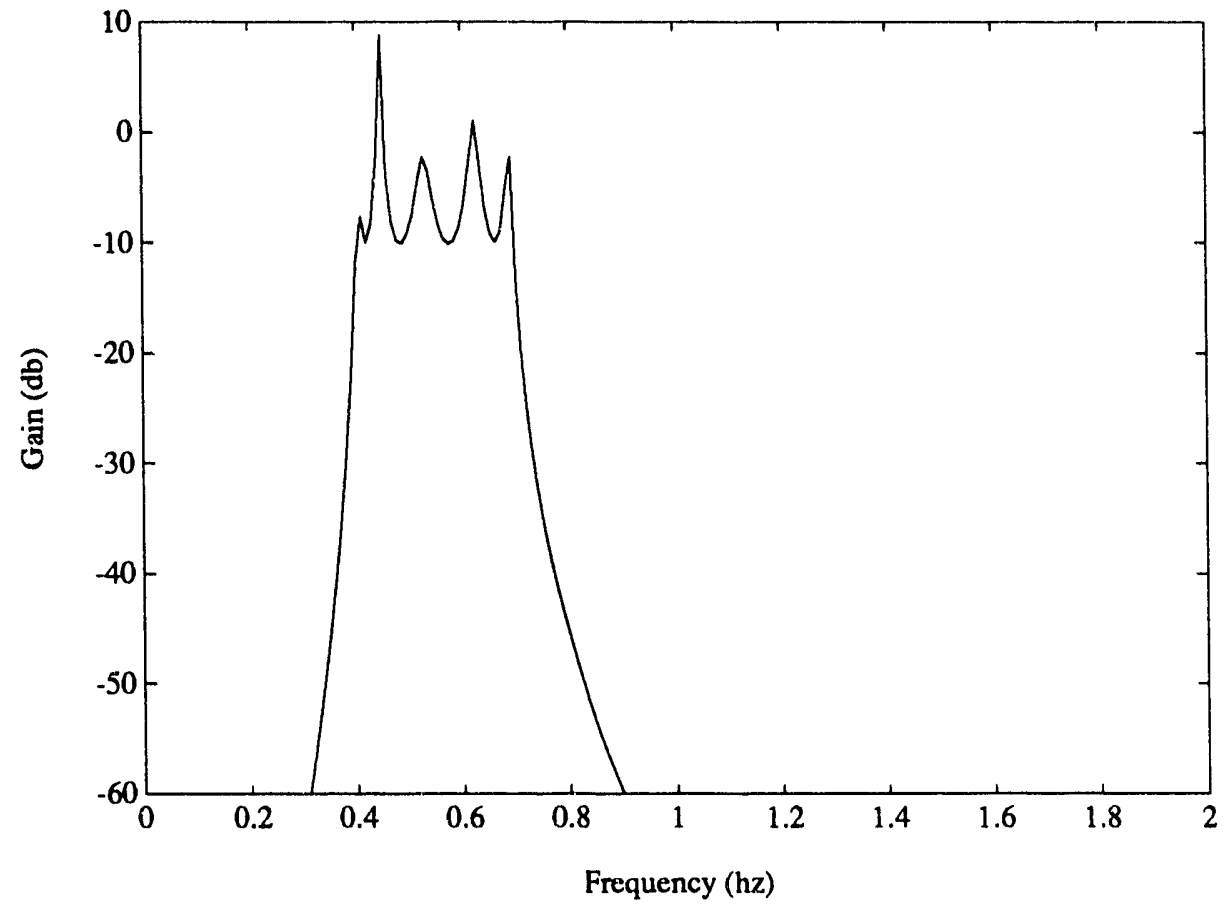

Figure 4.11. Frequency response of coloring filter.

Figures 4.12 through 4.14 show the DFTs of the noise sequences used in the examples in Section 4. Two methods of measuring the noise level are employed in later examples. One is the covariance of the noise sequence, and the other is the signal to noise (SNR) ratio. The covariance is an absolute measurement that is a function of the noise only. The SNR is defined here as

$$
S N R=10 \log _{10}\left(\frac{\operatorname{cov}(y(t))}{\operatorname{cov}(n(t))}\right)
$$

where cov is the covariance, $y(t)$ is the deterministic signal, and $n(t)$ is the noise. 


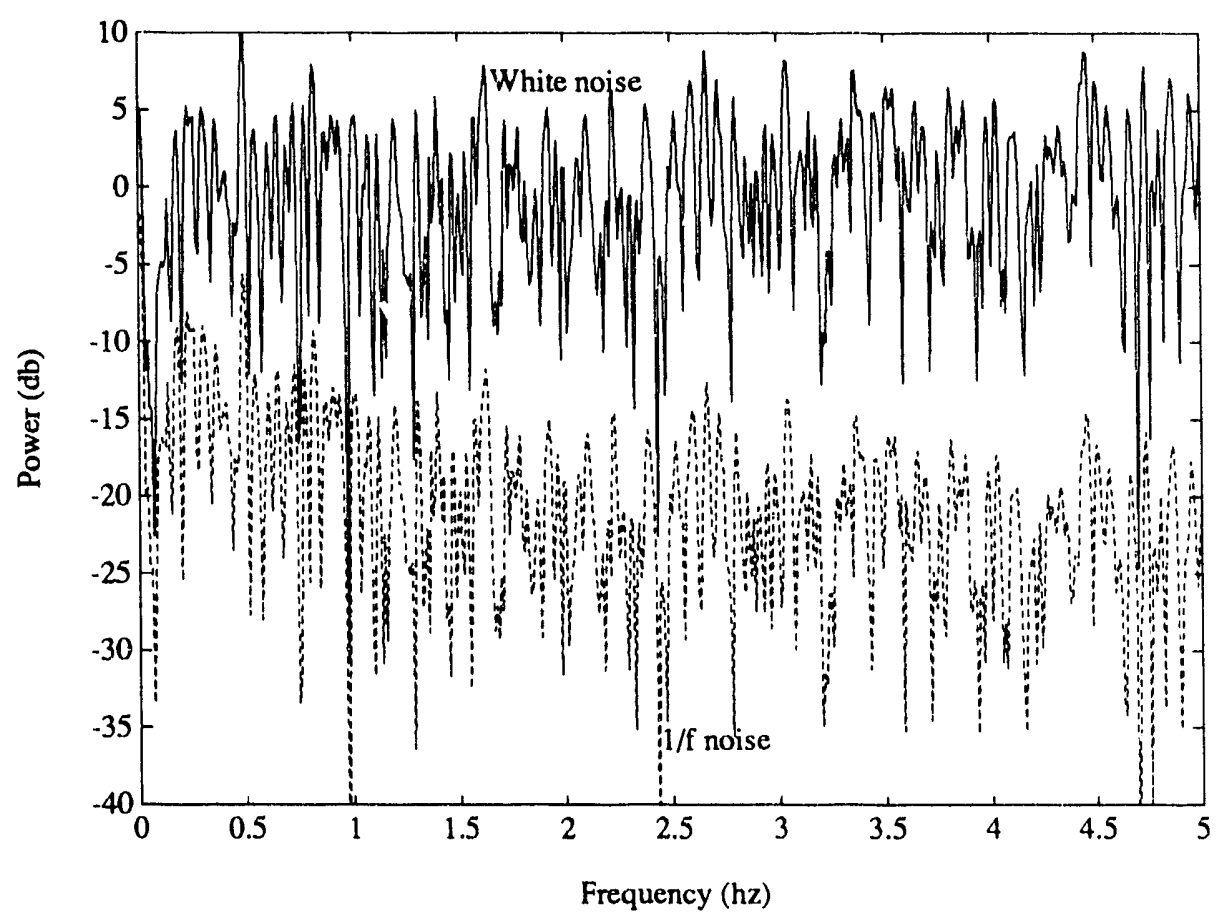

Figure 4.12. Frequency response of white and $1 / f$ noise.

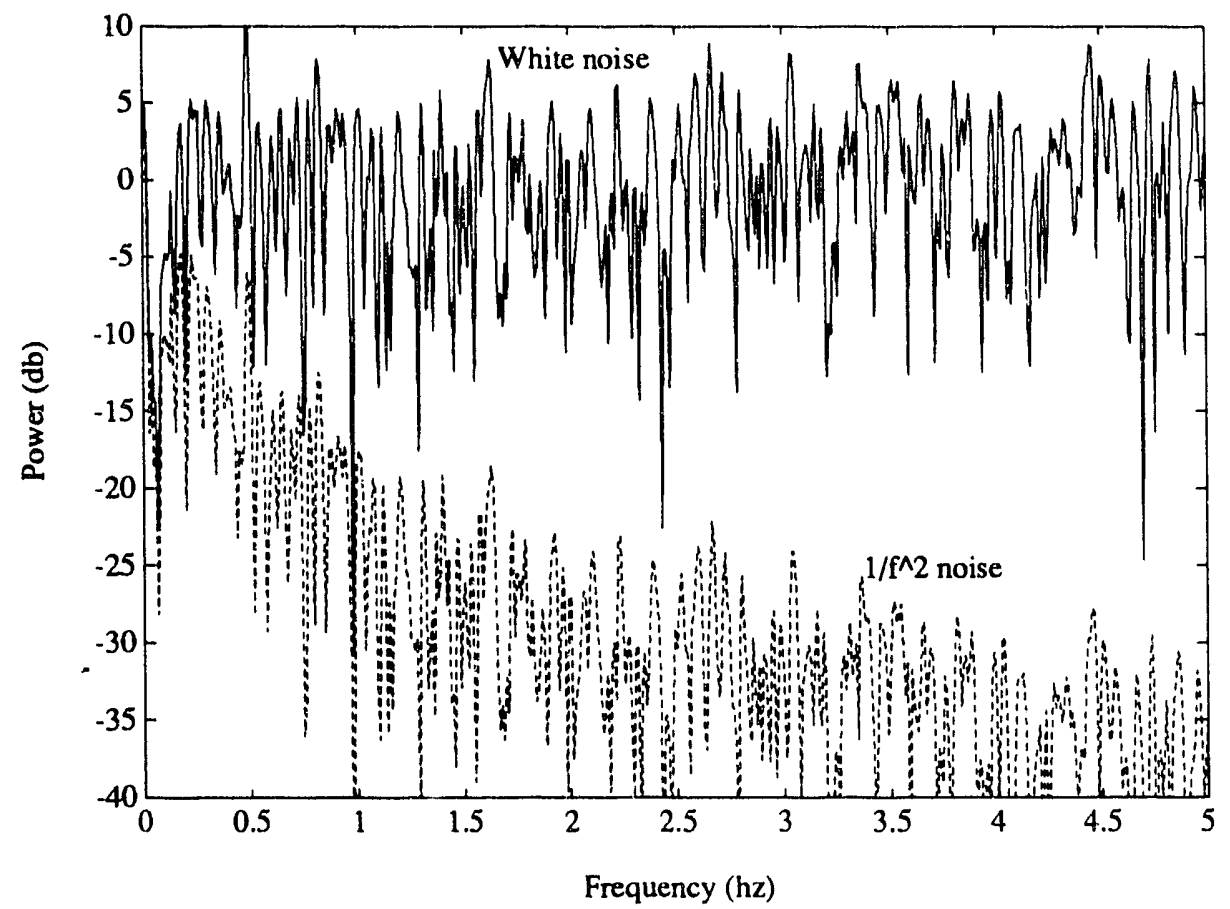

Figure 4.13. Frequency response of white and $1 / f^{2}$ noise. 


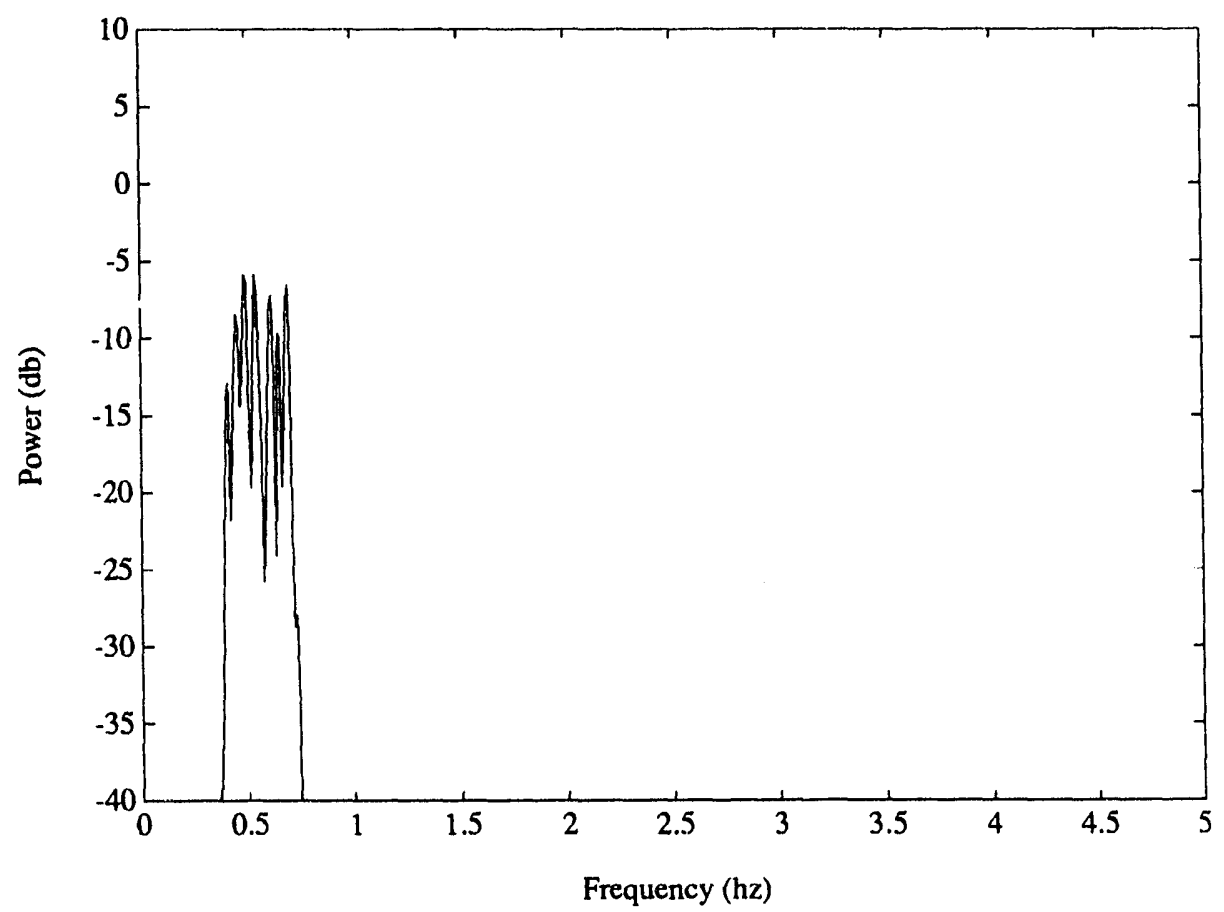

Figure 4.14. Frequency response of colored noise. 


\subsection{Properties of Frequency-Domain Fitting}

To fully use an advanced fitting program such as SYSFIT, one must understand the general characteristics of fitting linear models to frequency-domain data. Once these characteristics are understood, general "rules-of-thumb" can be demonstrated for the proper use of fitting options. In this section, some important characteristics of frequency domain-fitting are presented, and general usage rules are created from these characteristics. These rules and characteristics are developed by studying many specific examples. The examples involve fitting linear systems to generated frequency response data under various controlled conditions. The investigations conducted are classified into three general areas: 1) fitting to exact frequency response data; 2 ) fitting to the discrete Fourier transform (DFT) of noisy data; and 3) fitting to multi-path systems.

The remainder of this section is organized as follows. In Section 5.1, the characteristics of fitting to exact frequency response data are investigated. Properties of fitting to the DFT of noisy impulse response data are discussed in Section 5.2, and multi-path fitting is addressed in Section 5.3. Many examples are presented in that section. The SYSFIT input control files for these examples are provided in the Appendix to this report.

\subsection{Fitting to Exact Frequency Response Data}

Under ideal conditions, one is given the exact frequency response of a system. In this section the characteristics of fitting to exact frequency response data under different system and fitting conditions are presented. The conditions studied involve investigating the effects of

- using alternative optimization cost function options

- using different optimization search routines

- incorrect model order

- missing low- or high-frequency response data

- closely-spaced poles

- closely-spaced pole-zero pairs.

These effects are discussed in the sections to follow.

\subsubsection{Different Optimization Routines}

As discussed in Section 3, SYSFIT has five search options: steepest descent (SD); PARTAN; conjugate gradient (CG); Davidson Fletcher Powell (DFP); and self-scaling variable metric (SSVM). All of these are nonlinear gradient-based search methods that require the calculation of a gradient. Several linear-system tests were conducted to determine which method is the best to use with SYSFIT. These tests clearly indicated that the DFP method is the best. 


\section{Example 1}

The exact frequency response data from test system 2 is fit using its initial model. Each optimization routine's ability to fit the data is summarized in Table 5.1. As indicated in Table 5.1, only the DFP routine satisfies the Kuhn-Tucker conditions and results in an exact fit. The cost weights were adjusted so that the initial cost function for each case is 139 . The final cost for the SD and PARTAN methods is relatively large, and the final model is inaccurate (as indicated by the maximum parameter error in Table 5.1). Although the CG and SSVM routines do not converge, their final models are accurate within three decimal places.

Table 5.1. Comparison of optimization search routines for Example 1 (100 iterations).

\begin{tabular}{|c|c|c|c|}
\hline $\begin{array}{c}\text { Search } \\
\text { Routine }\end{array}$ & $\begin{array}{c}\text { Kuhn-Tucker } \\
\text { Convergence }\end{array}$ & $\begin{array}{c}\text { Final } \\
\text { Cost }\end{array}$ & $\begin{array}{c}\text { Max. Parameter } \\
\text { Error }\end{array}$ \\
\hline SD & No & 88.95514 & 0.81297 \\
\hline PARTAN & No & 32.24400 & 0.36250 \\
\hline CG & No & 0.05278 & 0.00018 \\
\hline DFP & Yes, 35 iter. & 0.00000 & 0.00000 \\
\hline SSVM & No & 0.00133 & 0.00020 \\
\hline
\end{tabular}

Example 1 demonstrates that the DFP routine tends to converge to the proper solution in fewer iterations. The difference between the routines becomes even larger as the testing conditions become more stringent (such as fitting to noisy DFTs).

\subsubsection{Alternative Cost Function Options}

An important advantage of SYSFIT is that it provides many options in forming the fitting optimization cost function as described in Section 3. This includes incorporating squared-magnitude data, log-magnitude data, magnitude-slope, phase, and phase-slope data. Also, appropriate weighting can be placed on each of these terms as well as the measured response data. The cost function for a single path fit is written as Equation (3.2). Some general rules based upon experience gained from this project include the following:

1. Use the log-magnitude option to formulate cost error $E_{l}$.

2. Inclusion of phase error $E_{2}$ can enhance fitting under many conditions, including

- avoiding identified poles and zeros being reflected about the $j \omega$ axis

enhancing convergence rate

- providing convergence to the proper solution when use of $E_{l}$ alone fails. 
3. When using $E_{i}$ and $E_{2}$ to form $J(\underline{x})$, adjust $W_{1}$ and $W_{2}$ so that the initial cost on the phase error is of the same order of magnitude as the cost on the gain error. That is, adjust $W$, and $W_{2}$ so that

$$
\left.W_{1} E_{1}\left(\underline{x_{0}}\right) \approx W_{2} E_{2} \underline{x_{0}}\right)
$$

where $\underline{x}_{0}$ is the vector of initial parameters.

4. Cost weights $\left(W_{m}\right.$ 's) should be equally scaled so that

$$
J\left(\underline{x_{0}}\right) \approx 100
$$

This improves the fitting performance primarily because of increased numerical stability.

5. If slope cost errors $E_{3}$ and $E_{4}$ are included, $W_{3}$ and $W_{4}$ should be scaled so that their contribution to $J\left(\underline{x}_{0}\right)$ is less than that of $E_{l}$ and $E_{2}$. That is,

$$
W_{1} E_{1}\left(\underline{x_{0}}\right)+W_{2} E_{2}\left(\underline{x_{0}}\right)>W_{3} E_{3}\left(\underline{x_{0}}\right)+W_{4} E_{4}\left(\underline{x_{0}}\right)
$$

The advantage of using log-magnitude gain data is especially evident with data near system zeros. Near zeros, the system gain decreases to a minimum. Such a minimum is easily "seen" using logmagnitude data (i.e., decibel gain) versus squared-magnitude data. For example, the gain for test system 2 is shown in both Figures 5.1 and 5.2. The log-magnitude data has considerable change near a zero while the squared magnitude data is essentially null near system zeros.

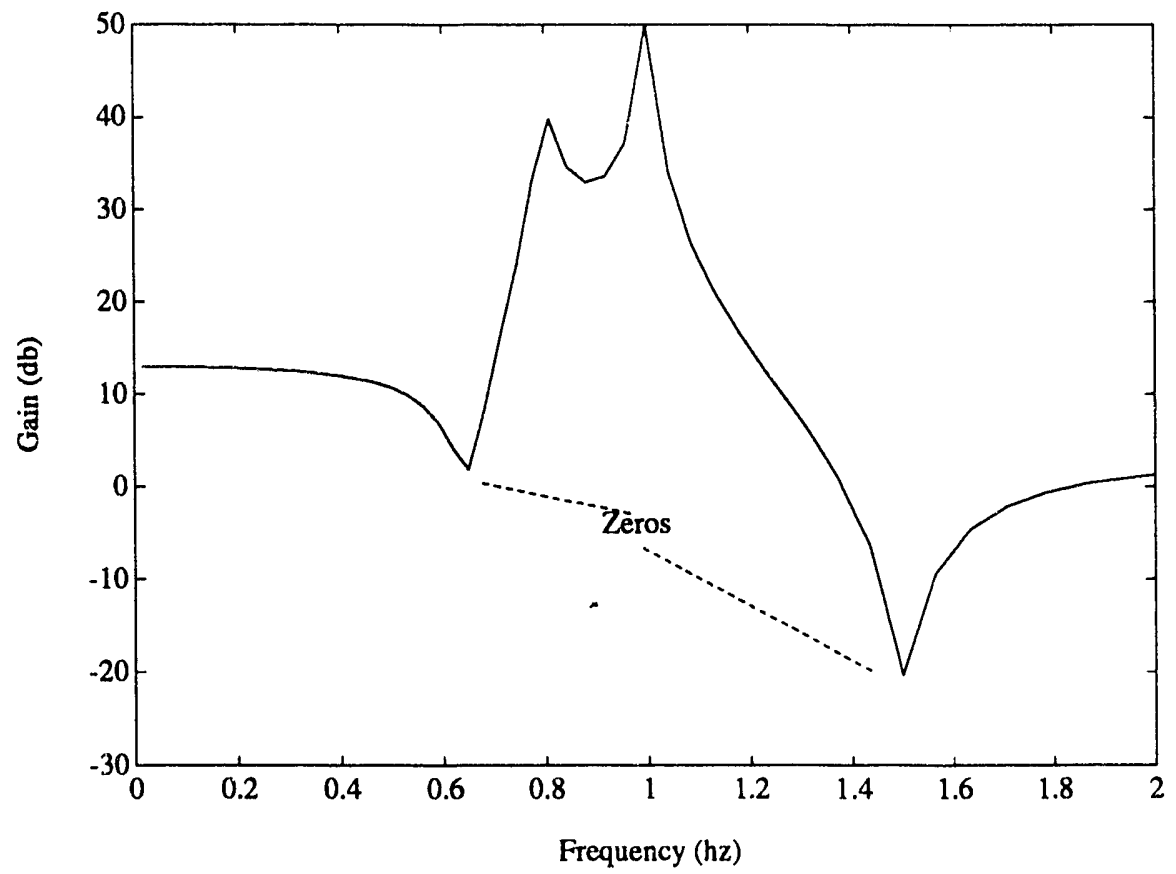

Figure 5.1. Log-magnitude response of test system 2 . 


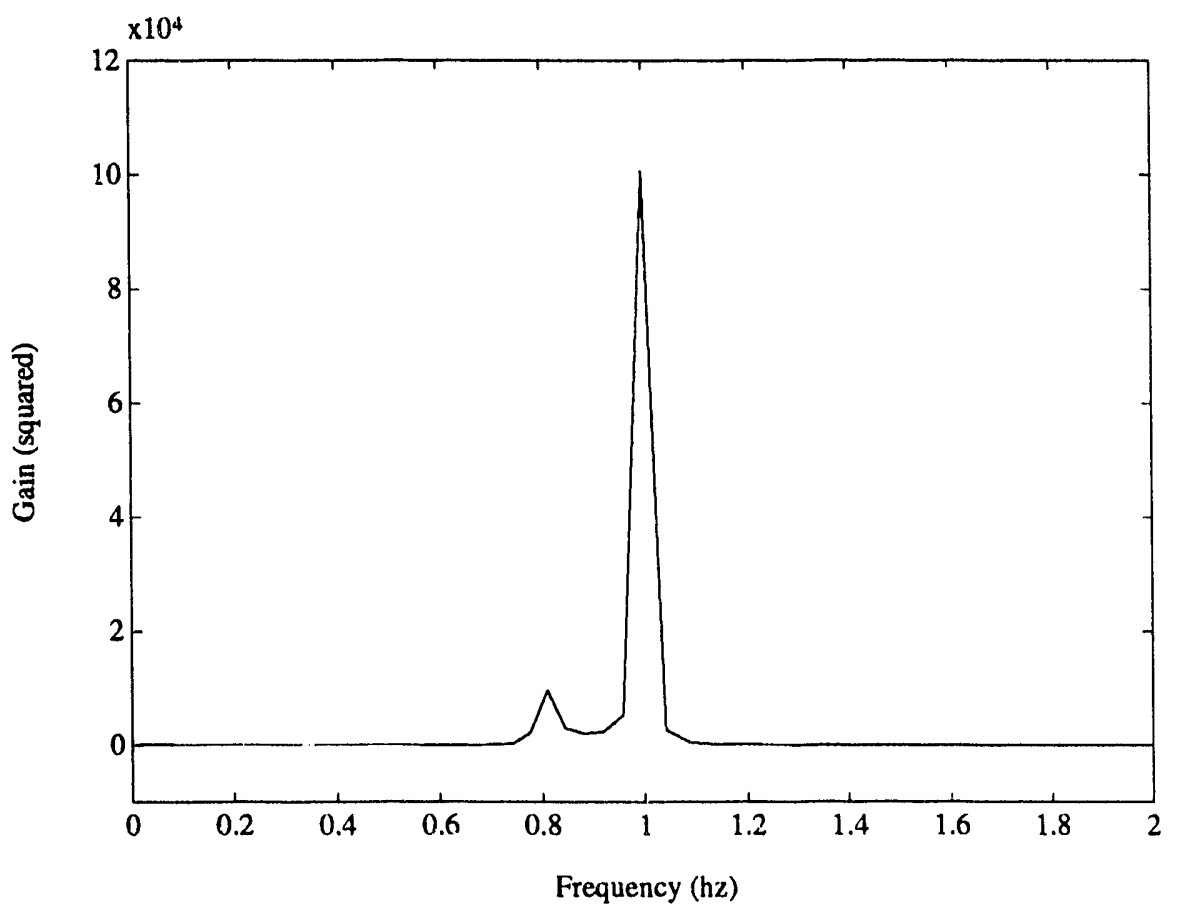

Figure 5.2. Magnitude-squared response for test system 2 .

The following example illustrates the advantage of using log-magnitude data.

\section{Example 2}

Consider fitting to the exact gain data of test system 2. With log-magnitude data, the final model is reached with Kuhn-Tucker conditions satisfied in 48 iterations. The final model exactly fits the parent parameters to six decimal places, except that one identified zero is reflected about the $j \omega$ axis (this occurs because no phase data is included in the fit).

The same test is conducted using magnitude-squared data. After 100 iterations, Kuhn-Tucker conditions are not satisfied. The fit to system poles is very good, but, as shown in Figure 5.3, the fit to the zeros is not as accurate. Figure 5.3 shows the actual system response gain in decibels versus the final model identified by fitting to magnitude-squared data. The identified zeros are accurate only to one decimal place. In both cases, the cost weight $W_{l}$ is adjusted using Equation 5.2 .

The fitting tests in Example 2 are conducted using a low-order system with no noise and actual frequency response data. As one considers the effects of higher-order dynamics, noise, and "smearing" resulting from a DFT, the advantage of using log-magnitude data is intensified.

To demonstrate the effects of phase data, tests from Examples 1 and 2 are compared. In Example 2 , the first fit used log-magnitude data with the DFP search and converged in 48 iterations; the 


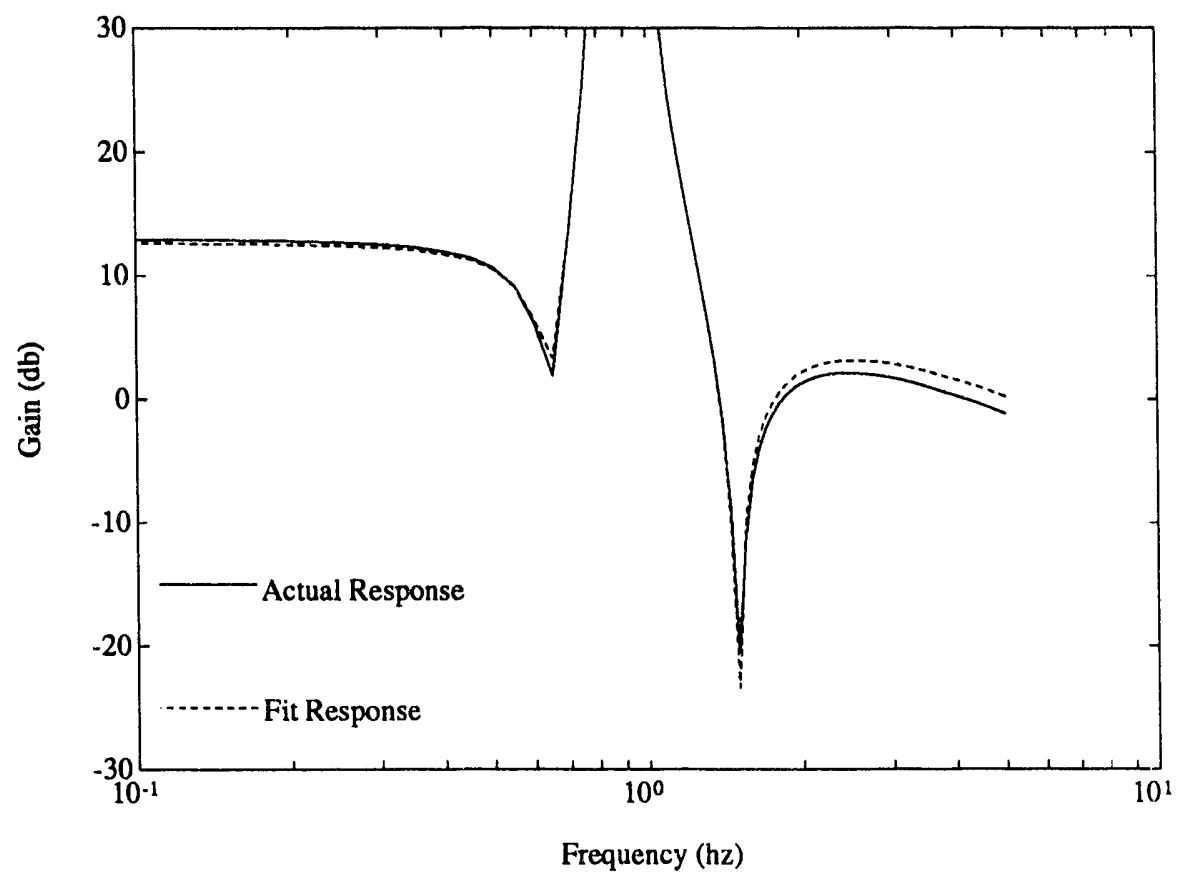

Figure 5.3. Squared-magnitude fit versus actual response for Example 2.

identified model has one zero reflected into the right-half plane (RHP). The DFP fit in Example 1 used both log-magnitude and phase data in the fitting cost function and converged in 35 iterations to the exact model. In both cases, cost weights were adjusted using the rules listed at the beginning of this section. This comparison demonstrates how phase data helps prevent reflection of poles and zeros, and how it increases the convergence rate.

Equations (5.1) through (5.3) give general rules for choosing the cost function weights. The following example demonstrates the effectiveness of these rules.

\section{Example 3}

Once again, consider fitting to the actual frequency response of test system 2. Three cost weight cases are tested: 1) $\left.W_{1}=10, W_{2}=1, W_{l} E_{l}\left(x_{0}\right)=0.38895, W_{2} E_{2}\left(x_{0}\right)=0.00761 ; 2\right) W_{1}=$ $10, W_{2}=55, W_{l} E_{l}\left(x_{0}\right)=0.38895, W_{2} E_{2}\left(x_{0}\right)=0.41872 ;$ and 3$) W_{l}=1000, W_{2}=5500, W_{l} E_{l}\left(x_{0}\right)=$ $38.895, W_{2} E_{2}\left(x_{0}\right)=41.872$. Table 5.2 outlines the results of the three cases. With case 1 , neither Equation (5.1) nor (5.2) is satisfied. The search did not converge after 100 iterations. In addition, the final model is accurate to only one decimal place and has a pole reflected about the $j \omega$ axis. Cases 2 and 3 both converge to accurate solutions. With case 2, Equation (5.1) is satisfied but (5.2) is nfi. Both Equations (5.1) and (5.2) are satisfied for case 3, which converged more than twice as fast as case 2. 
Table 5.2. Comparison of fit cases for Example 3.

\begin{tabular}{||c|c|c|c|}
\hline Case & 1 & 2 & 3 \\
\hline Convergence & No $(100$ iter. $)$ & 77 iterations & 37 iterations \\
\hline Fit accuracy & $\begin{array}{c}1 \text { decimal } \\
1 \text { reflection }\end{array}$ & 6 decimals & 6 decimals \\
\hline
\end{tabular}

\subsubsection{Incorrect Model Order}

One drawback of SYSFIT is that the user is required to supply the program with an initial guess for the plant. The first question that must be answered is, What is the order of the initial model? Two cases are possible: estimating too small an order, and estimating too large an order. In general, SYSFIT produces a "compromise" fit when the model order is too small. That is, none of the true parameters is identified, but a low-order model with a frequency response close to the high-order one is identified. If the estimate is too large, SYSFIT tends to "reduce" the order through pole-zero cancellation. The following examples illustrate these points.

\section{Example 4}

Consider the exact frequency response of version 2 of test system 1, which is a 9th-order system. From this system's frequency response in Figure 5.1, one might suspect that the plant is 6th- or 7th-order. Using the ad hoc method of choosing an initial model as described in Section 4 , the following initial 7th-order model is developed:

$$
\begin{gathered}
G_{l}(s)=56\left(\frac{s^{2}+0.2 s+\left(0.1^{2}+(1.3 \pi)^{2}\right.}{s^{2}+0.4 s+\left(0.2^{2}+(0.7 \pi)^{2}\right.}\right)\left(\frac{s^{2}+0.2 s+\left(0.1^{2}+(1.8 \pi)^{2}\right)}{s^{2}+0.1 s+\left(0.05^{2}+(1.6 \pi)^{2}\right)}\right) \\
\left(\frac{s^{2}+0.1 s+\left(0.05^{2}+(3 \pi)^{2}\right)}{s^{2}+0.1 s+\left(0.05^{2}+(2 \pi)^{2}\right)}\right)\left(\frac{1}{s+5 \pi}\right)
\end{gathered}
$$

Figures 5.4 and 5.5 show the frequency response of this initial model in comparison to that of the test system data. For this reduced-order fit, SYSFIT converges with Kuhn-Tucker conditions satisfied in 176 iterations. Figures 5.6 and 5.7 show the identified reduced-order and actual system response data. As can be seen, SYSFIT seems to identify a "compromise" fit. Figure 5.8 compares the identified poles to the poles of the test system. As can be seen, the poles near $0.8 \mathrm{~Hz}$ and $1.0 \mathrm{~Hz}$ are accurately identified. However, the model does not have enough degrees of freedom to identify the actual poles at $0.35 \mathrm{~Hz}$ and $0.45 \mathrm{~Hz}$. Consequently, it identifies a compromise near $0.38 \mathrm{~Hz}$. 


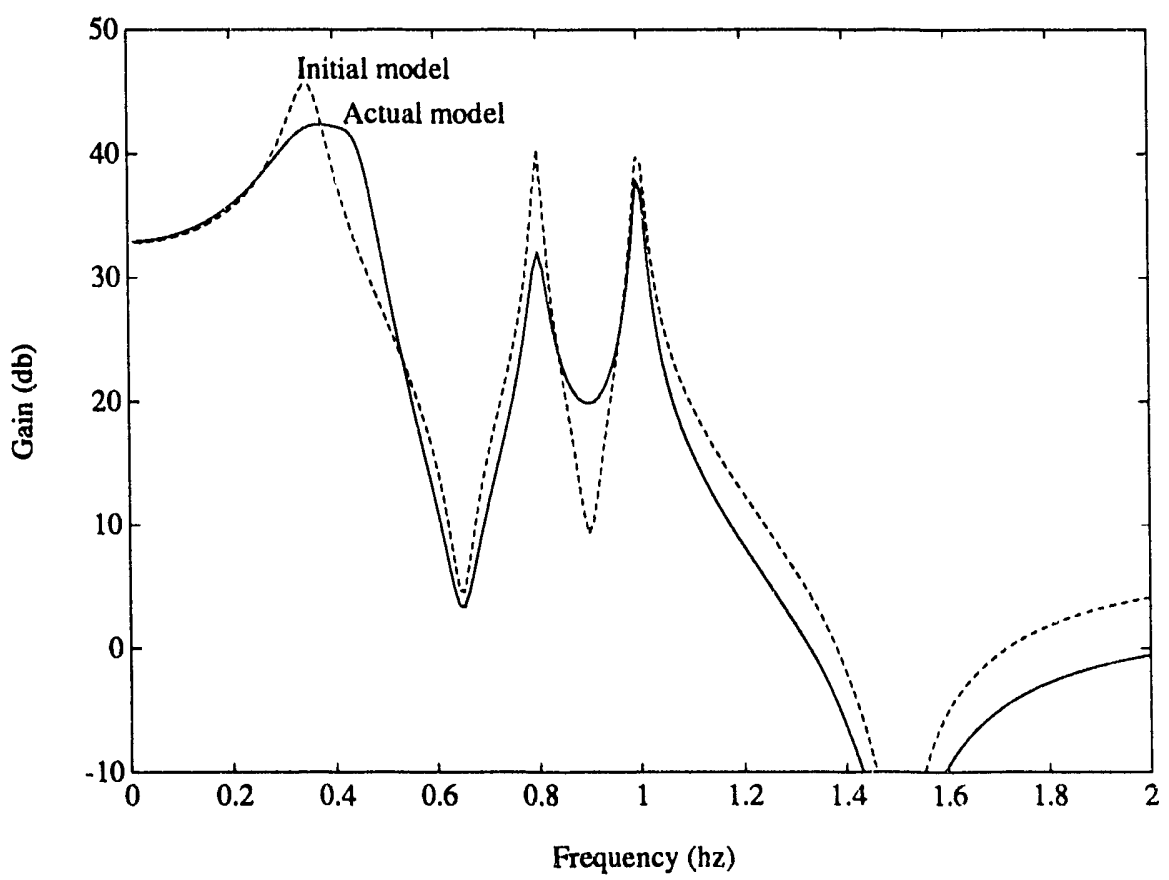

Figure 5.4. Gain of initial and actual models for Example 4.

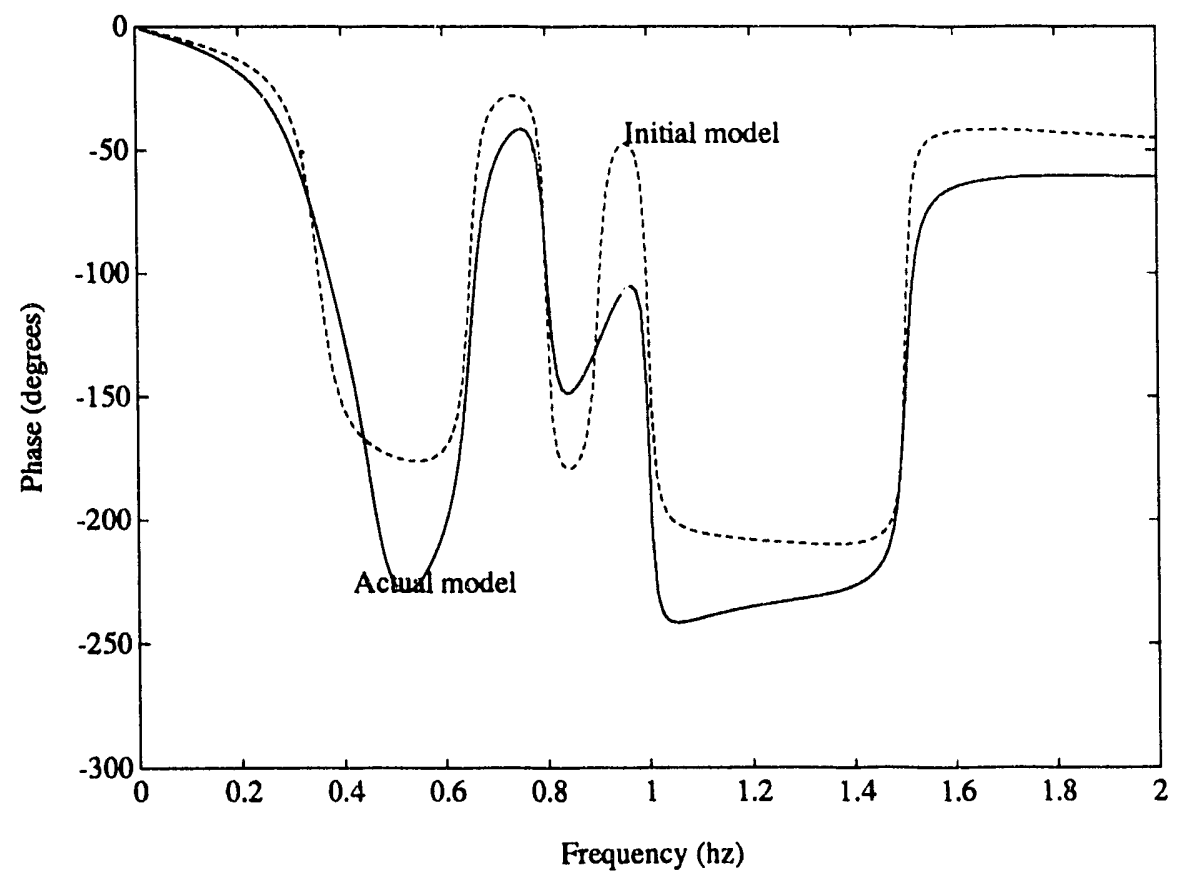

Figure 5.5. Phase of initial and actual models for Example 4. 


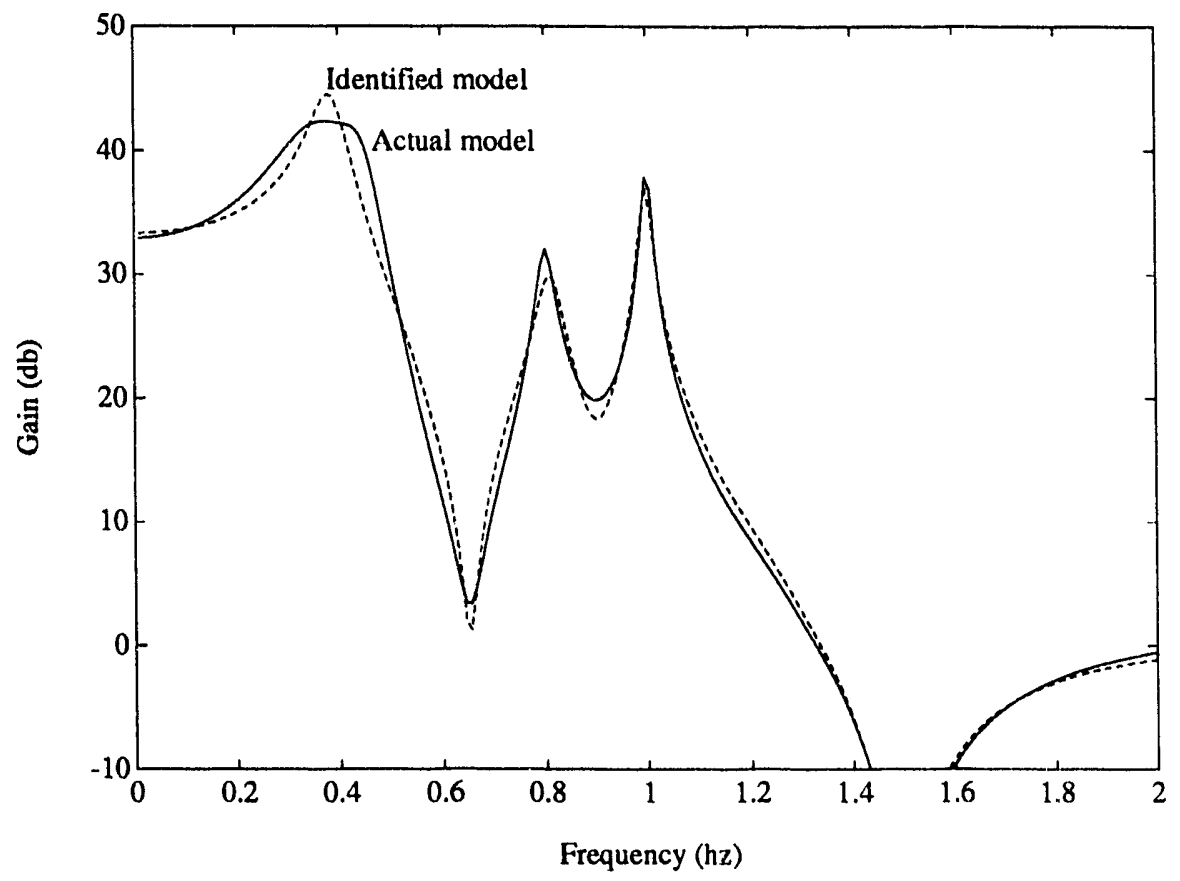

Figure 5.6. Gain of identified model for Example 4 .

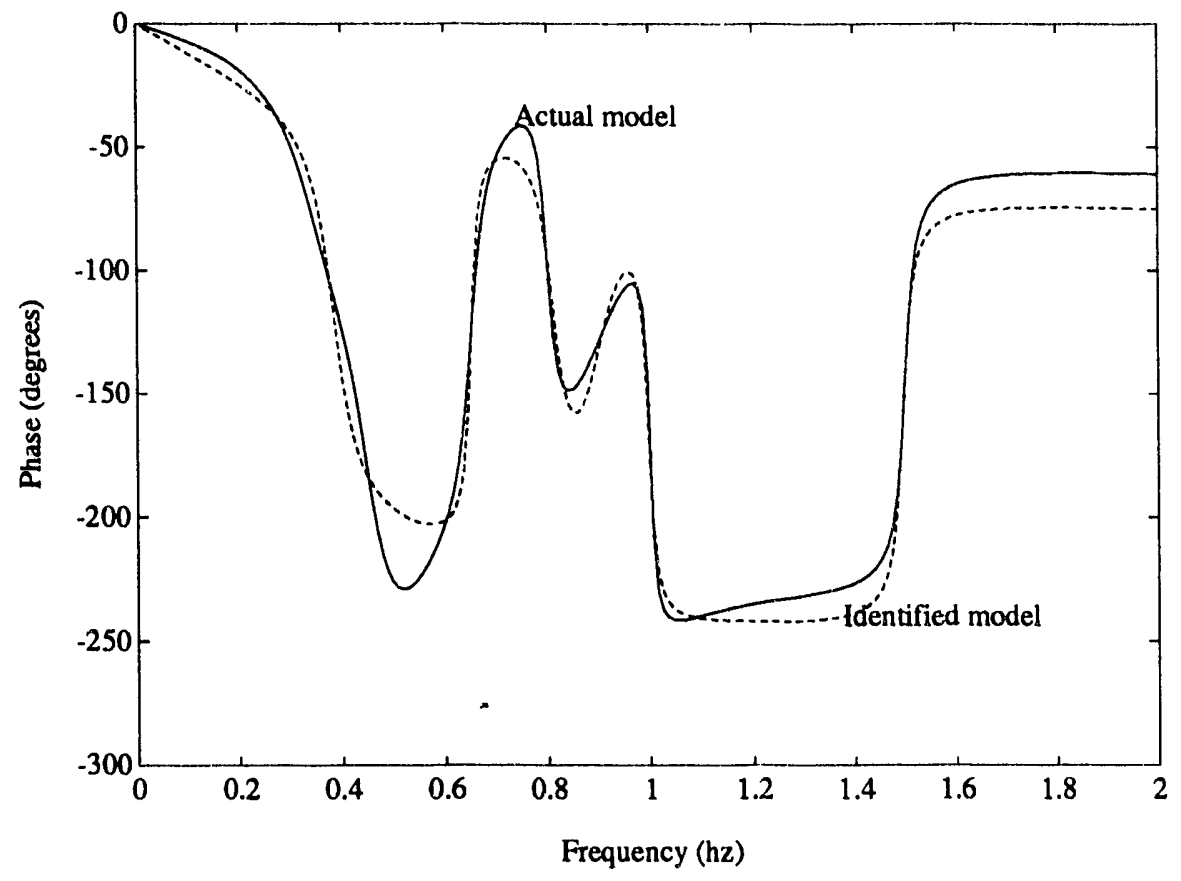

Figure 5.7. Phase of identified model for Example 4. 


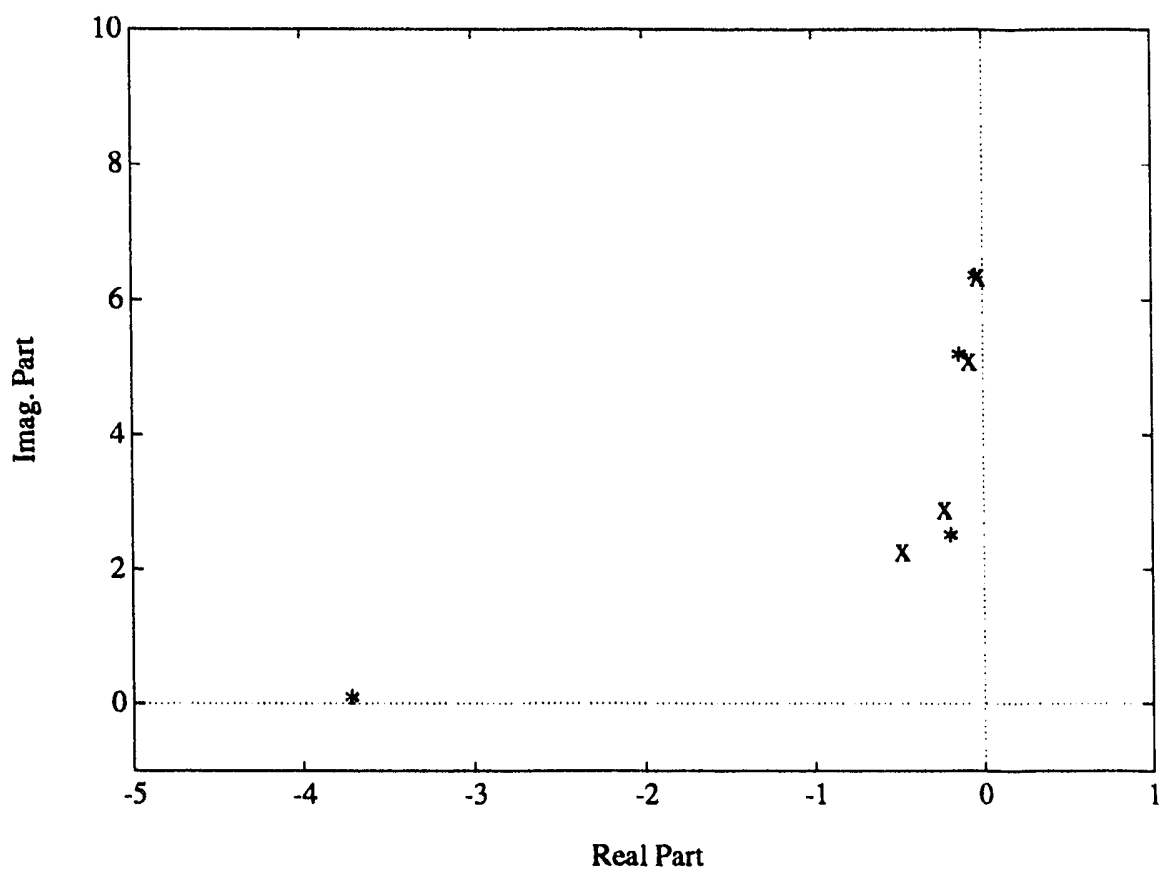

Figure 5.8. Pole plot for final fit for Example $4\left(x=\right.$ system, ${ }^{*}=$ identified).

\section{Example 5}

In this example, the model is assumed to be 11 th-order for the 9 th-order plant of version 2 , test system 1 , and the initial model is

$$
G_{l}(s)=\left(G_{l}(s) \text { of } E q .(4.2)\right)\left(\frac{0.125(s+0.8 \pi)^{2}}{s^{2}+0.5 s+0.25^{2}+(0.9 \pi)^{2}}\right)
$$

Figures 5.9 and 5.10 show the response of the initial model versus that of the test system. SYSFIT does not converge in this case, even after 600 iterations. But, the final model provides an excellent fit to the plant (as shown in Figures 5.11 and 5.12). Figure 5.13 shows a plot of the poles and zeros of the identified model. All poles and zeros of this test system are accurately identified, and extra poles and zeros cancel each other. 


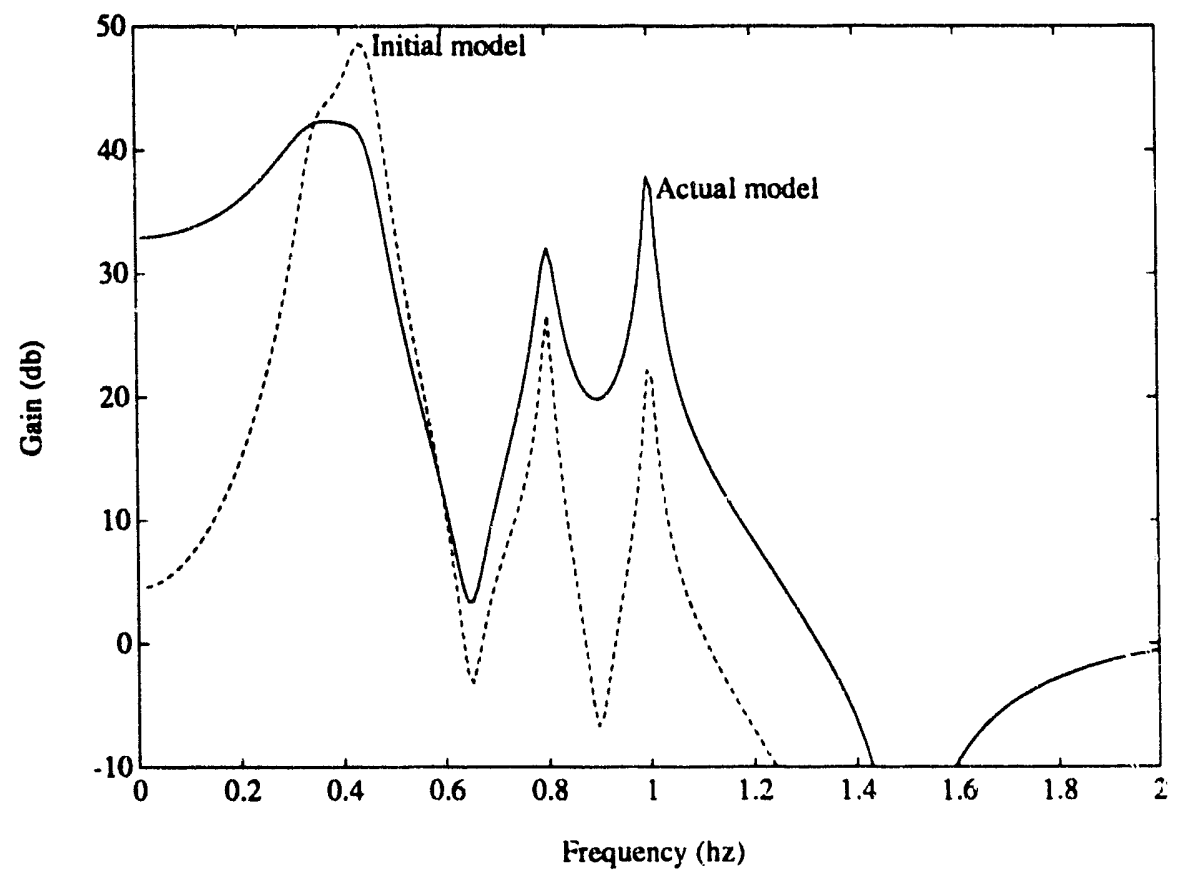

Figure 5.9. Gain of initial monel compared to accual for Example 5.

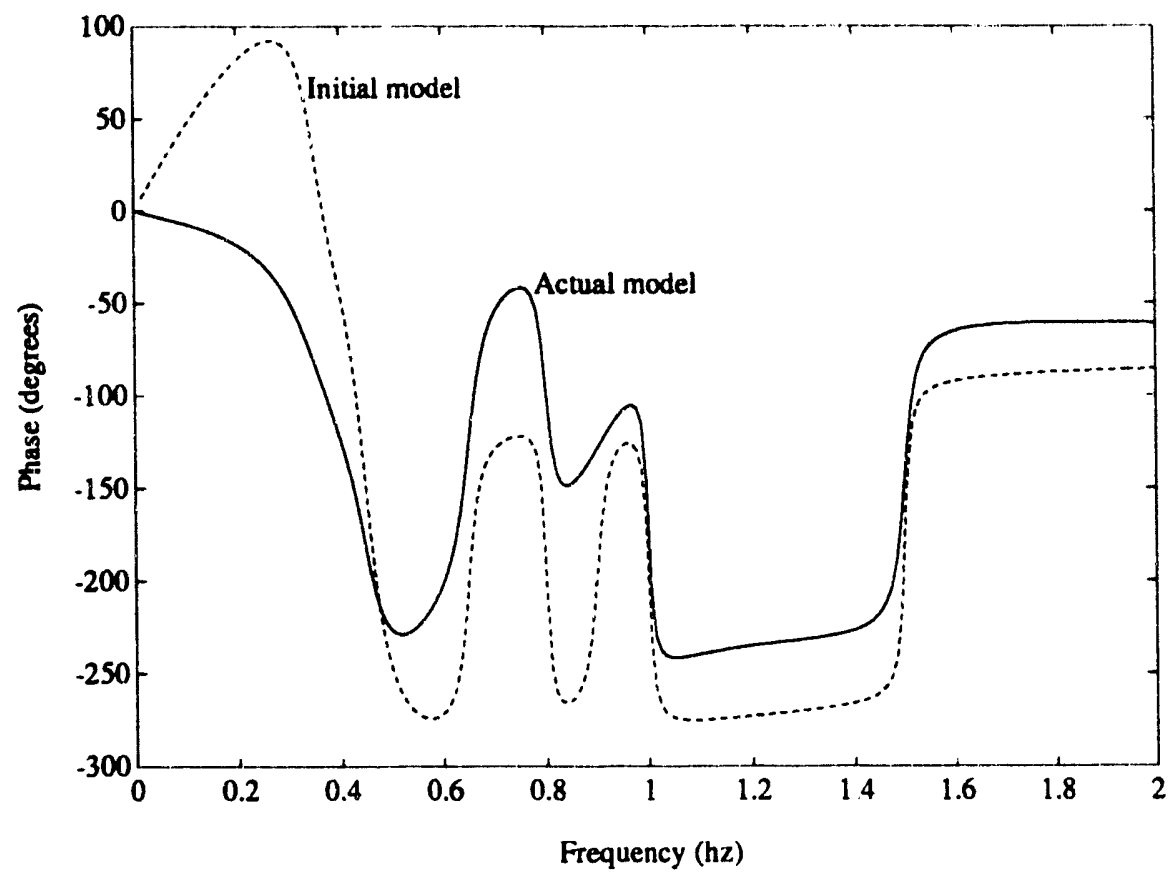

Figure 5.10. Phase of initial model compared to actual for Example 5. 


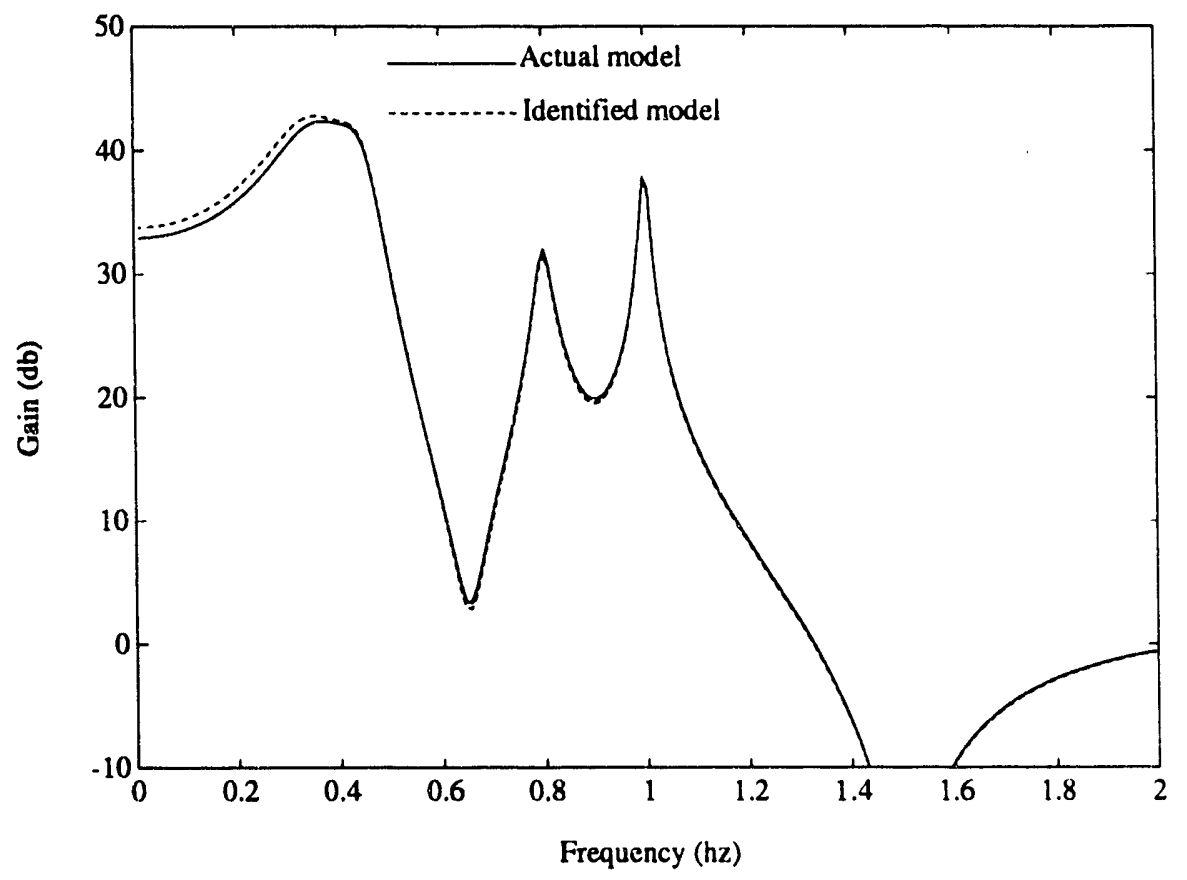

Figure 5.11. Identified model gain compared to actual for Example 5.

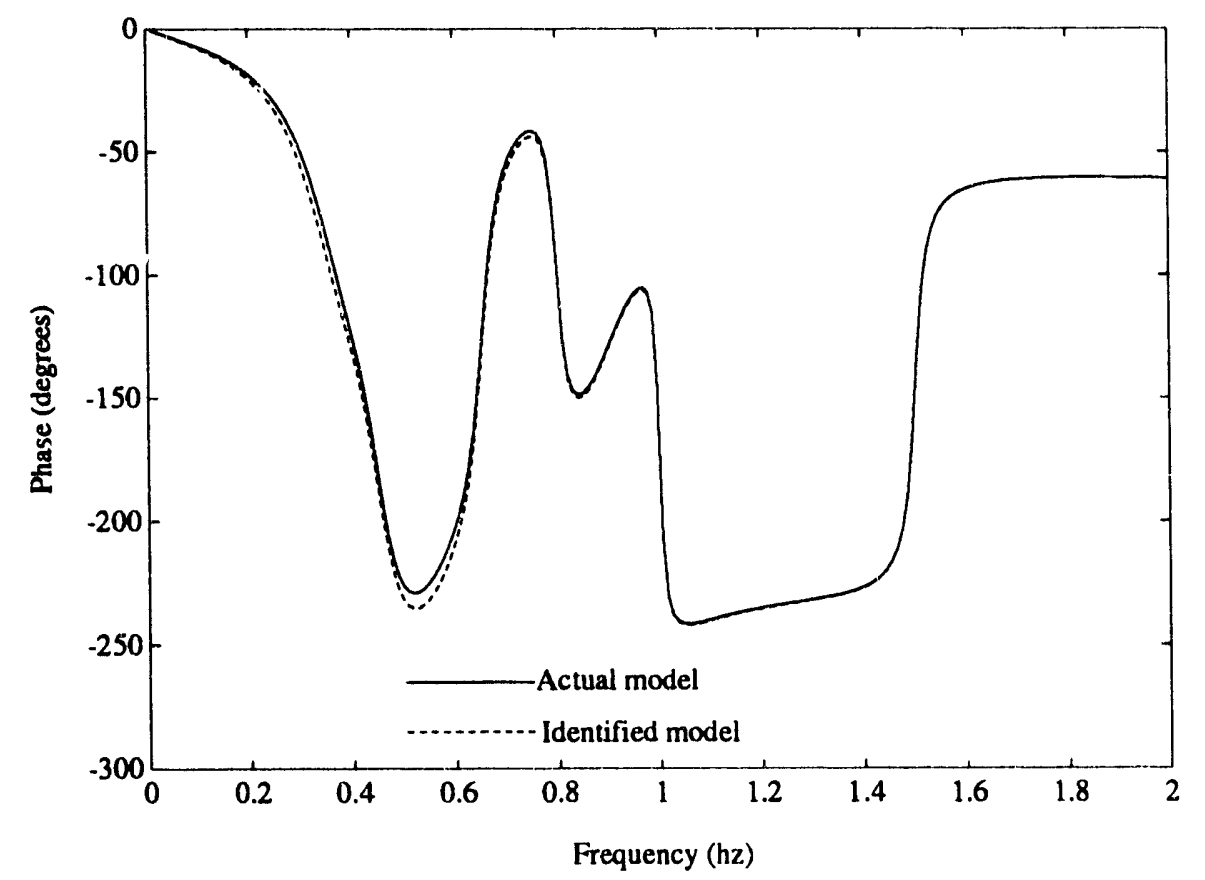

Figure 5.12. Identified model phase compared to actual for Example 5. 


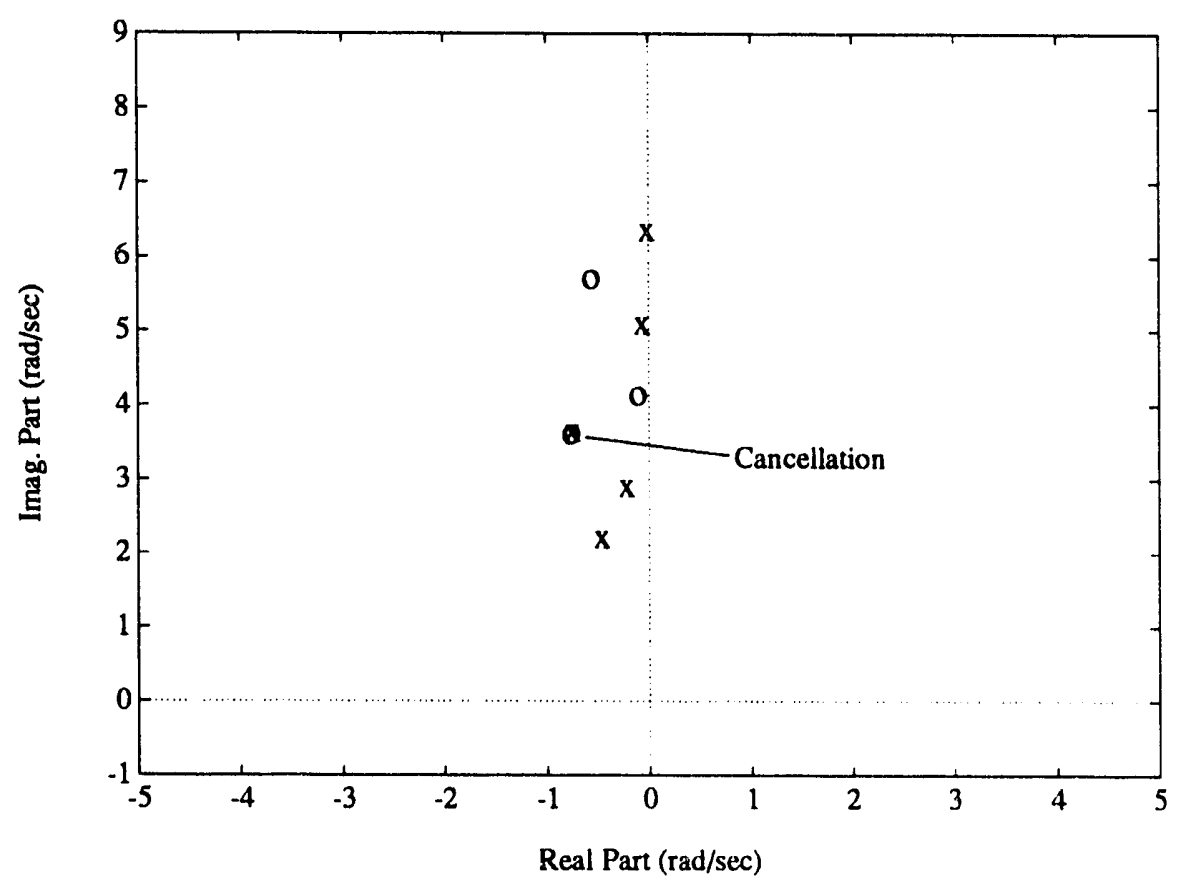

Figure 5.13. Poles and zeros of identified model for Example 5.

\subsubsection{Inaccurate or Missing Low- or High-Frequency Data}

Inaccurate frequency response data can occur for many reasons. In some cases, the inaccuracy is only slight; in other cases, it can be very large. One potentially drastic inaccuracy is to have missing data. It would be impossible to test every possible form of inaccurate data; therefore, investigation is limited to the cases in which data is missing.

The effects of missing low-frequency response data ivere investigated by observing the characteristics of system fits to data with progressively less low-frequency response data for several test cases. Some interesting observations from the study include the following. Low-frequency response data is very critical if modes occur at the low end. As data is removed from the upward slope of the first peak, the fit can become much less accurate, although graphically it appears good. Errors in the identified model can extend well beyond the general bandwidth of the missing data. If the missing data is well below the lowest modal peak or zero, an accurate model is often identified. Also, using phase data in the fit improves SYSFIT's ability to make up for the missing low-frequency data. The follow examples illustrate many of these effects.

\section{Example 6}

For this example, fits are made to the exact frequency response of test system 3 . The test system has two pole-pairs and one zero-pair closely spaced at the low-frequency end near $0.25 \mathrm{~Hz}$. Fits are made using progressively less actual data at the low frequency. The frequency-domain sample rate for the data is $\Delta f=1 / 102.4 \mathrm{~Hz}$. Fitting to gain only, SYSFIT results in a perfect fit 
when using data from $f=1 / 102.4 \mathrm{~Hz}$ to $f=2 \mathrm{~Hz}$. But, if the first 10 data points are excluded from the data, SYSFIT does not converge, even after 200 iterations. The frequency-response of the identified model in this case is shown in Figure 5.14. Note that the fit near the low end is not accurate. Figure 5.15 shows the poles of the actual and identified models in this case. SYSFIT does not identify the poles at 0.2 and $0.3 \mathrm{~Hz}$ but, instead, identifies extra terms on the real axis.

Now the identification is performed using both gain and phase data. In this case, SYSFIT performs much better. Figure 5.16 shows the identified model for the case in which the first 40 data points are excluded. The pole and zero parameters for the terms above the starting point are identified nearly perfectly, while parameters for the terms near $0.25 \mathrm{~Hz}$ are accurate within three decimal places.

Similar effects are seen with missing high-frequency data, but with much less severity. This is likely because the systems studied have a lower gain at the high end.

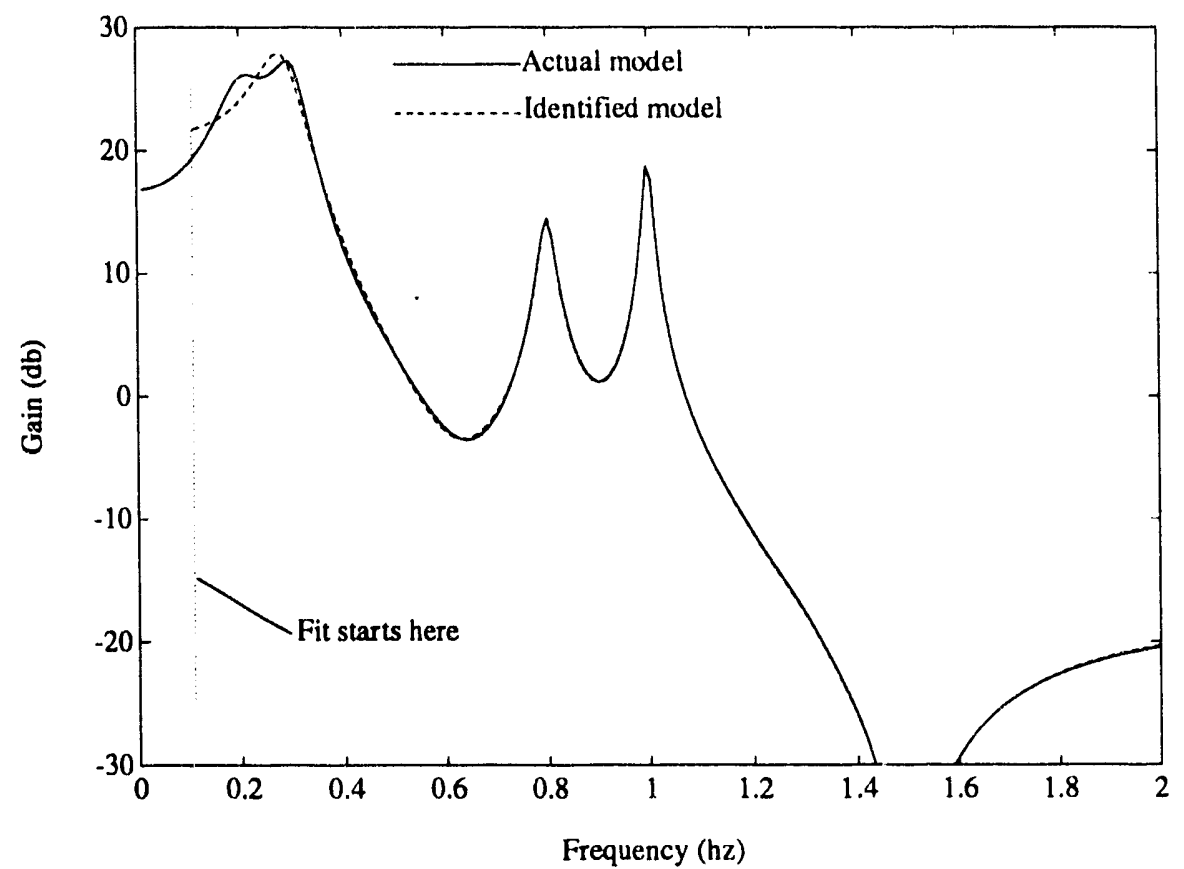

Figure 5.14. Identified model with first 10 data points missing in Example 6 (gain fit). 


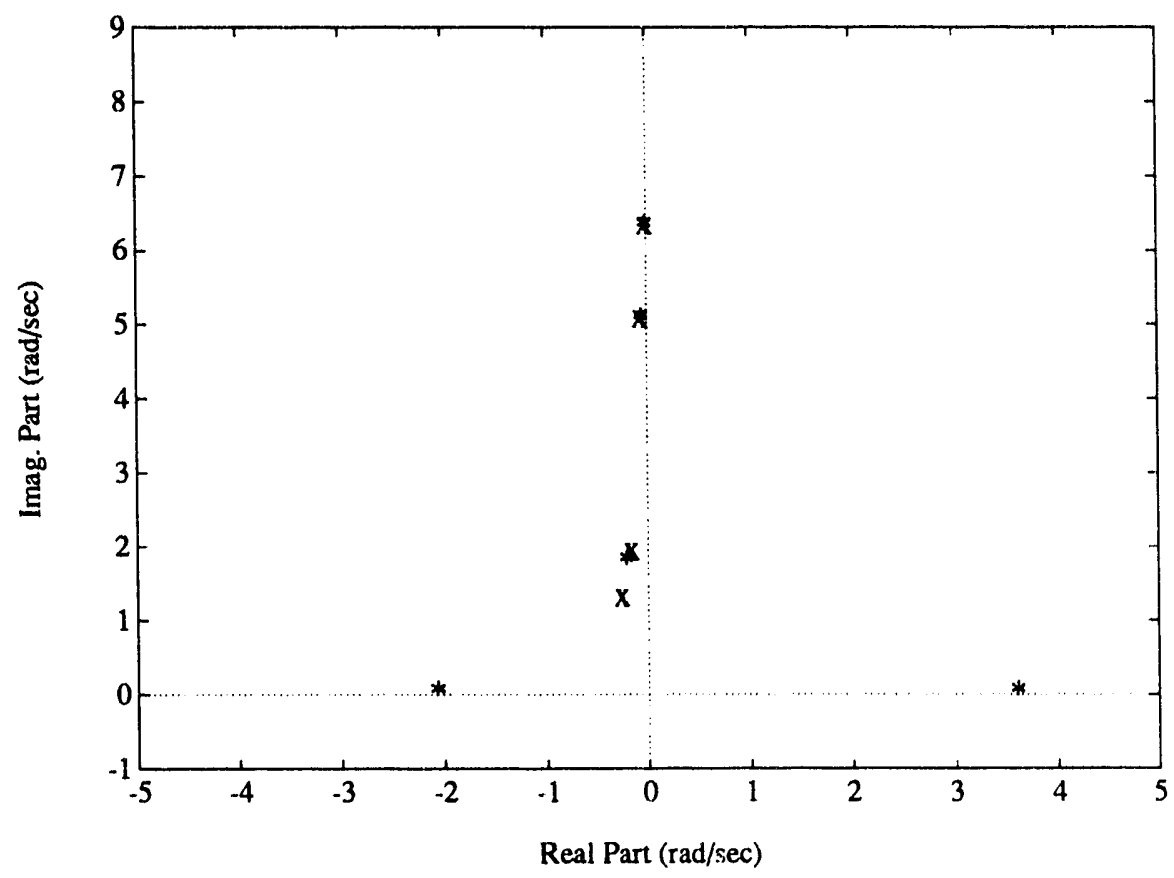

Figure 5.15. Actual poles $(x)$ and identified poles $\left({ }^{*}\right)$ with first 10 data points missing (gain fit) for Example 6.

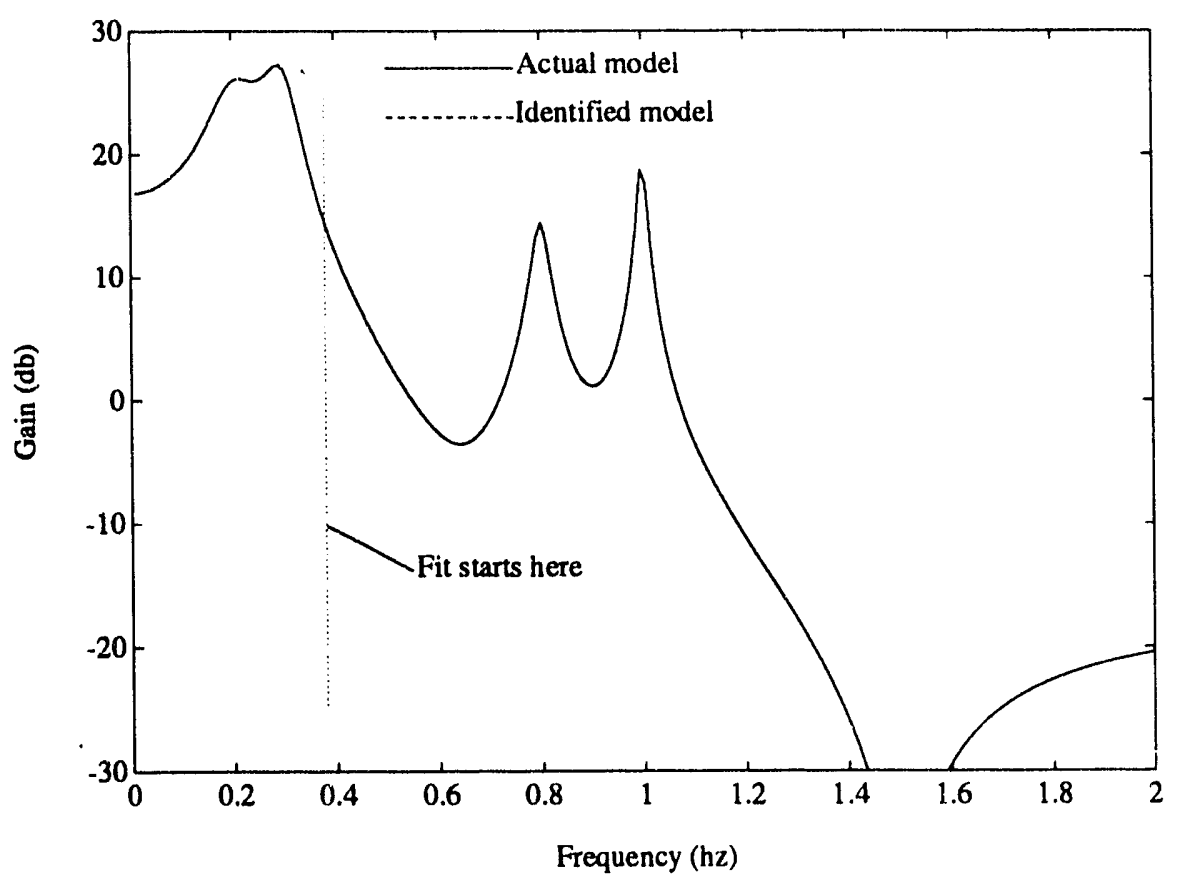

Figure 5.16. Identified model with first 40 data points missing for Example 6 (gain and phase fit). 


\subsubsection{Closely-Spaced Poles}

The effects of closely-spaced poles is of considerable interest, as this is a phenomenon often encountered in actual systems. Two types of tests were conducted to investigate the effects of closelyspaced poles. In one case, modes with the same damping were slowly moved closer in frequency. In the other case, modes with the same frequency were slowly moved closer in damping.

Several interesting observations were made. As poles converge, phase information becomes critical to obtaining an accurate fit. This is likely the result of the nearly composite modes acting like a single mode in the gain data. Fitting to systems with modes having the same frequency but different damping is generally more difficult than vice versa. When an accurate model is identified, parameter errors are always largest for the closely-spaced poles, w:th the errors on the damping coefficients for the closely-spaced terms being the largest. Example 7 details these points.

\section{Example 7}

Consider the following test system similar to test system 1 .

$$
\begin{aligned}
& G(s)=\left(\frac{s^{2}+0.2 s+0.1^{2}+(3 \pi)^{2}}{s^{2}+0.1 s+0.05^{2}+(2 \pi)^{2}}\right)\left(\frac{s^{2}+1.2 s+0.6^{2}+(1.8 \pi)^{2}}{s^{2}+0.2 s+0.1^{2}+(1.6 \pi)^{2}}\right) \\
& \left(\frac{s^{2}+0.3 s+0.15^{2}+(1.3 \pi)^{2}}{s^{2}+0.5 s+0.25^{2}+(0.9 \pi)^{2}}\right)\left(\frac{9.6 \pi}{s+3.2 \pi}\right) \\
& \left(\frac{s^{2}+1.6 s+0.8^{2}+(1.1 \pi)^{2}}{s^{2}+2(0.5-p 0.25) s+(0.5-p 0.25)^{2}(0.9 \pi)^{2}}\right)
\end{aligned}
$$

As $p$ is varied from 0 to 1 , the poles at $0.45 \mathrm{~Hz}$ converge. Figures 5.17 and 5.18 show the frequency response for $p=0,0.75$, and 1.0. For $p=0$, SYSFIT converges to the correct solution when fitting to gain data only. If $p=0.75$, the fit in Figure 5.19 results. Figure 20 compares the poles of this model with those of the actual model. Note that only one pole was identified near the closely-spaced ones.

Now the same tests are conducted while fitting both gain and phase data. For $p=0$ to 0.75 , a perfect fit is obtained. For $p=0.99$, all terms are accurately identified, but the identified damping associated with the closely-spaced poles has the largest error (see Table 5.3). 


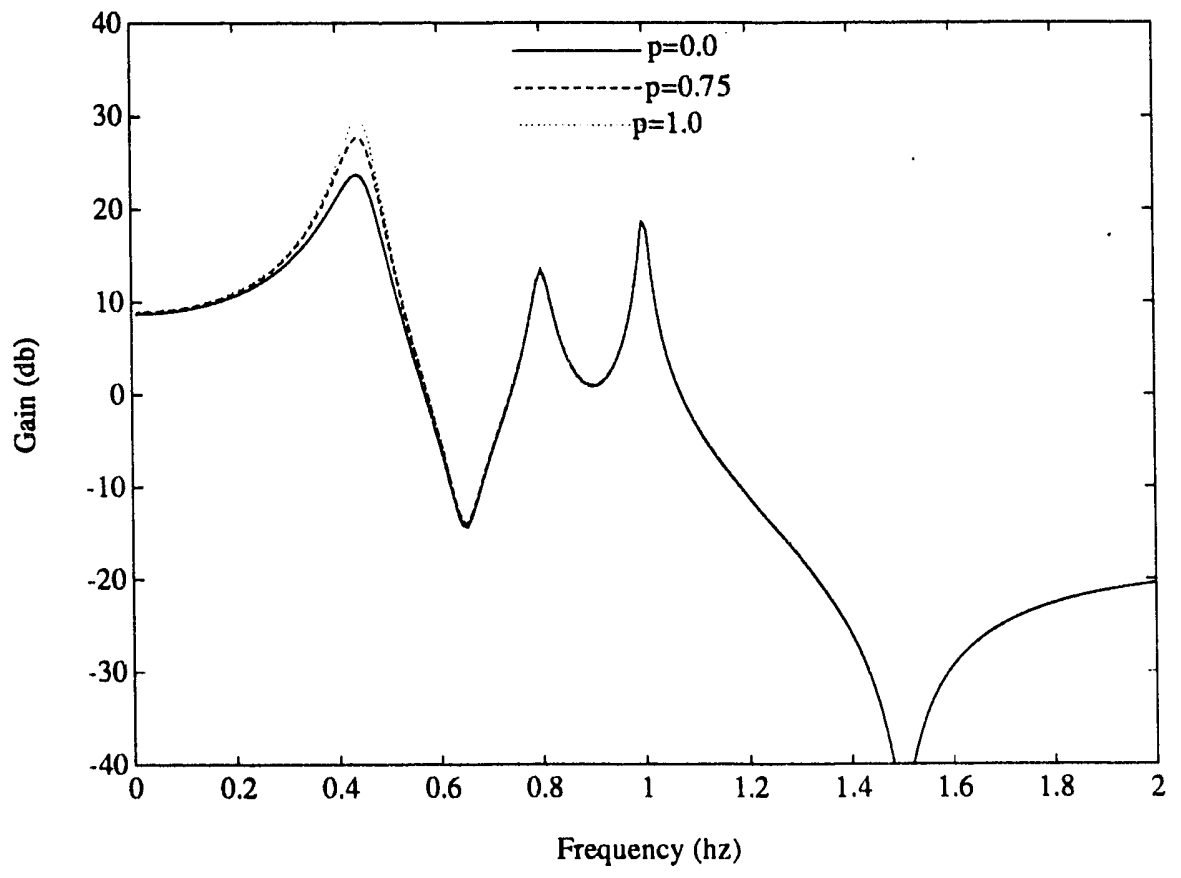

Figure 5.17. Test system (5.6) for Example 7.

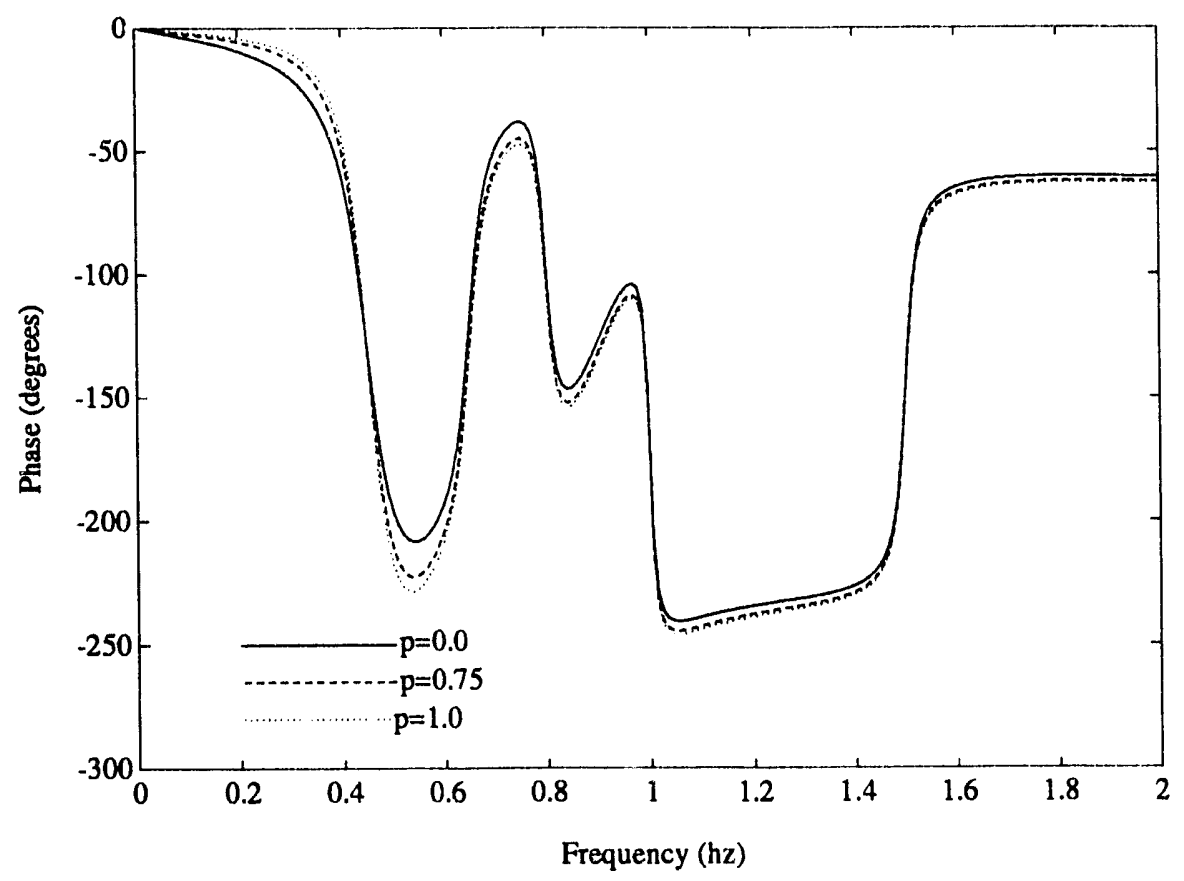

Figure 5.18. Test system (5.6) for Example 7. 


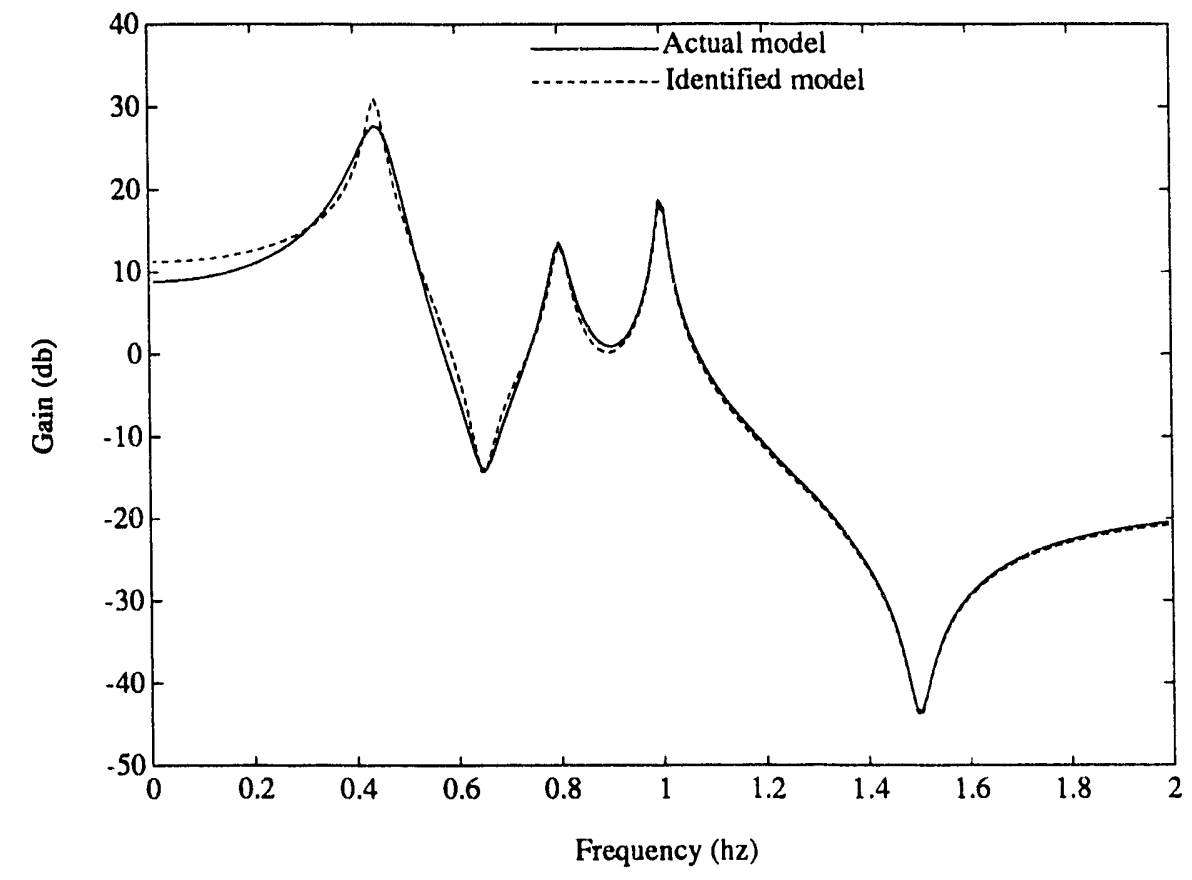

Figure 5.19. Identified model for $p=0.75$ (gain fit) for Example 7 .

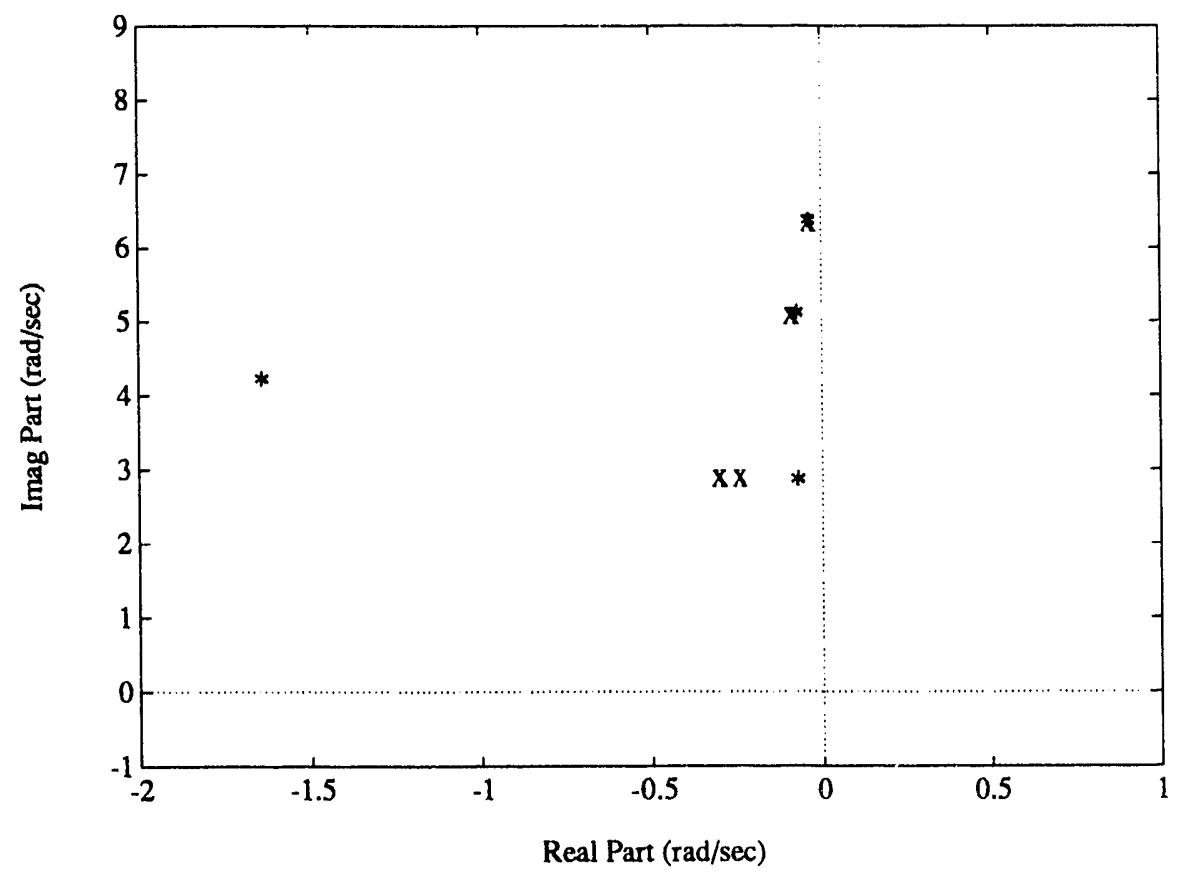

Figure 5.20. Actual poles (x) and identified poles $(*)$ for Example 7 . 
Table 5.3. Parameter errors for $p=0.99$ identified model for Example 7 .

\begin{tabular}{||c|c||}
\hline Actual Poles & $\begin{array}{c}\text { Identified model } \\
\text { \% error (real, imag.) }\end{array}$ \\
\hline$-0.2500 \pm j 0.9 \pi$ & $1.10,0.00$ \\
\hline$-0.2525 \pm j 0.9 \pi$ & $1.08,0.00$ \\
\hline All others & $0.00,0.00$ \\
\hline
\end{tabular}

\section{Example 8}

SYSFIT handles closely-spaced poles with slightly different damping better than poles with slightly different imaginary terms. Consider the system

$$
G(s)=3\left(\frac{s^{2}+0.3 s+0.15^{2}+(1.3 \pi)^{2}}{s^{2}+0.1 s+0.05^{2}+(2 \pi(0.8+p 0.2))^{2}}\right)\left(\frac{s^{2}+0.2 s+0.1^{2}+(3 \pi)^{2}}{s^{2}+0.1 s+0.05^{2}+(2 \pi)^{2}}\right)
$$

where again $p$ is varied from 0 to 1 . Table 5.4 shows the results to fitting to Equation (5.7) for both gain-only fits as well as gain and phase fits for various $p$ 's. All fits converge, but as the poles move closer, the errors on the identified damping coefficients increase. This is especially true for the gain-only fit.

Table 5.4. Errors of identified poles for Example 8.

\begin{tabular}{||c|l|l|l||}
\hline & \multicolumn{1}{|c|}{$\begin{array}{c}\text { System } \\
\text { poles }\end{array}$} & $\begin{array}{c}\text { Error (real, imag.) } \\
\text { (gain fit) }\end{array}$ & $\begin{array}{c}\text { \% Error (real, imag) } \\
\text { (gain \& phase fit) }\end{array}$ \\
\hline $\mathrm{p}=0.0$ & $-0.05 \pm \mathrm{j} 0.80$ & $0.00 \pm \mathrm{j} 0.00$ & $0.00 \pm \mathrm{j} 0.00$ \\
& $-0.05 \pm \mathrm{j} 1.0$ & $0.00 \pm \mathrm{j} 0.00$ & $0.00 \pm \mathrm{j} 0.00$ \\
\hline $\mathrm{p}=0.99$ & $-0.05 \pm \mathrm{j} 0.998$ & $2.00 \pm \mathrm{j} 0.00$ & $0.08 \pm \mathrm{j} 0.00$ \\
& $-0.05 \pm \mathrm{j} 1.0$ & $2.00 \pm \mathrm{j} 0.00$ & $0.08 \pm \mathrm{j} 0.00$ \\
\hline $\mathrm{p}=1.0$ & $-0.05 \pm \mathrm{j} 1.0$ & $8.00 \pm \mathrm{j} 0.00$ & $1.20 \pm \mathrm{j} 0.00$ \\
& $-0.05 \pm \mathrm{j} 1.0$ & $8.00 \pm \mathrm{j} 0.00$ & $1.20 \pm \mathrm{j} 0.00$ \\
\hline
\end{tabular}




\subsubsection{Closely-Spaced Pole-Zero Pairs}

Closely-spaced pole-zero pairs were investigated by siowly moving a pole-zero pair together both in the frequency parameter and the same damping paramster. A closely-spaced pole-zero pair does not seem to adversely affect the fit as much as closely-spaced poles.

As the pole and zero converge, SYSFIT has more difficulty in identifying the parameters. If the proper parameters are identified, the errors are consistently larger for the closely-spaced terms. As the pole-zero pairs move very close together and SYSFIT converges, a near pole-zero cancellation is often identified, but not necessarily at the proper location. In fact, in most cases, the cancellation is identified at the wrong location while other model parameters are accurately identified. As with closely-spaced poles, use of phase data in the fitting cost function often provides much needed information. The following example demonstrates some of these issues.

\section{Example 9}

Consider the system

$$
\begin{aligned}
& G(s)=\left(\frac{s^{2}+0.2 s+0.1^{2}+(3 \pi)^{2}}{s^{2}+0.1 s+0.05^{2}+(2 \pi)^{2}}\right)\left(\frac{s^{2}+1.2 s+0.6^{2}+(1.8 \pi)^{2}}{s^{2}+0.2 s+0.1^{2}+(1.6 \pi)^{2}}\right) \\
& \left(\frac{s^{2}+1.3 s+0.65^{2}+(1.3 \pi)^{2}}{s^{2}+s+0.5^{2}+(0.7 \pi)^{2}}\right)\left(\frac{9.6 \pi}{s+3.2 \pi}\right) \\
& \left(\frac{s^{2}+0.5 s+0.25^{2}+((1.2-p 0.3) \pi)^{2}}{s^{2}+0.5 s+0.25^{2}+(0.9 \pi)^{2}}\right)
\end{aligned}
$$

which is a modified version of test system 1 . As $p$ moves from 0 to 1 , the $0.6-\mathrm{Hz}$ zero moves to the $0.35-\mathrm{Hz}$ pole. Note that these two values have the same damping coefficients. Figure 5.21 shows the response of Equation (5.8) for $p=0,0.75$, and 0.99. Fitting to the gain only, SYSFIT results in a near-perfect fit for $p=0$. However, for $p \geq 0.75$, SYSFIT does not converge to the proper solution.

When fitting to both gain and phase, SYSFIT performs much better. As the pole and zero converge, SYSFIT identifies a pole-zero cancellation, but not necessarily at the proper location. Figure 5.22 shows the poles and zeros of Equation (5.8) with $p=0.99$, and Figure 5.23 shows the identified model. Note that all the terms are fairly accurately identified except the near pole-zero cancellation. 


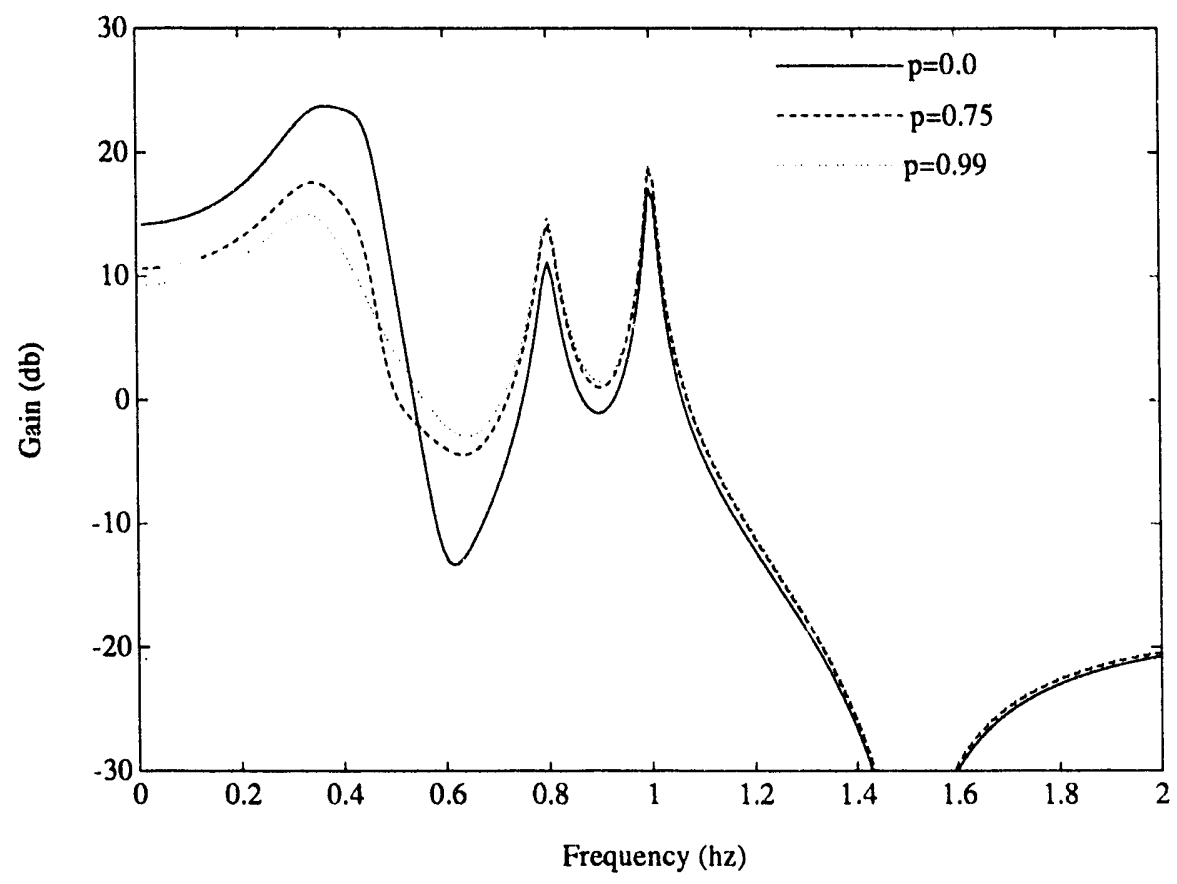

Figure 5.21. Response of test system (5.8) for Example 9.

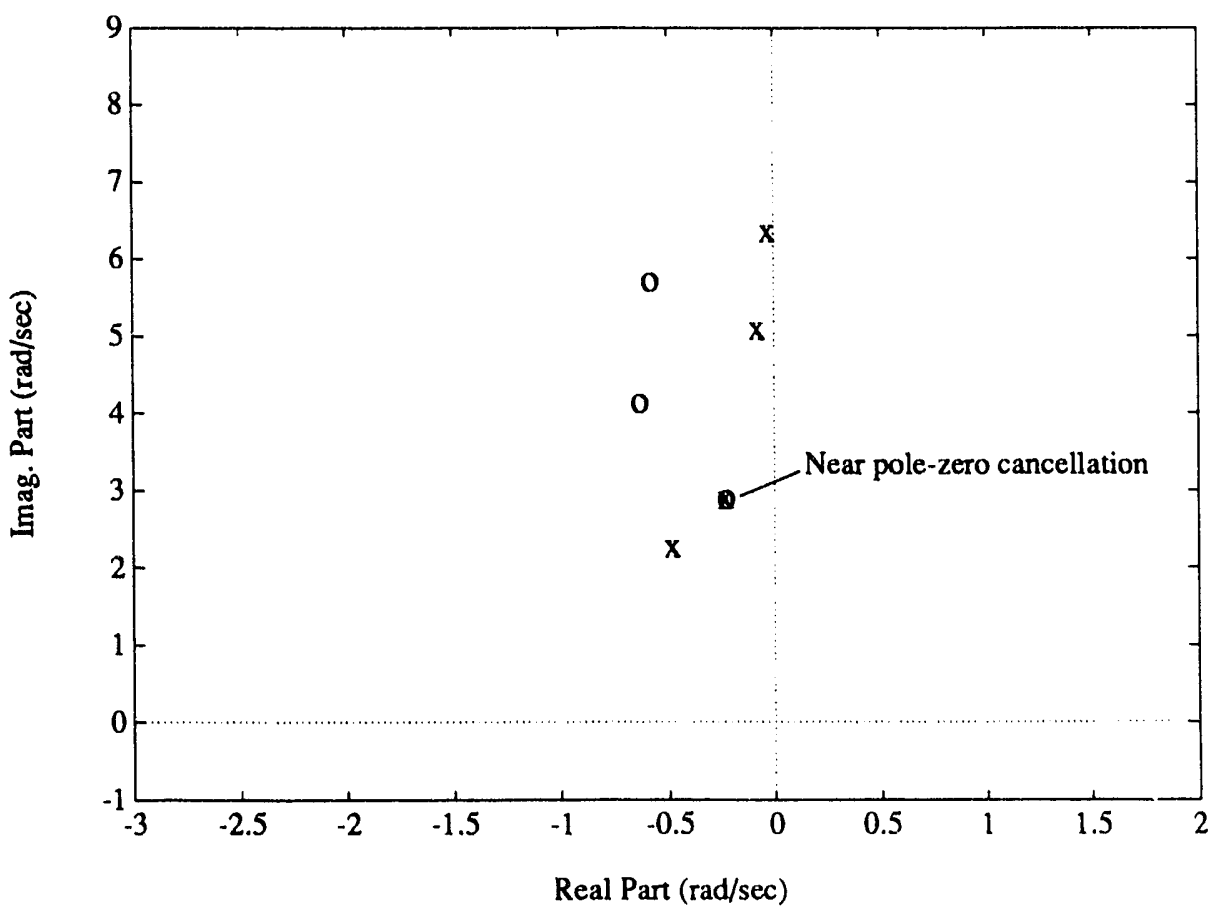

Figure 5.22. Actual poles ( $\mathrm{x}$ ) and zeros (o) for $p=0.75$ for Example 9 . 


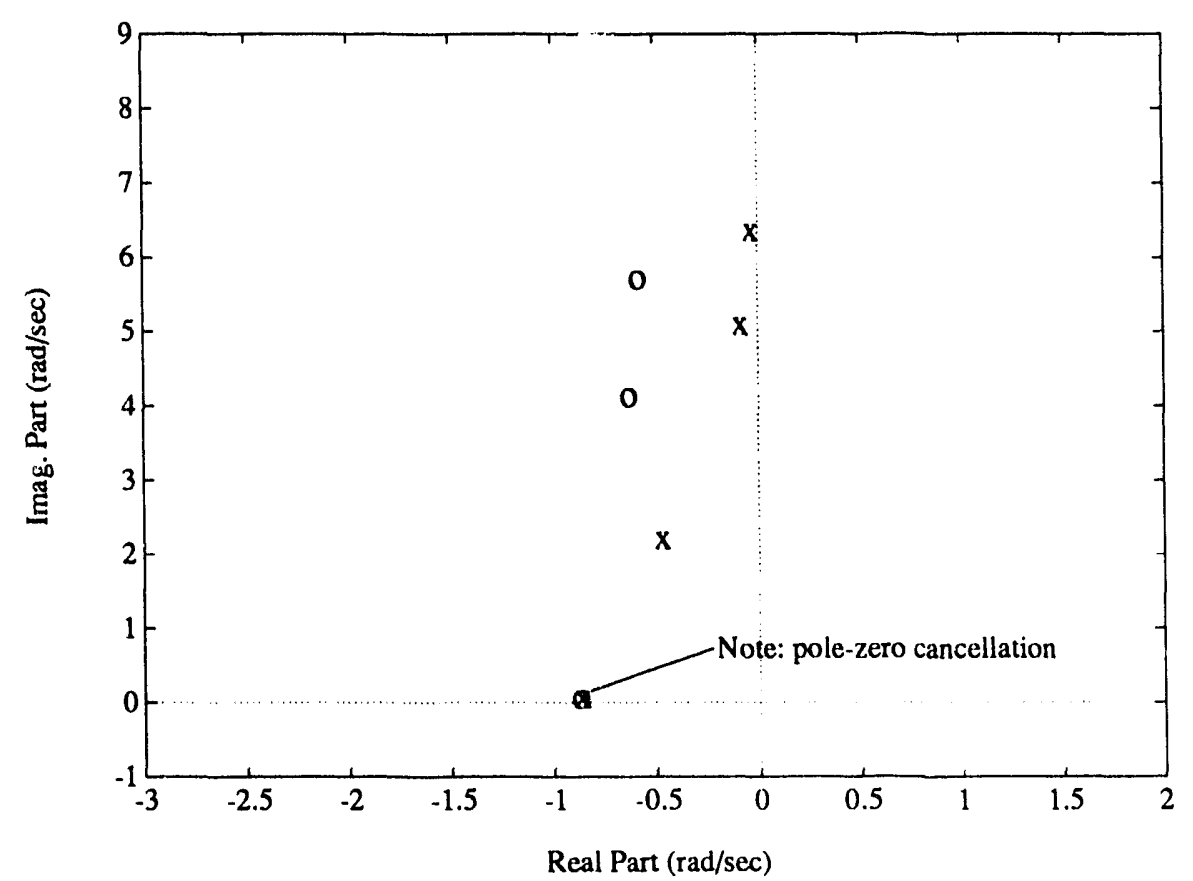

Figure 5.23. Identified poles (x) and zeros (o) for Example 9 (gain and phase fit).

\subsection{Fitting to the DFT of Noisy Data}

In most situations, it is unlikely that true frequency response data will be available; therefore, the effects of a DFT as wel' as time-domain noise are important. In this section. SYSFIT's performance in fitting to the DFT of noisy impulse response signals are investigated.

To perform the investigations, exact time-domain impulse response data are generated from variations of the linear test systems presented. Noise signals from Section 4 are added to these impulse responses, and the frequency response is calculated from the time-domain signal. Specific attention is paid to the effects of

record length

- noise level and coloration.

The BPADFT and folding DFT methods are used to calculate the frequency response from the time-domain data. 


\subsubsection{Effects of Record Length}

In selecting the length of time-domain record for the DFT analysis, there is a tradeoff between noise effects and DFT resolution. For a damped ringdown signal, the tail contains relatively little energy. Therefore, the longer the response signal, the lower the signal-to-noise ratio (SNR). The resolution of a DFT is $\Delta f=1 /(N T)$ where $N$ is the number of samples and $T$ is the sample period. Because $a$ he Nyquist criterion, one does not have considerable freedom in choosing $T$; therefore, $N$ must be large enough to make $\Delta f$ sufficiently small.

The proper record length represents an optimal tradeoff between noise effects and DFT resolution in that the best identified model is obtained. This optimal tradeoff is dependent on many issues including the system damping and modes, noise level and coloration, and excitation level. Typical results for the systems investigated indicate that with a sample period of 0.05 second, 1500 to 2048 samples should be analyzed. It is importart to emphasize that this is only a general rule-ol-thumb based on experience. The following example illustrates the noise/resolution tradeoff.

\section{Example 10}

For this example, several fits are made to various DFT record lengths of the impulse response of test system 1. Figure 5.24 shows the impulse response of the test system with noise. The noise is type $/ / f$ with a variance of 5.0, and the sample period is 0.05 second. Three record-length cases are used in SYSFIT: 1) 2048-point BPADFT; 2) 1536-point BPADFT; and 3) 1024-point BPADFT. The identified models are shown in Figures 5.25 through 5.27. In the 2048- and 1024point cases, the modes near $0.4 \mathrm{~Hz}$ are not accurately identified. But, the fit using 1536 points is relatively very accurate. The SNR is $15 \mathrm{db}$ at 2048 points, $16 \mathrm{db}$ at 1536 points, and $18 \mathrm{db}$ at 1024. 


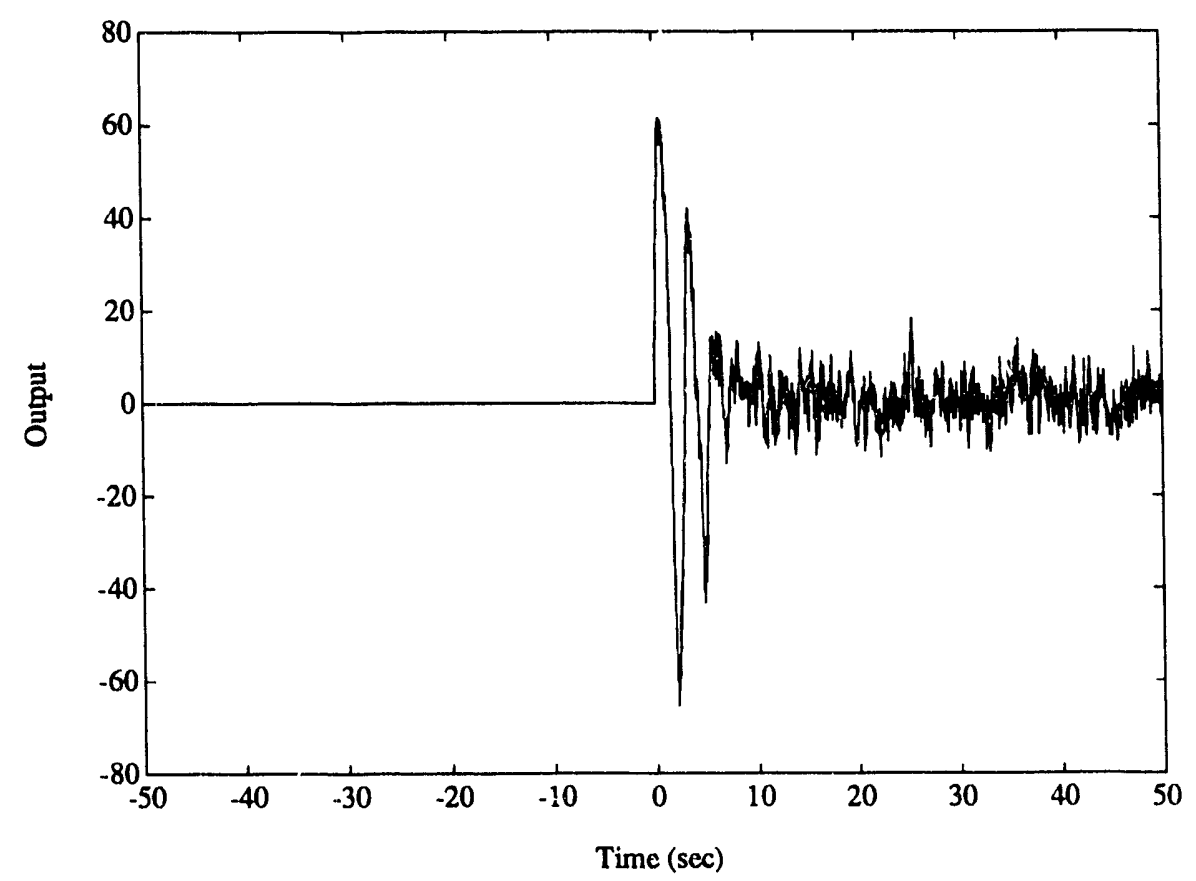

Figure 5.24. Test system impulse response with noise for Example 10.

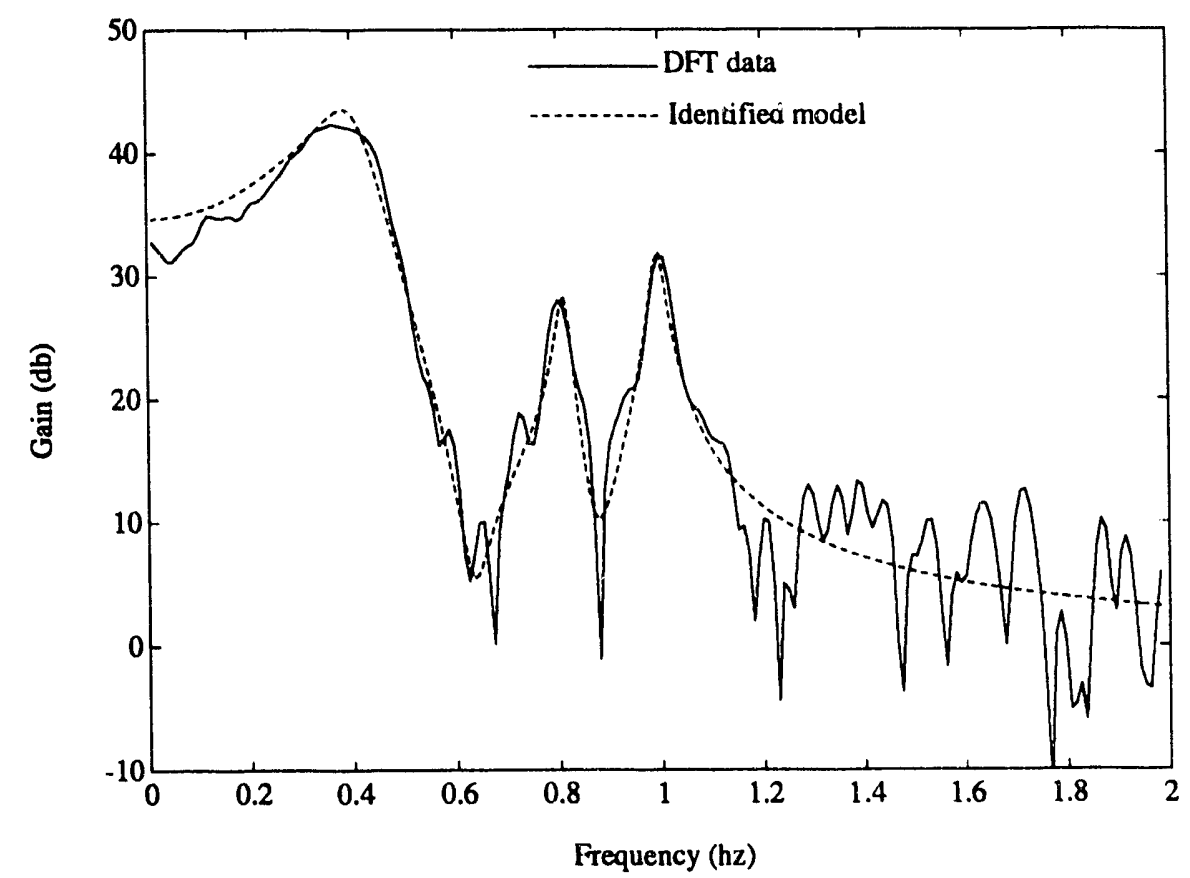

Figure 5.25. Identified model for a 2048-point DFT for Example 10 . 


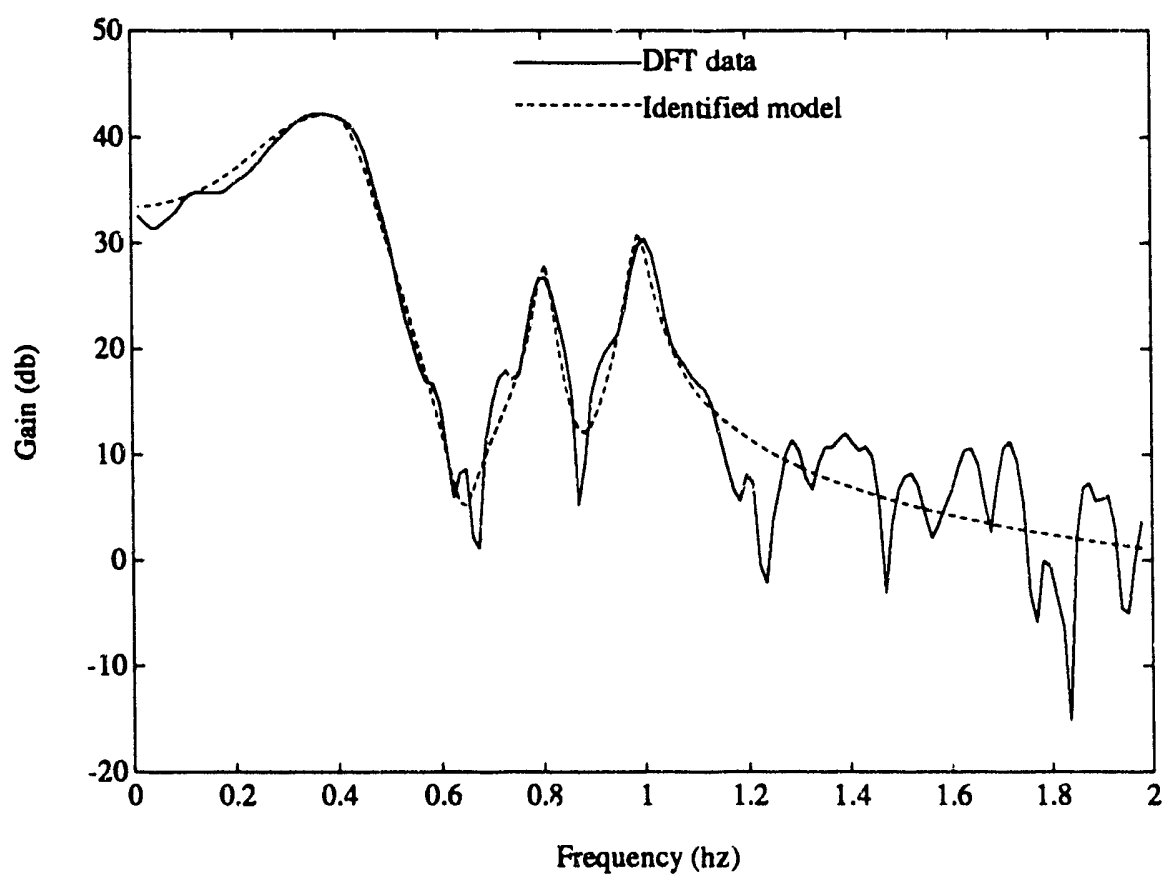

Figure 5.26. Identified model for a 1536-point DFT for Example 10.

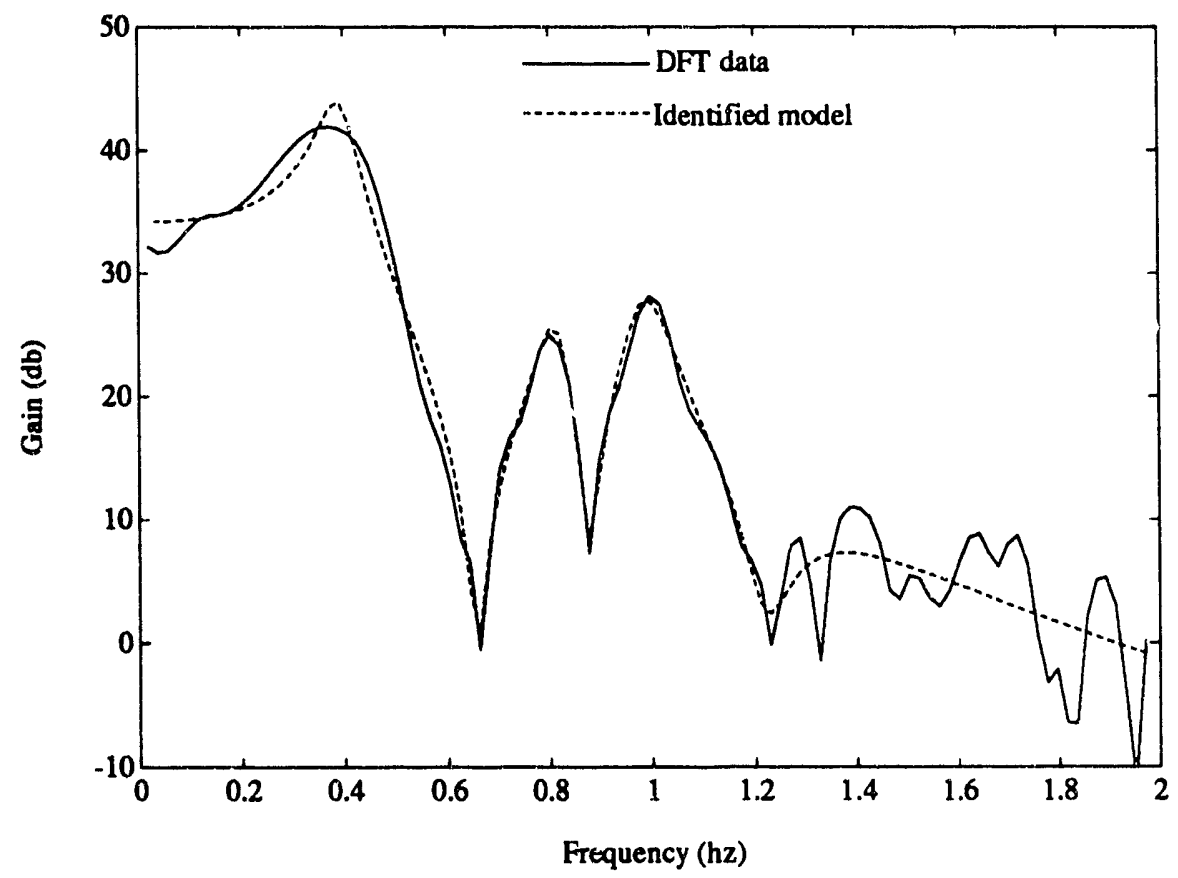

Figure 5.27. Identified model for a 1024-point DFT for Example 10. 


\subsubsection{Effects of Noise Level and Coloration}

To investigate noise level and coloration effects, many cases were run with the different noise signals added with different variances. For the most part, SYSFIT calculated accurate fits, even in high-level noise.

As the level of the noise increases, the accuracy of the fit decreases. Fits to system zeros become inaccurate at much lower noise levels than fits to system poles. This is expected because the gain at poles is peaked. For low noise levels, the resolution-degrading effects of a Hanning window used with the BPADFT cause a larger error in the fit than the noise itself. In this case, use of the folding DFT to calculate the frequency-domain data provides better results. As noise levels increase, the advantage of the folding DFT declines, and the BPADFT becomes the better choice. This is expected because the windowing and zero padding used with the BPADFT act much like a filter.

Using measurement weights equal to the absolute gain of the frequency response tends to improve the fit, especially at high noise levels. This is particularly true if phase data is included in the cost function. Improvement occurs because the data with a large gain is dominated by the system poles near that frequency range, while the low-gain data is dominated by the noise.

SYSFIT appeared to have the most trouble with $l / f$ and colored noise. This seems reasonable, as these two concentrate their energy in the bandwidth of the system, while white noise spreads its energy across the entire spectrum, and $(1 / f)^{n}(n \geq 2)$ noise concentrates its energy at the very low frequencies.

\section{Example 11}

This example shows the difference in using the folding DFT and the BPADFT. Consider test system 1. In one case, a 2048-point BPADFT is used; in the other, a 1024-point folding DFT. The BPADFT uses twice as many points because of zero padding. Table 5.5 shows the errors in the identified parameters for the two cases. Note that the folding DFT provides much more accurate data to SYSFIT.

Now $1 / f$ noise with a variance of $1.0(\mathrm{SNR}=21 \mathrm{db})$ is added to the time-domain response and the fits are repeated. The results are shown in Table 5.6. Now the difference between folding DFT and BPADFT is not as evident.

\section{Example 12}

In this example, the effects of noise level are examined. Again consider test system 1. A 2048-point BPADFT of the noisy impulse response is used to calculate the frequency response data. Figure 5.28 shows the fits for two white noise levels, 21-db SNR and 11-db SNR, respectively. At 11-db SNR, the zero near $1.5 \mathrm{~Hz}$ is not identified, while at 21-db SNR, it is fairly accurately identified. 
Table 5.5. Fitting to noise-free DFT for Example 11.

\begin{tabular}{||l|l|l||}
\hline \multicolumn{1}{|c|}{ Poles } & \multicolumn{1}{|c|}{$\begin{array}{c}\text { \% Error (real, imag.) } \\
\text { (BPADFT) }\end{array}$} & \multicolumn{1}{c|}{$\begin{array}{c}\text { Error (real, imag.) } \\
\text { (folding DFT) }\end{array}$} \\
\hline$-1.6 \pi 2$ & 19.0 & 18.8 \\
\hline$-0.50 \pm \mathrm{j} 0.35 \pi 2$ & $4.0,1.0$ & $0.4,1.7$ \\
\hline$-0.25 \pm \mathrm{j} 0.45 \pi 2$ & $3.6,1.0$ & $1.6,0.7$ \\
\hline$-0.10 \pm \mathrm{j} 0.80 \pi 2$ & $21.0,0.0$ & $3.3,0.0$ \\
\hline$-0.05 \pm \mathrm{j} 1.00 \pi 2$ & $57.0,0.0$ & $4.0,0.0$ \\
\hline
\end{tabular}

Table 5.6. Fitting to noisy LFT for Example 11.

\begin{tabular}{||l|l|l||}
\hline \multicolumn{1}{|c|}{ Poles } & \multicolumn{1}{|c|}{$\begin{array}{c}\text { \% Error (real, imag.) } \\
\text { (BPADFT) }\end{array}$} & \multicolumn{1}{c|}{$\begin{array}{c}\text { Error (real, imag.) } \\
\text { (folding DFT) }\end{array}$} \\
\hline$-1.6 \pi 2$ & Not Identified & 14.4 \\
\hline$-0.50 \pm j 0.35 \pi 2$ & $39.6,12.4$ & $6.2,1.7$ \\
\hline$-0.25 \pm j 0.45 \pi 2$ & $1.9,5.7$ & $12.4,0.9$ \\
\hline$-0.10 \pm \mathrm{j} 0.80 \pi 2$ & $25.0,0.0$ & $61.0,0.6$ \\
\hline$-0.05 \pm \mathrm{j} 1.00 \pi 2$ & $6.0,0.0$ & $2.4,0.3$ \\
\hline
\end{tabular}

\section{Example 13}

Different noise colorations are compared in this example. Once again, the test system is test system 1. Three different noise colorations are added to the time-domain signal: white noise, $1 / f$ noise, and $(1 / f)^{2}$ noise. All noise levels are added to the signal so that the SNR is $14 \mathrm{db}$. Figure 5.29 shows the identified models for the three cases. Comparing with Figure 4.1, one sees that the $(1 / f)^{2}$ noise degrades the fit the least and the $1 / f$ degrades the most.

\section{Example 14}

Now highly colored noise effects are presented by fitting the BPADFT of the impulse of test system 1 with added colored noise (band-limited between 0.4 and $0.7 \mathrm{~Hz}$ ). The noise is adjusted to obtain a SNR of $14 \mathrm{db}$. Figure 5.30 shows the identified model, and Table 5.7 lists the identified parameters. The poles and zeros well outside the bandwidth of the noise are accurately identified, while the terms close to the bandwidth have large errors. 


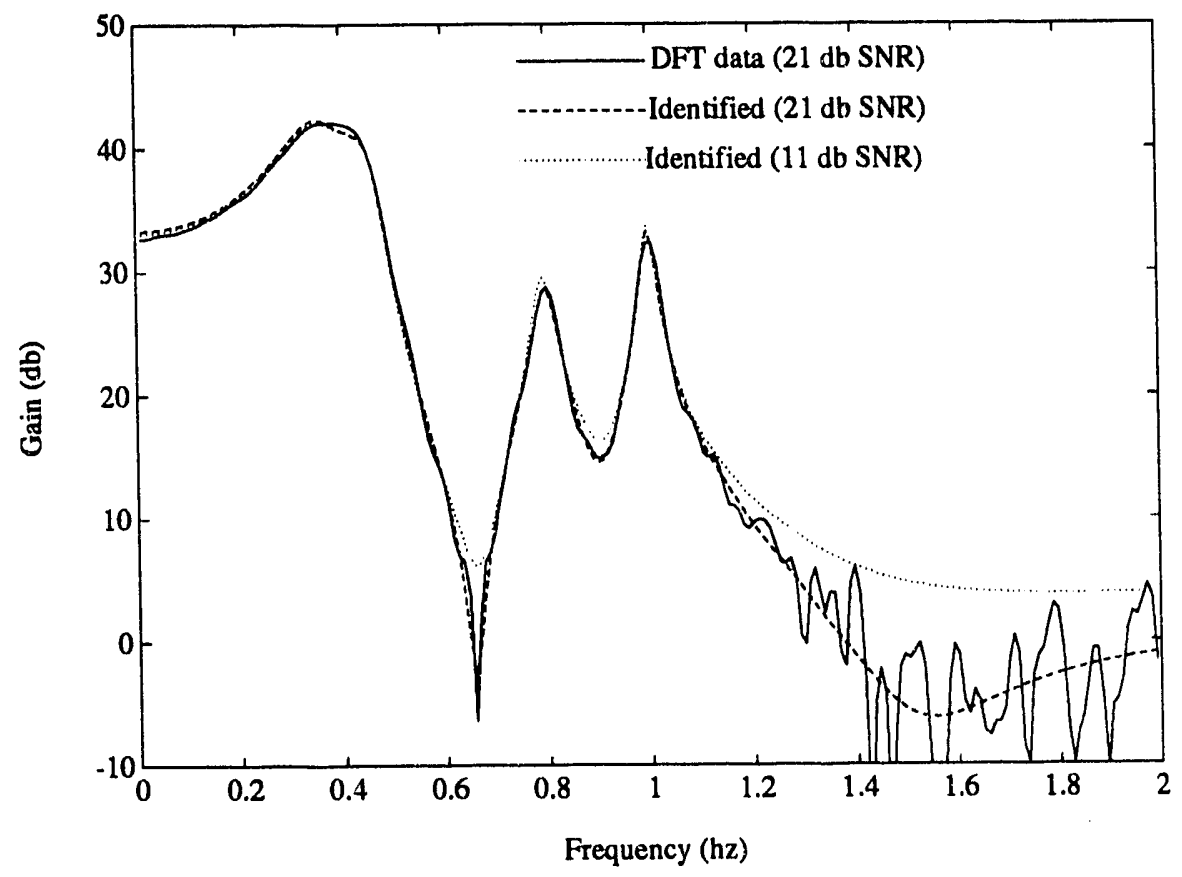

Figure 5.28. Identified model for $21-\mathrm{db}$ and $11-\mathrm{db}$ SNR for Example 12 .

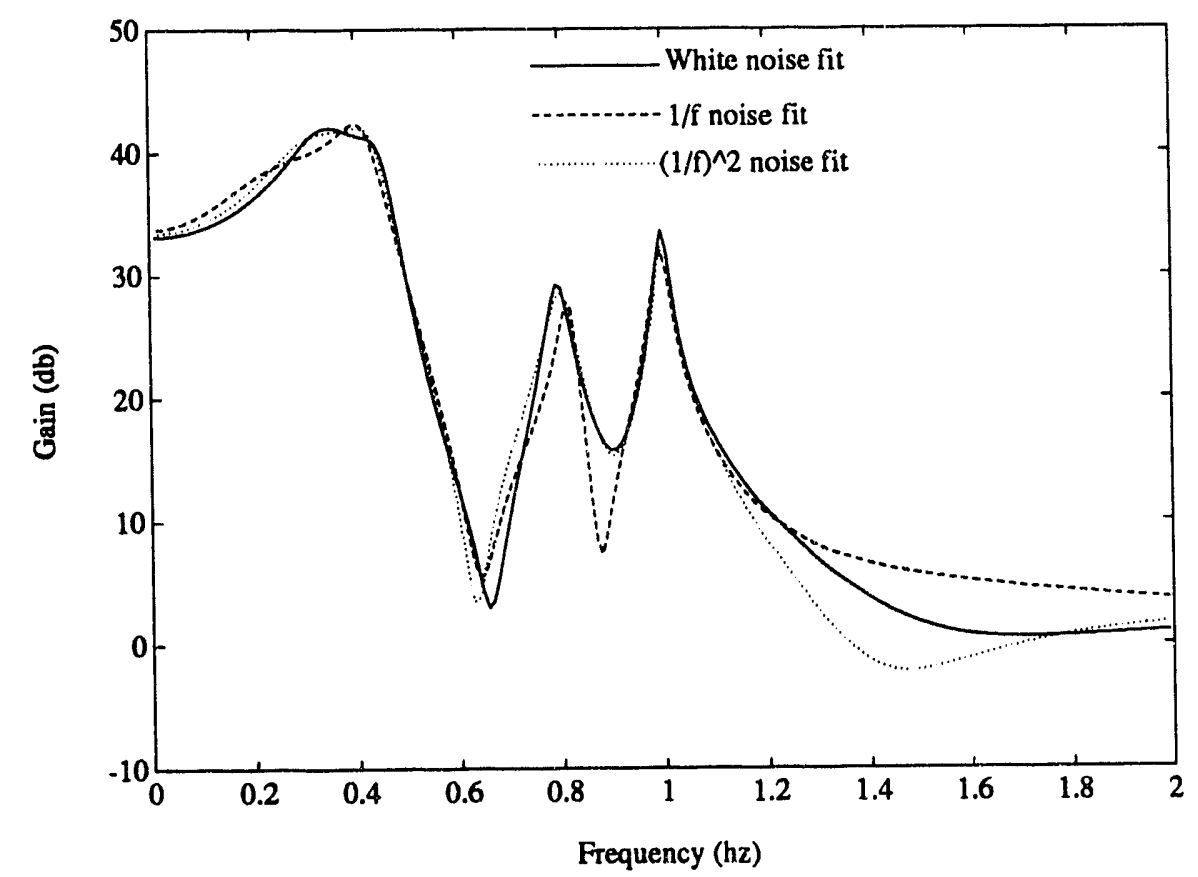

Figure 5.29. Identified models under different noise colorations for Example 13. 


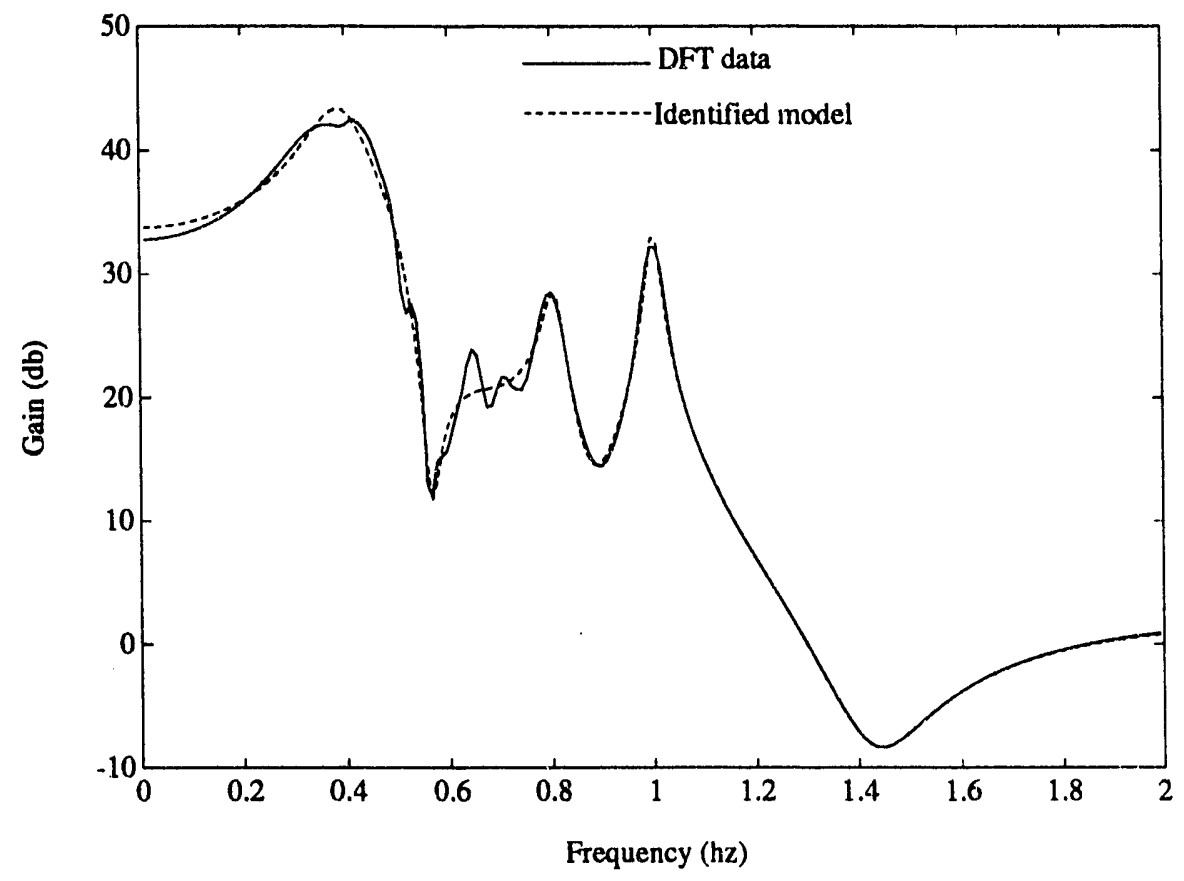

Figure 5.30. Identified model with colored noise for Example 14 .

Table 5.7. Identified model errors for Example 14.

\begin{tabular}{|c|c||c|c||}
\hline Poles & Pole Error (\%) & Zeros & Zero Error (\%) \\
\hline$-0.5 \pm j 0.7 \pi$ & $20 \pm j 11$ & $-0.8 \pm j 1.1 \pi$ & $91 \pm j 4$ \\
\hline$-0.25 \pm j 0.9 \pi$ & $68 \pm j 12$ & $-0.15 \pm j 1.3 \pi$ & $674 \pm j 22$ \\
\hline$-0.1 \pm j 1.6 \pi$ & small & $-0.3 \pm j 1.8 \pi$ & $7 \pm j 2$ \\
\hline$-0.05 \pm j 2 \pi$ & small & $-0.6 \pm j 3 \pi$ & small \\
\hline
\end{tabular}

\subsection{Fitting to Multi-Path Systems}

In many situations, the system may have multiple paths or a multi-path fit may be used to improve the fit of a single-path system. Consider a situation in which the path to identify has a near pole-zero cancellation or a high noise level near a significant pole. Because system poles are path-independent, one could use a second "clean" path to fit the system poles. SYSFIT"s ability to perform multi-path fitting allows considerable flexibility in attacking such problems. 
It would be difficult to investigate all possible options of using multi-path fitting to mitigate problems with single-path fitting, because each fit often has a unique combination of difficulties. But, certain situations tend to often occur (e.g., closely-spaced poles and zeros).

In performing multi-path fitting, proper formation of the fitting cost function is very important. With single-path fitting, one set of gain and phase weights is adjusted; now each path has gain and phase weights that must be considered. With multi-path fitting, the cost function is written as

$$
J(\underline{x})=\sum_{i=1}^{q}\left(\sum_{m=1}^{4} W_{i, m} E_{i, m}(\underline{x})\right)
$$

where $W_{i, m}$ are the weights for path $i$, and there are $q$ paths. In forming the cost function, one should follow the general rules in Equations (5.1) and (5.3) for each path and Equation (5.2) for the overall cost function. In addition, one should make the initial cost of each path relatively the same, which can be written mathematically as

$$
\sum_{m=1}^{4} W_{1, m} E_{1, m}\left(\underline{x_{0}}\right) \approx \sum_{m=1}^{4} W_{2, m} E_{2, m}\left(x_{0}\right) \approx \ldots \approx \sum_{m=1}^{4} W_{q, m} E_{q, m}\left(\underline{x_{0}}\right)
$$

Some advantages of using multi-path fitting are outlined in the following example.

\section{Example 15}

Consider a two-path system with path 1 represented by test system 1 and the second path being

$$
\begin{aligned}
G(s)= & 0.01 \pi\left(\frac{s^{2}+1.2 s+0.6^{2}+(3.3 \pi)^{2}}{s^{2}+0.1 s+0.05^{2}+(2 \pi)^{2}}\right)\left(\frac{s^{2}+0.22 s+0.11^{2}+(1.62 \pi)^{2}}{s^{2}+0.2 s+0.1^{2}+(1.6 \pi)^{2}}\right) \\
& \left(\frac{s^{2}+0.8 s+0.4^{2}+(0.56 \pi)^{2}}{s^{2}+0.5 s+0.25^{2}+(0.9 \pi)^{2}}\right)\left(\frac{(s+0.4 \pi)(s-1.4 \pi)}{s^{2}+s+0.5^{2}+(0.7 \pi)^{2}}\right)
\end{aligned}
$$

Performing a single-path fit to Equation (5-11) is challenging because it has a closely-spaced polezero pair near $0.8 \mathrm{~Hz}$. A single-path fit is performed on the true frequency response of Equation (5-11) using the initial model

$$
\begin{array}{r}
G_{I}(s)=0.01\left(\frac{s^{2}+2 s+1+(4 \pi)^{2}}{s^{2}+0.1 s+0.05^{2}+(2 \pi)^{2}}\right)\left(\frac{s^{2}+0.5 s+0.25^{2}+(1.6 \pi)^{2}}{s^{2}+0.1 s+0.05^{2}+(1.6 \pi)^{2}}\right) \\
\left(\frac{s^{2}+2 s+1+(0.44 \pi)^{2}}{s^{2}+0.5 s+0.25^{2}+(0.9 \pi)^{2}}\right)\left(\frac{(s+0.2 \pi)(s-2 \pi)}{s^{2}+0.4 s+0.2^{2}+(0.7 \pi)^{2}}\right)
\end{array}
$$

Figure 5.31 shows the identified model for fitting to the gain of path 2 after 550 iterations. As can be seen, SYSFIT does not converge to the proper solution. 


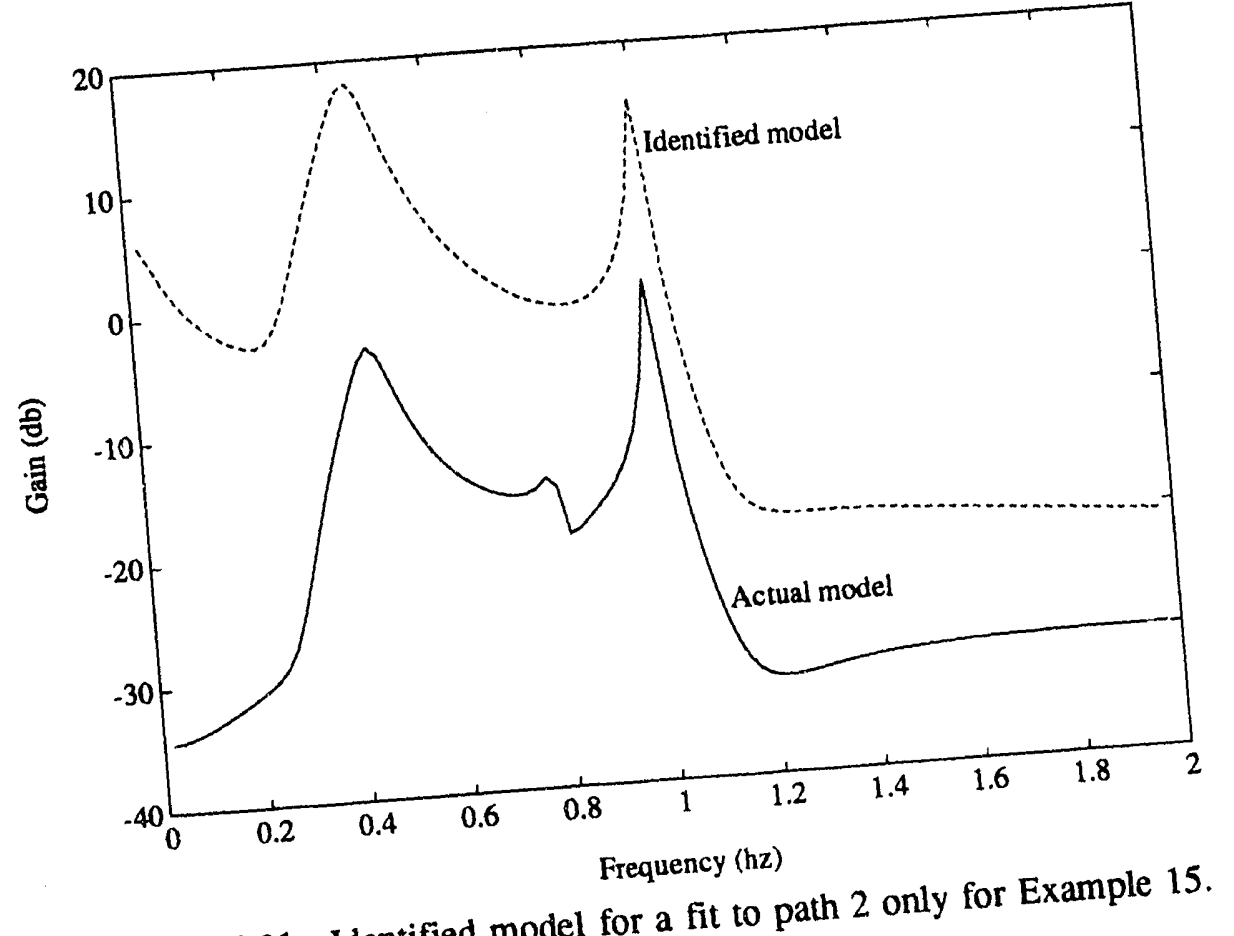

Figure 5.31. Identified model for a fit to path 2 ony for Examp poles with 2 poles

Now a multi-path fit is performed. Path 1 is used to fit the system poer solution in 345 iterations. 


\subsection{Conclusions and Recommendations}

In this report, several characteristics of fitting linear models to freque.רcy response data are demonstrated. Special attention is paid to systems with several closely-spaced damped modes. For the most part, the characteristics are established by conducting a number of fits under controlled conditions and then studying the results of these fits. Proposed future work centers around using the results presented in this report to further advance the capabilities of SYSFIT.

\subsection{Conclusions}

This report has centered around investigating the characteristics of fitting transfer functions to the frequency response of dynamic systems using optimization search techniques. From this investigation, several rules of thumb have been developed for performing such analysis intelligently. These rules range from methods of forming the frequency-response data using DFT methods to how one might form the optimization cost function. In many cases, intelligent use means the difference between convergence to proper solution and no convergence.

The following is a list of guidelines and properties for fitting a transfer function to the frequency response of a system using optimization search methods.

- In forming the optimization cost function: 1) represent the system gain using log-magnitude data; 2) if phase data is used, equally penalize gain and phase contributions to the initial cost function; and 3) the initial cost function should approximately be 100 .

- Use of both gain and phase data in the optimization cost function can improve fitting results under many conditions, such as 1) closely-spaced poles, 2) missing low- or high-frequency data, and 3) nonminimum phase characteristics.

- Of the search options available in SYSFIT, use the DFP method first as it often converges with the least number of iterations.

- In estimating the model order, it is better to over-estimate which often results in near pole/zero cancellations for the extra terms.

- In fitting to systems with closely-spaced poles, expect the identified closely-spaced terms to have relatively larger errors.

- In fitting to the DFT of impulse response data, be aware of the following: 1) if a windowing scheme is used with the DFT (such as hanning), false damping will be introduced into the system poles, an alternative is to use the folding DFT discussed in the report; 2) if too long of a data record is used, noise can begin to dominate the response and cause poor fitting; 3) if too short of a data record is used, the resolution of the DFT data is too poor for accurate fits; 4) in general, noise levels with a SNR of $20 \mathrm{db}$ or greater allow for accurate fitting to dominate system poles; and 5) highly-rolored noise can cause significant errors in the bandwidth of the noise.

- Successful convergence to the proper solution is highly dependent on the initial model. 


\subsection{Recommendations}

The work presented here was conducted as part of a first phase in the development of a Power System Identification (PSI) Toolbox. Extensions of this work are proposed, with the objective being the further development of methods for fitting models to frequency-response data. Four primary areas are proposed for future work: 1) modifications to SYSFIT; 2) implementation of a formal revision control system; 3) development of a users manual; and 4) development of a least-squares frequency domain identification program to complement SYSFIT.

The first proposed modification to SYSFIT involves the input control file format. The first four elements of the optimization control record in the input control file are not needed, as these are later automatically calculated (see Hauer and Taylor 1990). The variables as described in Hauer and Taylor (1990) are

$$
\begin{aligned}
& \text { NV - number of optimization decision variables } \\
& \text { NC - number of explicit constraints } \\
& \text {. NEQ - nu:nber of explicit equality constraints } \\
& \text {. NPF - number of penalty functions. }
\end{aligned}
$$

By setting these values to zero, SYSFIT can automatically calculate their actual value. Other modifications would involve minor variable cleanup and cross-platforms modifications.

Currently, no revision control system is employed with the SYSFIT routines. In the work documented in this report, an initial revision system was implemented using the public domain Revision Control System (RCS) by Tichy (1985). With this system, modifications and version numbers are tracked automatically. Several options are possible with RCS for customizing to the users needs.

Because SYSFIT requires an advanced understanding of optimization techniques and transter function fitting methods, it is highly recommended that a tutorial type of manual be developed. The manual would contain a tutorial on using SYSFIT as well as several examples, both simple and advanced. Much of this work will be performed in conjunction with BPA.

A significant disadvantage of using search methods (as used in SYSFIT) is that an initial guess must be provided for the model. Other methods, such as least-squares techniques, do not require an initial model, but these methods are limited in the allowed formulation of the model and are less numerically robust. Despite these limitations, in many cases, it would be very useful to have a fitting method for developing initial models for certain SYSFIT blocks. With this in mind, it is recornmended that a computer program be developed for forming the initial models. This program will be developed as a complement to SYSFIT. 
Recent work at PNL has included investigation into techniques for fitting models to frequencyresponse data without providing an initial guess. The model is limited to being of the form

$$
G(s)=\frac{b_{m} s^{m}+b_{m-1} s^{m-1}+\ldots+b_{0}}{s^{n}+a_{n-1} s^{n-1}+a_{n-2} s^{n-2}+\ldots+a_{0}}
$$

where the orders $m$ and $n$ may or may not be known. The unknown coefficients in system (6.1) can be determined by solving the over-determined set of equations

$$
\left[\begin{array}{cccccccc}
\left(j \omega_{1}\right)^{n} G\left(j \omega_{1}\right) & \left(j \omega_{1}\right)^{n-1} G\left(j \omega_{1}\right) & \ldots & G\left(j \omega_{1}\right) & \left(j \omega_{1}\right)^{m} & \left(j \omega_{1}\right)^{m-1} & \ldots & 1 \\
\left(j \omega_{2}\right)^{n} G\left(j \omega_{2}\right) & \left(j \omega_{2}\right)^{n-1} G\left(j \omega_{2}\right) & \ldots & G\left(j \omega_{2}\right) & \left(j \omega_{2}\right)^{m} & \left(j \omega_{2}\right)^{m-1} & \ldots & 1 \\
\vdots & \vdots & & \vdots & \vdots & \vdots & & \vdots \\
\left(j \omega_{N}\right)^{n} G\left(j \omega_{N}\right) & \left(j \omega_{N}\right)^{n-1} G\left(j \omega_{N}\right) & \ldots & G\left(j \omega_{N}\right) & \left(j \omega_{N}\right)^{m} & \left(j \omega_{N}\right)^{m-1} & \ldots & 1
\end{array}\right]\left[\begin{array}{c}
a_{n-1} \\
a_{n-2} \\
\vdots \\
a_{0} \\
-b_{m} \\
-b_{m-1} \\
\vdots \\
-b_{0}
\end{array}\right]=\left[\begin{array}{c}
0 \\
0 \\
\vdots \\
0
\end{array}\right]
$$

Unfortunately, Equation (6.2) is a very numerically ill-conditioned problem. This is seen by recognizing that the numerator and denominator polynomials are power series. As $\omega$ varies over a significant range, a standard power series polynomial behaves very poorly. Details of this are contained in Richardson and Formenti (1982) and Adcock (1987). A solution to this problem proposed in Richardson and Formenti (1982) is to rewrite Equation (6.1) using a different orthogonal polynomial set that can provide improved numerical robustness. A least-squares solution is obtained using the aiternative formulation, and then the identified parameters are transformed (the transformation is linear) to the formulation in Equation (6.1).

Several tests have been conducted at PNL to compare the methods in Richardson and Formenti (1982) using Chebyshev polynomials (Adcock 1987) and directly solving Equation (6.2). Also, frequency normalization methods have been tested. Using variations of these methods with overdetermined solution techniques, several very good results have been obtained. Accurate identification is often obtained for noise levels similar to that achieved with SYSFIT.

Based on these promising results, it is highly recommended that these fitting techniques be developed into a program for inclusion in the PSI Toolbox. The program will be developed as a generic subroutine that can easily be coupled with SYSFIT and other PSI Toolbox programs. 


\subsection{References}

Adcock, J. L. 1987. "Curve Fitter for Pole-Zero Analysis." HP Journal 38(1):33-37.

Akaike, H. 1974. "A New Look at the Statistical Model Identification." IEEE Transactions on Automatic Control AC-19:716-723.

Ausman, J. S. 1964. "Amplitude Frequency Response Analysis and Synthesis of Unfactored Transfer Functions." ASME Transactions. 86(1):32-36.

Balas, G. J. and J. C. Doyle. 1990. "Identification of Flexible Structures for Robust Control." IEEE Control Systems Magazine. pp. 51-58, June.

Berchin, G. B., and Soderstrand, M. A. 1989. "A Total Least-Squares Approach to Frequency Domain System Identification." In Proceedings of the 32nd Midwest Symposium on Circuits and Systems, pp. 709-711. Institute of Electrical and Electronics Engineers, Piscataway, New Jersey.

Black, C. G. and D. J. Murray-Smith. 1989. "A Frequency-Domain System Identification Approach to Helicopter Flight Mechanics Model Validation." Vertica. 13(3):343-368.

Braun, S. G., and Ram, Y. M. 1987. "Structural Parameter Identification in the Frequency Domain: The Use of Overdetennined Systems." Journal of Dynamic Systems, Measurement, and Control 109:120-123.

Chen, C. F., and Philip, B. L. 1963. "Graphical Determination of Transfer Function Coefficients of a System from Its Frequency Response." IEEE Transactions on Apply Ind. 83:42-45.

Hauer, J. F. 1974. MORPAK-II: An Accelerated Projection Program for Constrained Nonlinear Minimization. Technical Report TR74-13, Department of Computer Science, University of Alberta, Edmonton, Alberta, Canada.

Hauer, J. F. 1977. Computer Routines for Fitting Transfer Functions to System Response Measurements. Bonneville Power Administration, Portland, Oregon.

Hauer, J. F. 1982. "Power System Identification by Fitting Structured Models to Measured Frequency Response." IEEE Transactions on Power Systems PAS-101(4):915-922.

Hauer, J. F. 1989. "Identification of Power System Models for Large-Scale Damping Control." In Proceedings of the 28th IEEE Conference on Decision and Control, Tampa, Florida. pp. 1841-1846, Institute of Electrical and Electronics Engineers, Piscataway, New Jersey.

Hauer, J. F., and Taylor, C. W. 1990. Feedback Control and Frequency Domain Analysis of Large Electric Power Systems, Volume 1: Seminar Workbook. Carson Taylor Seminars, Portland, Oregon. 
Gu, G. and P. Misra. 1992. "Identification of Linear Time-Invariant Systems from FrequencyResponse Data Corrupted by Bounded Noise." IEE Proceedings-D. 139(2):135-140. cited on p. 2.5 of text

Jong, M. T., and Shanmugam, K. S. 1977. "Determination of Transfer Function from Amplitude Frequency Response Data." International Journal of Control 25:941-948.

Kumaresan, R. 1990. "On a Frequency Domain Analog of Prony's Method." IEEE Trans. on Acoustics, Speech, and Signal Processing 38(1):168-170.

Levy, E. C. 1959. "Complex Curve Fitting." IRE Trans. on Automatic Control AC-4:37-43.

Lin, P. L., and Wu, Y. C. 1982. "Identification of Multi-Input Multi-Output Linear Systems from Frequency Response Data." Transactions of the ASME, Journal of Dynamic Systems, Measurement, and Control 104:58-64.

Mau, S. T., and Wang, S. 1989. "Arch Dam System Identification Using Vibration Test Data." Earthquake Engineering and Structural Dynamics 18(4):491-505.

Moser, A. N., and Caughey, T. K. 1991. "Some Experience with Identification of the Caltech Experimental Space Structure." In Proceedings of the 1991 American Control Conference, vol. 2, pp. 1776-1781. Institute of Electrical and Electronics Engineers, Piscataway, New Jersey.

Nilsson, J. W. 1983. Electric Circuits. Addison-Wesley Publishing, Menlo Park, California.

Oppenheim, A. V., and Schafer, R. W. 1975. Digital Signal Processing. Prentice-Hall, Inc., Englewood Cliffs, New Jersey.

Payne, P. A. 1970. "An Improved Technique for Transfer Function Synthesis from Frequency Response Data." IEEE Transactions on Automatic Control AC-15:480-483.

Pierre, D. A. 1969. Optimization Theory with Applications. Dover Publications, New York.

Richardson, M. H., and Formenti, D. L. 1982. "Parameter Estimation from Frequency Response Measurements Using Rational Fraction Polynomials." In Proceedings of International Modal Analysis Conference, pp. 167-181. January, Schenectady, New York. Union College, Schenectady, New York.

Sanathanan, C. K., and Koemer, J. 1963. "Sequential Transfer Function Synthesis from Measured Data." IEEE Transactions on Automatic Control AC-8:56-58.

Suidel, R. C. 1975. Transfer-Function-Parameter Estimation from Frequency Response Data -- $A$ FORTRAN Program. NASA TM X-3286, Lewis Research Center, Cleveland, Ohio.

Sidman, M. D., Deangelis, F. E., and Verghese, G. C. 1991. "Parametric System Identification on Logarithmic Frequency Response Data." IEEE Transactions on Automatic Control 36(9):1065-1070. 
Steiglitz, K. 1970. "Computer-Aided Design of Recursive Digital Filters." IEEE Transactions on Audio and Electroacoustics AU-18(2):123-129.

Tichy, W. F. 1985. "RCS -- A System for Version Control." Software -- Practice \& Experience 15(7):637-654.

Tilly, D. M. 1984. Three Algorithms for Parametric Frequency Domain System Identification. UCID-20255, Lawrence Livermore National Laboratory, Livermore, Califormia.

West, B. J. 1990. "The Noise in Natural Phenomena." American Scientist 7:40-45. 


\section{Appendix}

SYSFIT Input Files for Examples 


\section{Appendix}

\section{SYSFIT Input Files for Examples}

Example 1: The following is for the DFP search. Other searches conducted by changing search algorithm option.

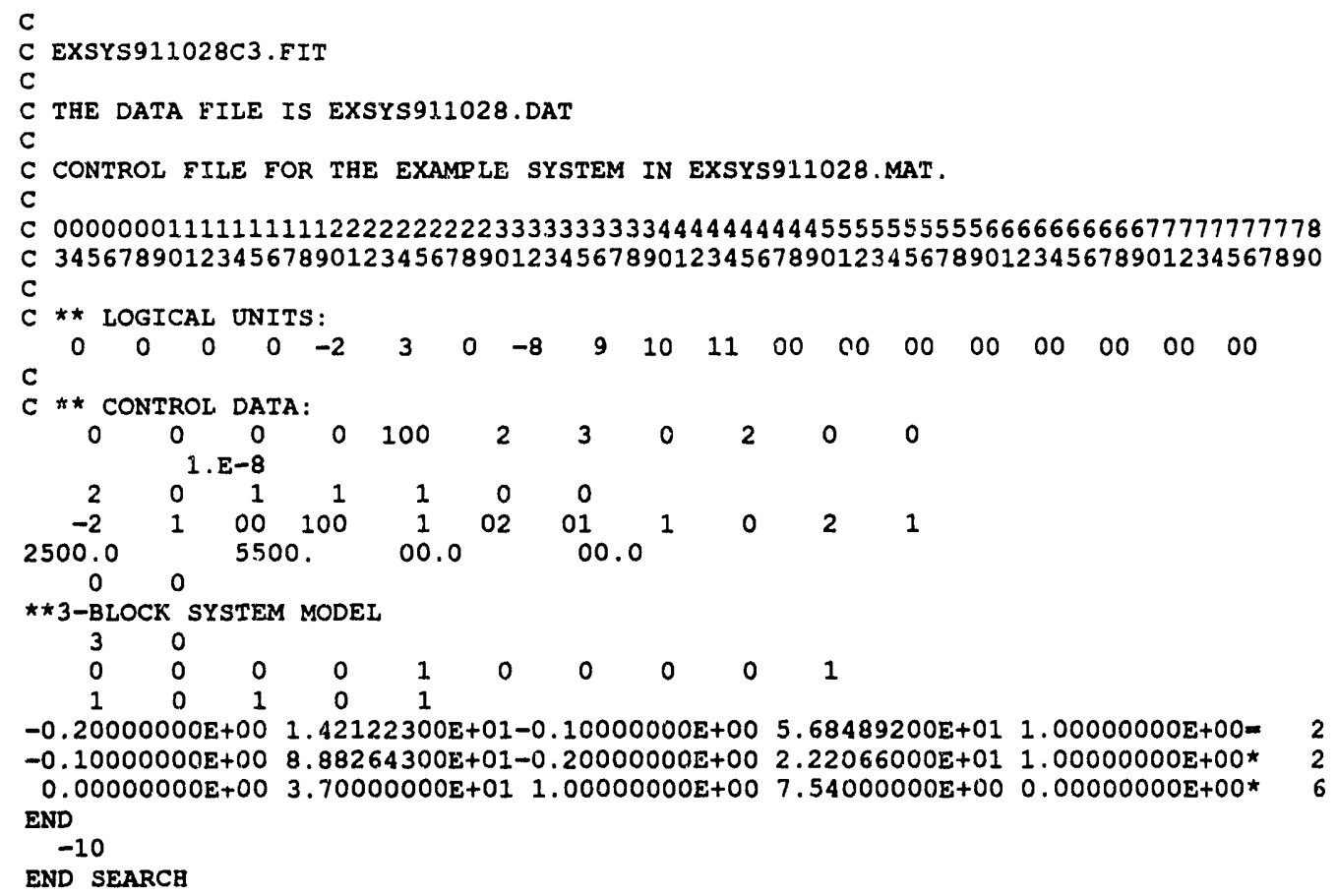

\section{Example 2:}

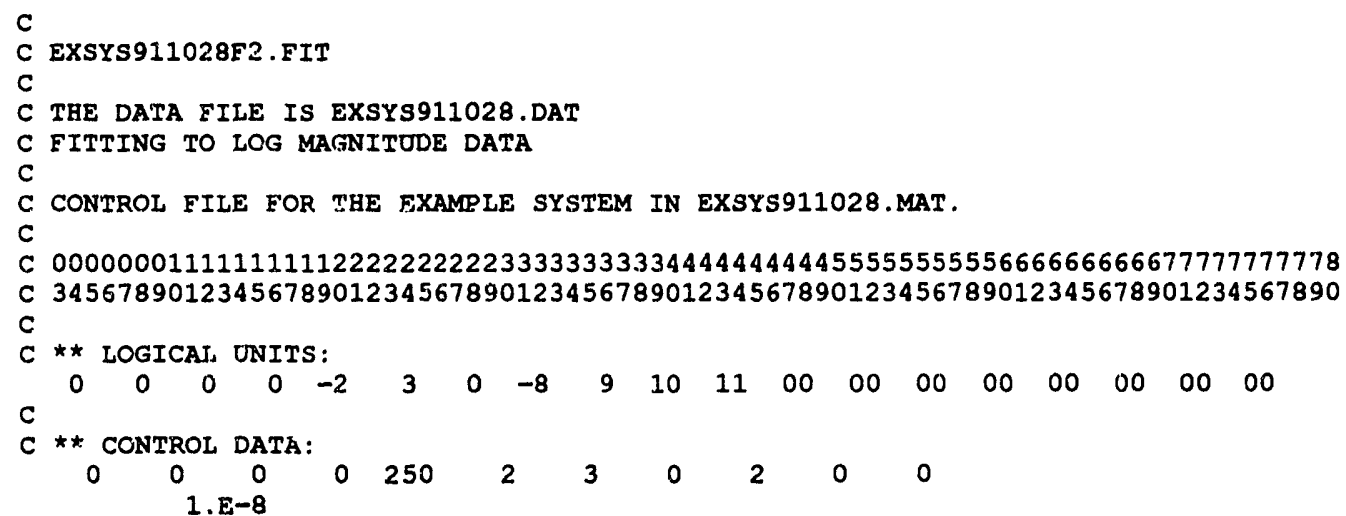


$\begin{array}{cccrcrrrrrrr}2 & 0 & 1 & 1 & 1 & 0 & 0 & & & \\ -2 & 1 & 00 & 100 & 1 & 02 & 01 & 1 & 0 & 2 & 1 \\ 2500.0 & & 0.0 & & 00.0 & & 00.0 & & & \end{array}$

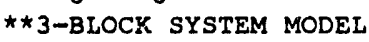

30

$\begin{array}{llllllllll}0 & 0 & 0 & 0 & 1 & 0 & 0 & 0 & 0 & 1\end{array}$

$-0.20000000 \mathrm{E}+00 \quad 1.42122300 \mathrm{E}+01-0.10000000 \mathrm{E}+00 \quad 5.68489200 \mathrm{E}+01 \quad 1.00000000 \mathrm{E}+00=$ $-0.10000000 \mathrm{E}+00 \quad 8.88264300 \mathrm{E}+01-0.20000000 \mathrm{E}+00 \quad 2.22066000 \mathrm{E}+011.00000000 \mathrm{E}+00$ * $0.00000000 \mathrm{E}+00 \quad 3.70000000 \mathrm{E}+01$ 1.00000000E+00 $7.54000000 \mathrm{E}+00 \quad 0.00000000 \mathrm{E}+00 *$ END

$-10$

END SEARCH

C EXSYS911028E2.FIT

C THE DATA EILE IS EXSYS911028.DAT

C FITTING TO ABSOLUTE GAIN

C

C CONTROL FILE FOR THE EXAMPLE SYSTEM IN EXSYS911028.MAT.

C 000000011111111112222222222333333333344444444445555555555666666666677777777778 C 345678901234567890123456789012345678901234567890123456789012345678901234567890

C $\star *$ LOGICAL UNITS:

C

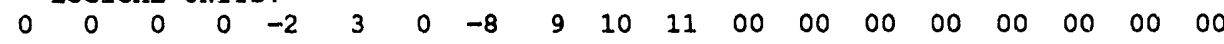

C $\star *$ CONTROL DATA

$\begin{array}{lllllllllll}0 & 0 & 0 & 0 & 100 & 2 & 3 & 0 & 2 & 0 & 0\end{array}$

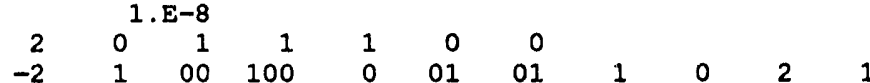

0.20

000.0

00.0

0
0 -BLOCK SYSTEM MODEL

30

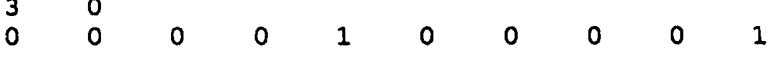

$-0.20000000 \mathrm{E}+00 \quad 1.42122300 \mathrm{E}+01-0.10000000 \mathrm{E}+00 \quad 5.68489200 \mathrm{E}+01 \quad 1.00000000 \mathrm{E}+00=$

$-0.10000000 E+008.88264300 E+01-0.20000000 E+002.22066000 E+011.00000000 E+00 *$

$0.00000000 \mathrm{E}+00 \quad 3.70000000 \mathrm{E}+01 \quad 1.00000000 \mathrm{E}+00 \quad 7.54000000 \mathrm{E}+00 \quad 0.00000000 \mathrm{E}+00 *$ END

$-10$

END SEARCB

\section{Example 3:}

C EXSYS911028A3.FIT, USE EXSYS911028.DAT

C $พ 1=10, W 2=1$

C CONTROL FILE FOR THE EXAMPLE SYSTEM IN EXSYS911028.MAT.

C 000000011111111112222222222333333333344444444445555555555666666666677777777778

C 345678901234567890123456789012345678901234567890123456789012345678901234567890

C ** LOGICAI UNITS:

C $\star \star$ CONTROL DATA:

$\begin{array}{lccccccccc}0 & 0 & 0 & 0 & 100 & 2 & 3 & 0 & 2 & 0\end{array}$

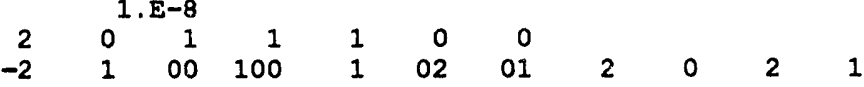




$$
\begin{array}{lllll}
10.0 & 1.0 & 00.0 & 00.0
\end{array}
$$

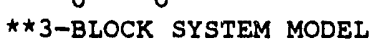

$\begin{array}{llllllllll}3 & 0 & & & & & & & \\ 0 & 0 & 0 & 0 & 1 & 0 & 0 & 0 & 0 & 1 \\ 1 & 0 & 1 & 0 & 1 & & & \end{array}$

$-0.20000000 \mathrm{E}+00 \quad 1.42122300 \mathrm{E}+01-0.10000000 \mathrm{E}+00 \quad 5.68489200 \mathrm{E}+01 \quad 1.00000000 \mathrm{E}+00=2$ $-0.10000000 E+00 \quad 8.88264300 E+01-0.20000000 E+00 \quad 2.22066000 E+01 \quad 1.00000000 E+00 * 2$ $0.00000000 \mathrm{E}+00 \quad 3.70000000 \mathrm{E}+01 \quad 1.00000000 \mathrm{E}+00 \quad 7.54000000 \mathrm{E}+00 \quad 0.00000000 \mathrm{E}+00 * \quad 6$ END

$-10$

END SEARCH

C

C EXSYS911028C.FIT

C THE DATA FILE IS EXSYS911028.DAT

C $\mathrm{W} 1=10$, $2=55$

$\mathrm{C}$

C CONTROL FILE FOR THE EXAMPLE SYSTEM IN EXSYS911028.MAT.

C

C 000000011111111112222222222333333333344444444445555555555666666666677777777778 C 345678901234567890123456789012345678901234567890123456789012345678901234567890

$C \star \star$ LOGICAL UNITS :

$\begin{array}{lllllllllllllllllll}0 & 0 & 0 & 0 & -2 & 3 & 0 & -8 & 9 & 10 & 11 & 00 & 00 & 00 & 00 & 00 & 00 & 00 & 00\end{array}$

** CONTROL DATA:

$\begin{array}{lcccccccccc}0 & 0 & 0 & 0 & 250 & 2 & 3 & 0 & 2 & 0 & 0\end{array}$

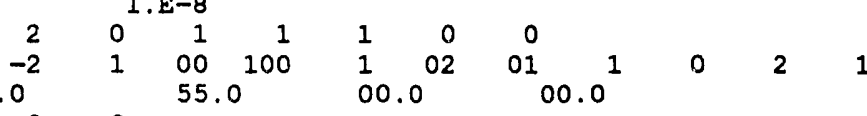

10.0

$0 \quad 0$

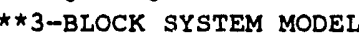

$\begin{array}{lllll}3 & 0 & & & \\ 0 & 0 & 0 & 0 & 1 \\ 1 & 0 & 1 & 0 & 1\end{array}$

$-0.20000000 \mathrm{E}+00 \quad 1.42122300 \mathrm{E}+01-0.10000000 \mathrm{E}+00 \quad 5.68489200 \mathrm{E}+01 \quad 1.00000000 \mathrm{E}+00=2$ $-0.10000000 \mathrm{E}+00 \quad 8.88264300 \mathrm{E}+01-0.20000000 \mathrm{E}+00 \quad 2.22066000 \mathrm{E}+01 \quad 1.00000000 \mathrm{E}+00 * 2$ $0.00000000 \mathrm{E}+00 \quad 3.70000000 \mathrm{E}+01 \quad 1.00000000 \mathrm{E}+00 \quad 7.54000000 \mathrm{E}+000.00000000 \mathrm{E}+00$ * 6 END

$-10$

END SEARCH

C

C EXSYS911028C 2.FIT

C THE DATA FILE IS EXSYS911028.DAT

C $W 1=1000, W 2=5500$

C CONTROL FILE FOR THE EXAMPLE SYSTEM IN EXSYS911028.MAT,

C 000000011111111112222222222333333333344444444445555555555666666666677777777778 C 345678901234567890123456789012345678901234567890123456789012345678901234567890 C * LCGICAL UNITS:

$\begin{array}{lllllllllllllllllll}0 & 0 & 0 & 0 & -2 & 3 & 0 & -8 & 9 & 10 & 11 & 00 & 00 & 00 & 00 & 00 & 00 & 00 & 00\end{array}$

$C \star \star$ CONTROL DATA:

$\begin{array}{lccccccccc}0 & 0 & 0 & 0 & 100 & 2 & 3 & 0 & 2 & 0\end{array}$

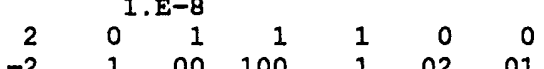

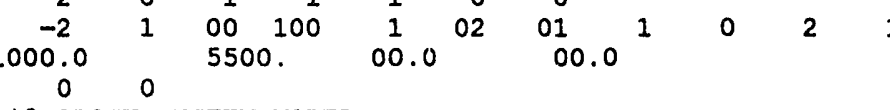

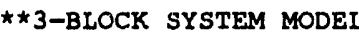

$\begin{array}{llllllllll}3 & 0 & & & & & & & & \\ 0 & 0 & 0 & 0 & 1 & 0 & 0 & 0 & 0 & 1\end{array}$ 
$\begin{array}{ccccc}1 & 0 & 1 & 0 & 1\end{array}$

$-0.20000000 \mathrm{E}+00 \quad 1.42122300 \mathrm{E}+01-0.10000000 \mathrm{E}+00 \quad 5.68489200 \mathrm{E}+01 \quad 1.00000000 \mathrm{E}+00=$ $-0.10000000 E+00 \quad 8.88264300 E+01-0.20000000 E+00 \quad 2.22066000 E+01 \quad 1.00000000 E+00$ * $0.00000000 \mathrm{E}+00 \quad 3.70000000 \mathrm{E}+01 \quad 1.00000000 \mathrm{E}+00 \quad 7.54000000 \mathrm{E}+00 \quad 0.00000000 \mathrm{E}+00 *$ END

$-10$

END SEARCH

\section{Example 4:}

$\mathrm{C}$

C EXSYS91110A.FIT, USE EXSYS911108.DAT

C

C A REDUCED-ORDER (7TH ORDER) FIT TO THE DATA.

C CONTROL FILE FOR THE EXAMPLE SYSTEM IN EXSYS911108.MAT.

C 00000001111111111222222222233333333333444444444455555555556666666666777777777778 C 345678901234567890123456789012345678901234567890123456789012345678901234567890 $C * *$ LOGICAL UNITS:

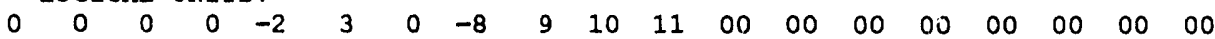

C $\star \star$ CONTROL DATA:

$\begin{array}{lcccccccccc}0 & 0 & 0 & 0 & 400 & 2 & 3 & 0 & 2 & 0 & 0\end{array}$

$2 \quad \begin{array}{lrrrrr}1 \cdot E-8 & 1 & 1 & 0 & 0\end{array}$

$\begin{array}{llllllllll}-2 & 1 & 01 & 207 & 1 & 02 & 01 & 2 & 0 & 2\end{array}$

$\begin{array}{llll}1.00000 \mathrm{E}+02 & 3.00000 \mathrm{E}+02 & 0.00000 \mathrm{E}+00 \quad 0.00000 \mathrm{E}+00\end{array}$

0

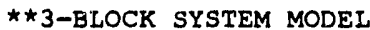

$\begin{array}{llllllllll}4 & 0 & & & & 0 & 0 & 0 & 0 & 1 \\ 0 & 0 & 0 & 0 & 1 & 0 & 0 & 1 & 0 & 1 \\ 0 & 0 & 0 & 0 & 1 & 1 & 0 & 1\end{array}$

$-0.10000000 \mathrm{E}+00 \quad 1.66796300 \mathrm{E}+01-0.20000000 \mathrm{E}+00 \quad 4.83610600 \mathrm{E}+00 \quad 1.00000000 \mathrm{E}+00 \mathrm{E}$

$-0.10000000 E+003.19775200 E+01-0.50000000 E-012.52661900 E+01 \quad 1.00000000 E+00 *$

$-0.50000000 \mathrm{E}-018.88264400 \mathrm{E}+01-0.50000000 \mathrm{E}-013.94784200 \mathrm{E}+011.00000000 \mathrm{E}+00 *$

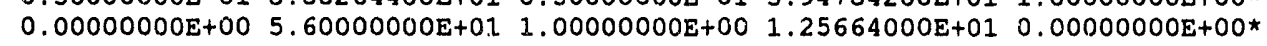
END

$-10$

END SEARCH

\section{Example 5:}

C

C EXSYS911202A.FIT, USE EXSYS911108.DAT

C

C A 11th ORDER FIT TO THE DATA OF A 9TH ORDER SYSTEM.

C

C CONTROL FILE FOR THE EXAMPL SYSTEM IN EXSYS911108.MAT.

C

C 000000011111111112222222222333333333344444444445555555555666666666677777777778 C 345678901234567890123456789012345678901234567890123456789012345678901234567890 C

C $\star \star$ LOGICAL UNITS:

C'

$\begin{array}{lllllllllllllllllll}0 & 0 & 0 & 0 & -2 & 3 & 0 & -8 & 9 & 10 & 11 & 00 & 00 & 00 & 00 & 00 & 00 & 00 & 00\end{array}$

$C \star \star$ CONTROL DATA:
$0 \quad 0 \quad 0$
$2 \quad 1 . E-8$
2
(
2
0
$\begin{array}{lllllll}-2 & 1 & 01 & 207 & 1 & 02 & 01\end{array}$ 


$$
00
$$

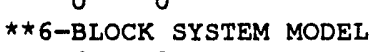

$\begin{array}{llllllllll}6 & 0 & & & & & & & & \\ 0 & 0 & 0 & 0 & 1 & 0 & 0 & 0 & 0 & 1 \\ 0 & 0 & 0 & 0 & 1 & 1 & 0 & 1 & 0 & 1 \\ 0 & 0 & 0 & 0 & 1 & 0 & 0 & 0 & 0 & 1\end{array}$

$-0.10000000 \mathrm{E}+00 \quad 1.66796300 \mathrm{E}+01-0.20000000 \mathrm{E}+00 \quad 4.83610600 \mathrm{E}+00 \quad 1.00000000 \mathrm{E}+00=$ $-0.10000000 \mathrm{E}+00 \quad 3.19775200 \mathrm{E}+01-0.50000000 \mathrm{E}-01 \quad 2.52661900 \mathrm{E}+01 \quad 1.00000000 \mathrm{E}+00$ * $-0.50000000 \mathrm{E}-01 \quad 8.88264400 \mathrm{E}+01-0.50000000 \mathrm{E}-01 \quad 3.94784200 \mathrm{E}+01 \quad 1.00000000 \mathrm{E}+00$ *

$0.00000000 \mathrm{E}+00 \quad 7.00000000 \mathrm{E}+00 \quad 1.00000000 \mathrm{E}+00 \quad 1.25664000 \mathrm{E}+01 \quad 0.00000000 \mathrm{E}+00$ * $-2.51330000 \mathrm{E}+006.31650000 \mathrm{E}+00-0.25000000 \mathrm{E}+00 \quad 8.05690000 \mathrm{E}+001.00000000 \mathrm{E}+00^{*}$ $-2.51330000 \mathrm{E}+006.31650000 \mathrm{E}+00-0.25000000 \mathrm{E}+00 \quad 8.05690000 \mathrm{E}+001.00000000 \mathrm{E}+00$ * END

$-10$

END SEARCH

\section{Example 6:}

C

C EXSYS920220B.FIT, USE EXSYSM920220A.DAT

C CONTROL FILE FOR THE EXAMPLE SYSTEM IN EXSYSM920220A.MAT.

C GAIN FIT WITH FIRST 10 DATA POINTS MISSING

C

C 000000011111111112222222222333333333344444444445555555555666666666677777777778 C 345678901234567890123456789012345678901234567890123456789012345678901234567890 C

C * $*$ LOGICAL UNITS:

$c$

$\star \star$ CONTROL DATA:

$\begin{array}{lccccccccc}0 & 0 & 0 & 0 & 200 & 2 & 3 & 0 & 2 & 0\end{array}$

$2 \quad 1 . \mathrm{E}-8$

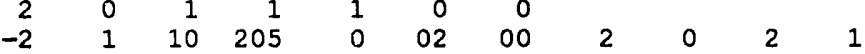

$\begin{array}{lllll}1.00000 \mathrm{E}+02 & 0.00000 \mathrm{E}+02 & 0.00000 \mathrm{E}+00 & 0.00000 \mathrm{E}+00\end{array}$

$0 \quad 0$

$\star \star 5-B L O C K$ SYSTEM MODEL

$\begin{array}{llllllllll}5 & 0 & & & & & & & \\ 0 & 0 & 0 & 0 & 1 & 0 & 0 & 0 & 0 & 1 \\ 0 & 0 & 0 & 0 & 1 & 0 & 0 & 0 & 0 & 1\end{array}$

$-1.88495559 \mathrm{E}+00 \quad 3.55305758 \mathrm{E}+00-0.03000000 \mathrm{E}+00 \quad 2.87887664 \mathrm{E}+00 \quad 1.00000000 \mathrm{E}+00=$

$-0.20000000 \mathrm{E}+00$ 1.19422213E+01-0.03000000E+00 4.29919968E+00 1.00000000E+00*

$-0.20000000 \mathrm{E}+003.94784176 \mathrm{E}+01-0.10000000 \mathrm{E}+002.52661873 \mathrm{E}+011.00000000 \mathrm{E}+00$ *

$-0.10000000 \mathrm{E}+00 \quad 8.88264396 \mathrm{E}+01-0.10000000 \mathrm{E}+00 \quad 3.94784176 \mathrm{E}+01 \quad 1.00000000 \mathrm{E}+00 *$

$0.00000000 \mathrm{E}+00 \quad 1.00000000 \mathrm{E}+00 \quad 1.00000000 \mathrm{E}+00 \quad 1.25664000 \mathrm{E}+01 \quad 0.00000000 \mathrm{E}+00$ * END

$-10$

END SEARCB

C

C EXSYS920220K.FIT, USE EXSYSM920220A.DAT

C GAIN FIT AND PHASE WITH FIRST 40 DATA POINTS MISSING

C CONTROL FILE FOR THE EXAMPLE SYSTEM IN EXSYSM920220A.MAT.

C 000000011111111112222222222333333333344444444445555555555666666666677777777778

C 345678901234567890123456789012345678901234567890123456789012345678901234567890

C

C * LOGICAL UNITS:

C $\star *$ CONTROL DATA:

$\begin{array}{rrr}0 & 0 & 0 \\ 1 . \mathrm{E}-8\end{array}$

$-8$

910

00

0000

$00 \quad 00$

$0000 \quad 00$$$
1.8-8
$$ 


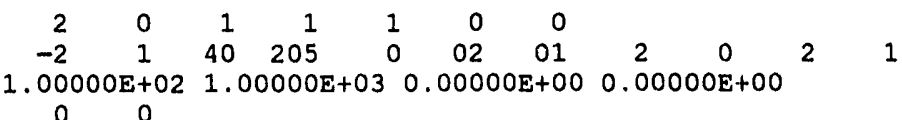

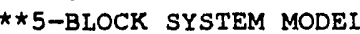

$\begin{array}{llllllllll}5 & 0 & & & & & & & \\ 0 & 0 & 0 & 0 & 1 & 0 & 0 & 0 & 0 & 1 \\ 0 & 0 & 0 & 0 & 1 & 0 & 0 & 0 & 0 & 1 \\ 1 & 0 & 1 & 0 & 1 & \end{array}$

$-1.88495559 \mathrm{E}+00 \quad 3.55305758 \mathrm{E}+00-0.03000000 \mathrm{E}+00 \quad 2.87887664 \mathrm{E}+00 \quad 1.00000000 \mathrm{E}+00=$ $-0.20000000 \mathrm{E}+001.19422213 \mathrm{E}+01-0.03000000 \mathrm{E}+00 \quad 4.29919968 \mathrm{E}+001.00000000 \mathrm{E}+00$ * $-0.20000000 \mathrm{E}+00 \quad 3.94784176 \mathrm{E}+01-0.10000000 \mathrm{E}+00 \quad 2.52661873 \mathrm{E}+01 \quad 1.00000000 \mathrm{E}+00$ * $-0.10000000 \mathrm{E}+00 \quad 8.88264396 \mathrm{E}+01-0.10000000 \mathrm{E}+00 \quad 3.94784176 \mathrm{E}+01 \quad 1.00000000 \mathrm{E}+00 *$ $0.00000000 \mathrm{E}+00 \quad 1.00000000 \mathrm{E}+00 \quad 1.00000000 \mathrm{E}+00 \quad 1.25664000 \mathrm{E}+010.00000000 \mathrm{E}+00$ * END

$-10$

END SEARCH

\section{Example 7:}

C

C EXSYS920211D.FIT, USE EXSYSM920211.DAT

C GAIN FIT

C See pg. 99 of the bpa task ordering notebook, 2-11-92.

C This is for $p=0.75$.

C 000000011111111112222222222333333333344444444445555555555666666666677777777778 C 345678901234567890123456789012345678901234567890123456789012345678901234567890

C ** LOGICAL UNITS:

C

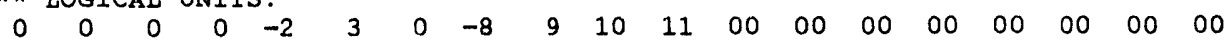

C $\star *$ CONTROL DATA:

$\begin{array}{lccccccccc}0 & 0 & 0 & 0 & 400 & 2 & 3 & 0 & 2 & 0\end{array}$

$2 \quad 1 . E-8$

$\begin{array}{rrrrrrrrrr}-2 & 5 & 00 & 205 & 0 & 02 & 00 & 2 & 0 & 2\end{array}$

$\begin{array}{llllll}1.00000 \mathrm{E}+02 & 0.00000 \mathrm{E}+04 & 0.00000 \mathrm{E}+00 & 0.00000 \mathrm{E}+00\end{array}$

$0 \quad 0$

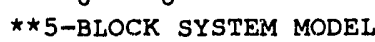

$\begin{array}{llllllllll}5 & 0 & & & & 0 & 0 & 0 & 0 & 1 \\ 0 & 0 & 0 & 0 & 1 & 0 & 0 & 1 & 0 & 1 \\ 0 & 0 & 0 & 0 & 1 & 1 & 0 & \end{array}$

$-0.10000000 \mathrm{E}+00 \quad 1.66796300 \mathrm{E}+01-0.20000000 \mathrm{E}+00 \quad 4.83610600 \mathrm{E}+00 \quad 1.00000000 \mathrm{E}+00=$ $-0.10000000 \mathrm{E}+00 \quad 3.19775200 \mathrm{E}+01-0.50000000 \mathrm{E}-01 \quad 2.52661900 \mathrm{E}+01 \quad 1.00000000 \mathrm{E}+00 *$

$-0.50000000 \mathrm{E}-01 \quad 8.88264400 \mathrm{E}+01-0.50000000 \mathrm{E}-01 \quad 3.94784200 \mathrm{E}+01 \quad 1.00000000 \mathrm{E}+00^{*}$

$0.00000000 \mathrm{E}+002.80000000 \mathrm{E}+01 \quad 1.00000000 \mathrm{E}+001.25664000 \mathrm{E}+010.00000000 \mathrm{E}+00$ * $-2.51330000 \mathrm{E}+006.31650000 \mathrm{E}+00-0.25000000 \mathrm{E}+00 \quad 8.05690000 \mathrm{E}+001.00000000 \mathrm{E}+00 *$ END

$-10$

END SEARCH

C EXSYS920211F.FIT, USE EXSYSM920211.DAT

C GAIN AND PHASE FIT

C See pg. 99 of the bpa task ordering notebook, 2-11-92.

C This is for $p=0.99$

C 000000011111111112222222222333333333344444444445555555555666666666677777777778 C 345678901234567890123456789012345678901234567890123456789012345678901234567890 C

C ** LOGICAL UNITS:

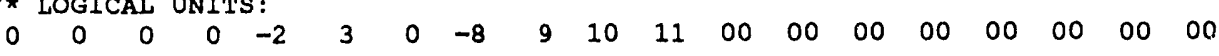

C $\star \star$ CONTROL DATA: 


$\begin{array}{ccccccccccc}0 & 0 & 0 & 0 & 400 & 2 & 3 & 0 & 2 & 0 & 0 \\ 2 & 0 & 1 & 1 & 1 & 0 & 0 & & & & \\ -2 & 3 & 00 & 205 & 0 & 02 & 01 & 2 & 0 & 2 & 1 \\ 1.00000 \mathrm{E}+02 & 1.00000 \mathrm{E}+04 & 0.00000 \mathrm{E}+00 & 0.00000 \mathrm{E}+00 & & \end{array}$

1. $00000 \mathrm{E}+02$

$\star \star 5-B L O C K$ SYSTEM MODEL

$\begin{array}{cccccccccc}5 & 0 & & & & & & & & \\ 0 & 0 & 0 . & 0 & 1 & 0 & 0 & 0 & 0 & 1 \\ 0 & 0 & 0 & 0 & 1 & 1 & 0 & 1 & 0 & 1\end{array}$

$-0.10000000 \mathrm{E}+00 \quad 1.66796300 \mathrm{E}+01-0.20000000 \mathrm{E}+00 \quad 4.83610600 \mathrm{E}+00 \quad 1.00000000 \mathrm{E}+00=$ $-0.10000000 \mathrm{E}+00 \quad 3.19775200 \mathrm{E}+01-0.50000000 \mathrm{E}-01 \quad 2.52661900 \mathrm{E}+01 \quad 1.00000000 \mathrm{E}+00$ * $-0.50000000 \mathrm{E}-01 \quad 8.88264400 \mathrm{E}+01-0.50000000 \mathrm{E}-01 \quad 3.94784200 \mathrm{E}+01 \quad 1.00000000 \mathrm{E}+00 *$ $\begin{array}{llllll}0.00000000 E+00 & 2.80000000 E+01 & 1.00000000 E+00 & 1.25664000 E+01 & 0.00000000 E+00 *\end{array}$ $-2.51330000 \mathrm{E}+00 \quad 6.31650000 \mathrm{E}+00-0.25000000 \mathrm{E}+00 \quad 8.05690000 \mathrm{E}+001.00000000 \mathrm{E}+00$ * END

$-10$

END SEARCH

\section{Example 8:}

C EXSYS920124A.FIT, USE EXSYSM920123A.DAT

C GAIN FIT

C see pg. 89 of the bpa task ordering notebook, 1-24-92.

C This is for $p=0$.

C 000000011111111112222222222333333333344444444445555555555666666666677777777778 C 345678901234567890123456789012345678901234567890123456789012345678901234567890

C $\star \star$ LOGICAL UNITS:

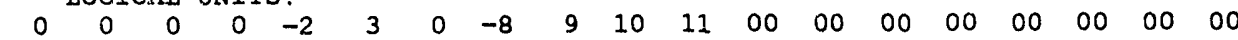

C

C $\star \star$ CONTROL DATA:

$\begin{array}{llcllllllll}0 & 0 & 0 & 0 & 600 & 2 & 3 & 0 & 2 & 0 & 0\end{array}$

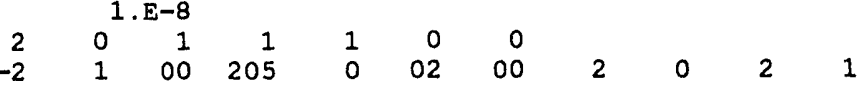

$\begin{array}{llll}1.00000 \mathrm{E}+02 & 0.00000 \mathrm{E}+02 & 0.00000 \mathrm{E}+00 & 0.00000 \mathrm{E}+00\end{array}$

$\begin{array}{cc}0 & 0 \\ C * * 2-B L O C K & \text { SYSTEM MODEL }\end{array}$

**2-BLOCK

$\begin{array}{llllllllll}2 & 0 & 0 & 0 & 0 & 0 & 0 & 0 & 0 & 1\end{array}$

$-0.25000000 \mathrm{E}+00 \quad 1.42122303 \mathrm{E}+01-0.25000000 \mathrm{E}+00 \quad 2.22066099 \mathrm{E}+01 \quad 4.00000000 \mathrm{E}+00=2$ $-0.25000000 \mathrm{E}+001.01064749 \mathrm{E}+02-0.25000000 \mathrm{E}+00 \quad 5.68489214 \mathrm{E}+01 \quad 1.00000000 \mathrm{E}+00=22$ END

$-10$

END SEARCH

C

C EXSYS920124C.FIT, USE EXSYSM920123A.DAT

C GAIN FIT

C See pg. 89 of the bpa task ordering notebook, 1-24-92.

C This is for $p=0.99$

$\mathrm{C}$

C 000000011111111112222222222333333333344444444445555555555666666666677777777778 C 345678901234567890123456789012345678901234567890123456789012345678901234567890 C

$C \star \star$ LOGICAL UNITS:

C $\star *$ CONTROL DATA:

$\begin{array}{lccccccccc}0 & 0 & 0 & 0 & 400 & 2 & 3 & 0 & 2 & 0\end{array}$

$20^{1 \cdot E-8} 1 \quad 1 \quad 1 \quad 000$ 
$\begin{array}{lllllllllll}-2 & 3 & 00 & 205 & 0 & 02 & 00 & 2 & 0 & 2 & 1\end{array}$

$\begin{array}{lll}1.00000 \mathrm{E}+02 & 0.00000 \mathrm{E}+02 \quad 0.00000 \mathrm{E}+00 \quad 0.00000 \mathrm{E}+00\end{array}$

00

$C \star \star 2-B L O C K$ SYSTEM MODEL

20

$\begin{array}{llllllll}0 & 0 & 0 & 0 & 0 & 0 & 0 & 1\end{array}$

$-0.25000000 \mathrm{E}+001.42122303 \mathrm{E}+01-0.25000000 \mathrm{E}+002.22066099 \mathrm{E}+014.00000000 \mathrm{E}+00=\quad 2$ $-0.25000000 \mathrm{E}+001.01064749 \mathrm{E}+02-0.25000000 \mathrm{E}+005.6848 .9214 \mathrm{E}+011.00000000 \mathrm{E}+00=2$ END

$-10$

END SEARCH

C EXSYS920124d.FIT, USE EXSYSM920123A.DAT

C GAIN FIT

C See pg. 89 of the bpa task ordering notebook, 1-24-92.

C This is for $p=1.0$

C 000000011111111112222222222333333333344444444445555555555666666666677777777778 C 345678901234567890123456789012345678901234567890123456789012345678901234567890 c 


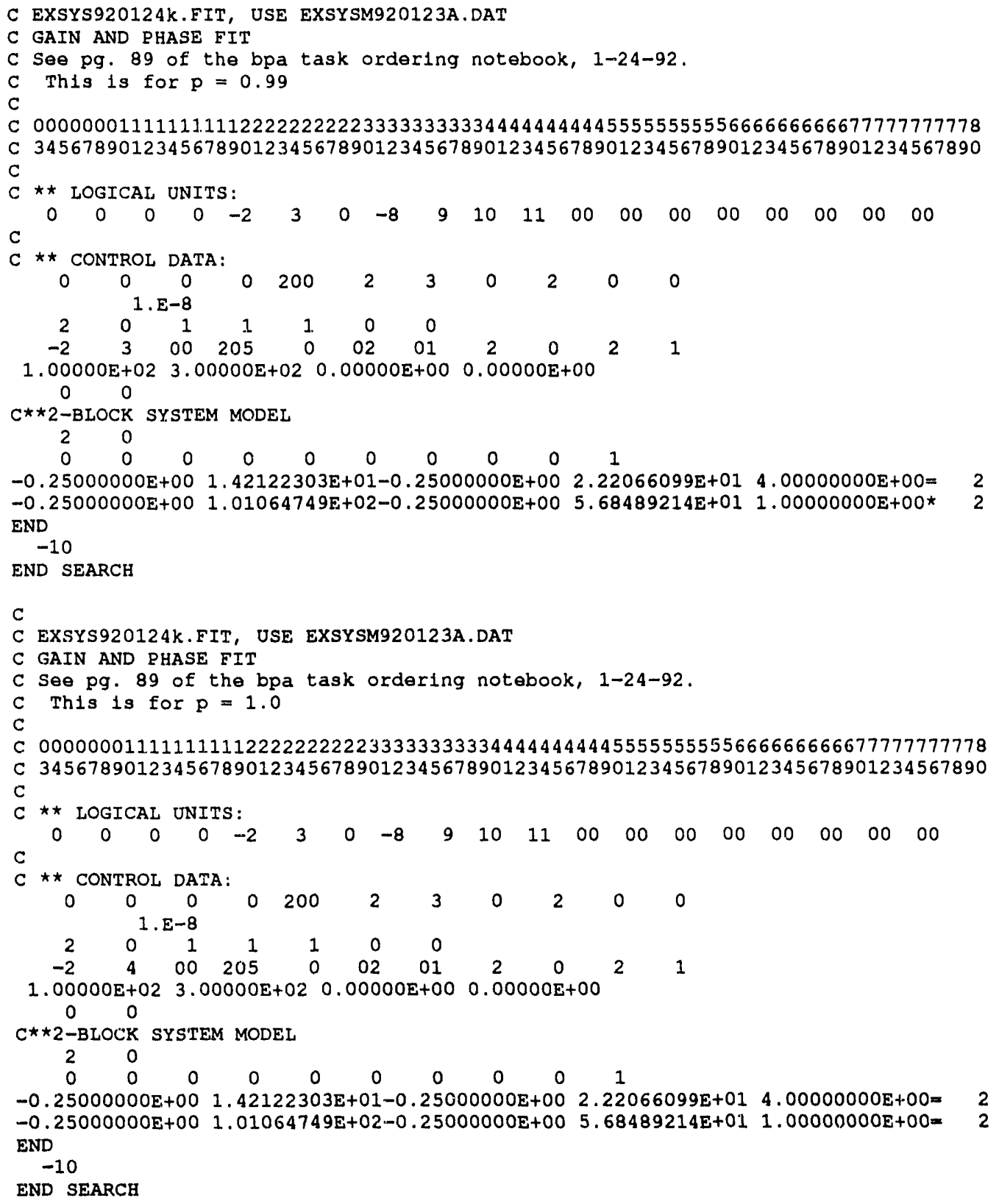

\section{Example 9:}

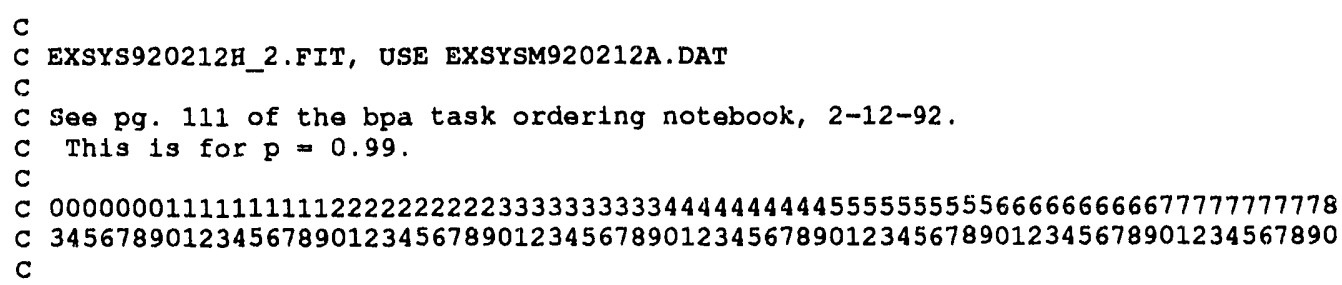




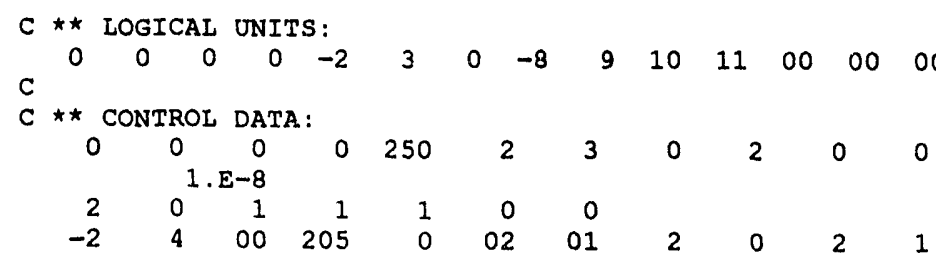

$-0.10000000 \mathrm{E}+00 \quad 1.66796300 \mathrm{E}+01-0.20000000 \mathrm{E}+00 \quad 4.83610600 \mathrm{E}+00 \quad 1.00000000 \mathrm{E}+00=$ $-0.10000000 \mathrm{E}+00 \quad 3.19775200 \mathrm{E}+01-0.50000000 \mathrm{E}-01 \quad 2.52661900 \mathrm{E}+01 \quad 1.00000000 \mathrm{E}+00 *$ $-0.50000000 E-01 \quad 8.88264400 E+01-0.50000000 E-01 \quad 3.94784200 E+01 \quad 1.00000000 E+00$ * $0.00000000 E+00 \quad 2.80000000 E+01 \quad 1.00000000 E+00 \quad 1.25664000 E+01 \quad 0.00000000 E+00 \star$ $-2.51330000 \mathrm{E}+00 \quad 6.31650000 \mathrm{E}+00-0.50000000 \mathrm{E}+00 \quad 5.65545954 \mathrm{E}+00 \quad 1.00000000 \mathrm{E}+00$ * END

$-10$

END SEARCH

\section{Example 10:}

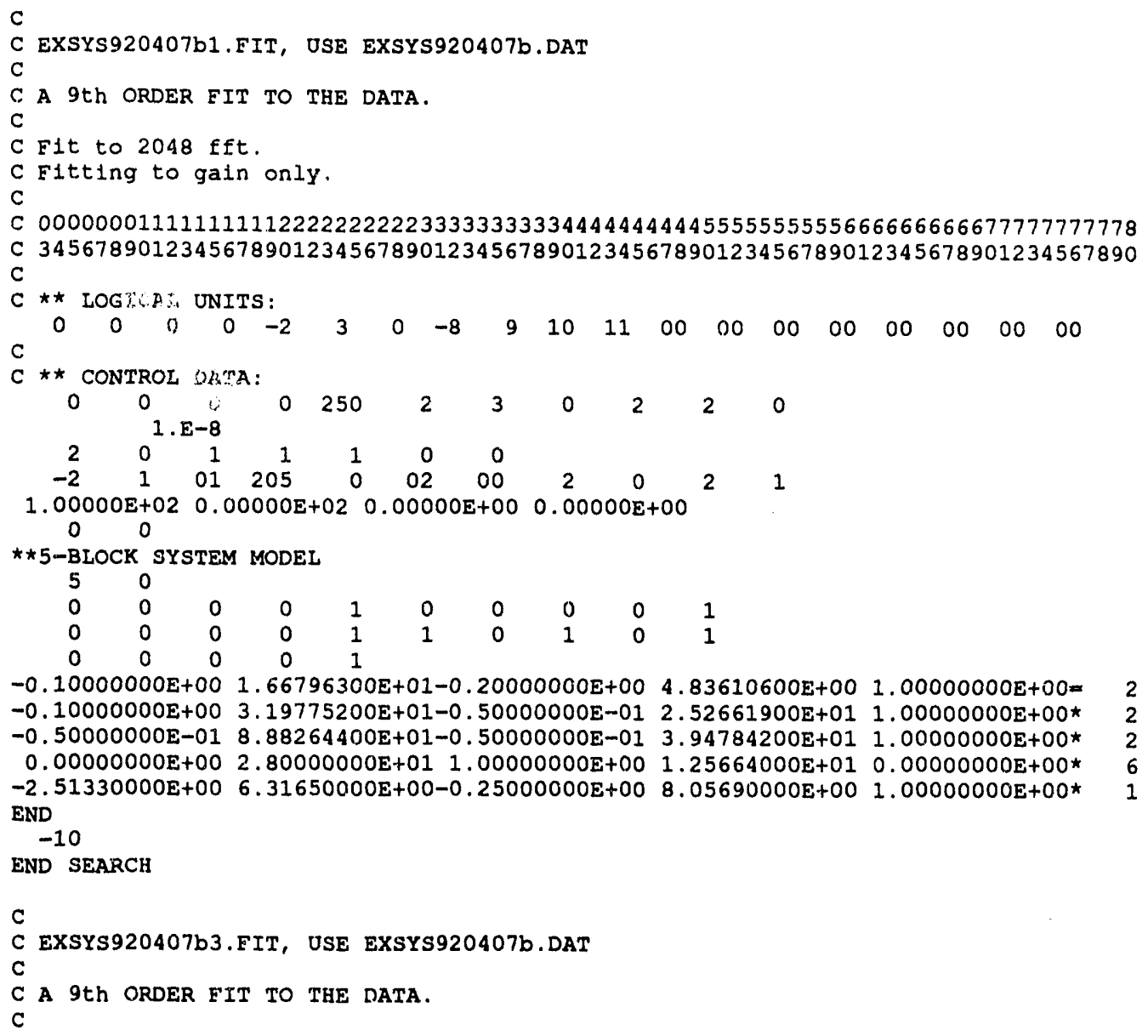


C Fit to 1536 fft.

C Fitting to gain only.

C

C 000000011111111112222222222333333333344444444445555555555666666666677777777778 C 345678901234567890123456789012345678901234567890123456789012345678901234567890 C

C * LOGICAL UNITS:

C

$\begin{array}{lllllllllllllllllll}0 & 0 & 0 & 0 & -2 & 3 & 0 & -8 & 9 & 10 & 11 & 00 & 00 & 00 & 00 & 00 & 00 & 00 & 00\end{array}$

C ** CONTROL DATA:

\begin{tabular}{rrrrrrrrrrr}
0 & 0 & 0 & 0 & 250 & 2 & 3 & 0 & 2 & 2 & 0 \\
& \multicolumn{1}{l}{$1 . \mathrm{E}-8$} & & & & & & & & \\
2 & 0 & 1 & 1 & 1 & 0 & 0 & & & & \\
-2 & 3 & 01 & 154 & 0 & 02 & 00 & 2 & 0 & 2 & 1
\end{tabular}

$\begin{array}{llll}1.00000 \mathrm{E}+02 & 0.00000 \mathrm{E}+02 & 0.00000 \mathrm{E}+00 & 0.00000 \mathrm{E}+00\end{array}$

00

**5-BLOCK SYSTEM MODEL

50

$\begin{array}{llllllllll}5 & 0 & 0 & 0 & 1 & 0 & 0 & 0 & 0 & 1 \\ 0 & 0 & 0 & 0 & 1 & 1 & 0 & 1 & 0 & 1\end{array}$

$.10000000 \mathrm{E}+00 \quad 1.66796300 \mathrm{E}+01-0.20000000 \mathrm{E}+00 \quad 4.83610600 \mathrm{E}+00 \quad 1.00000000 \mathrm{E}+00=$

$\begin{array}{llllll}-0.10000000 \mathrm{E}+00 & 1.66796300 \mathrm{E}+01-0.20000000 \mathrm{E}+00 & 4.83610600 \mathrm{E}+00 & 1.00000000 \mathrm{E}+00 \mathrm{E} \\ -0.10000000 \mathrm{E}+00 & 3.19775200 \mathrm{E}+01-0.50000000 \mathrm{E}-01 & 2.52661900 \mathrm{E}+01 & 1.00000000 \mathrm{E}+00 *\end{array}$

$-0.50000000 \mathrm{E}-01 \quad 8.88264400 \mathrm{E}+01-0.50000000 \mathrm{E}-01 \quad 3.94784200 \mathrm{E}+01 \quad 1.00000000 \mathrm{E}+00 *$

$0.00000000 \mathrm{E}+00 \quad 2.80000000 \mathrm{E}+01 \quad 1.00000000 \mathrm{E}+00 \quad 1.25664000 \mathrm{E}+010.00000000 \mathrm{E}+00 *$

$-2.51330000 \mathrm{E}+006.31650000 \mathrm{E}+00-0.25000000 \mathrm{E}+008.05690000 \mathrm{E}+001.00000000 \mathrm{E}+00$ *

END

$-10$

END SEARCH

C

C EXSYS920407b5.FIT, USE EXSYS920407b.DAT

C A 9th ORDER FIT TO THE DATA.

C

C Fit to 1024 fft.

C Fitting to gain only.

C

C 000000011111111112222222222333333333344444444445555555555666666666677777777778

c 345678901234567890123456789012345678901234567890123456789012345678901234567890 C

C ** LOGICAL UNITS:

$\begin{array}{lllllllllllllllllll}0 & 0 & 0 & 0 & -2 & 3 & 0 & -8 & 9 & 10 & 11 & 00 & 00 & 00 & 00 & 00 & 00 & 00 & 00\end{array}$

C

C * CONTROL DATA:

$\begin{array}{lllllllllll}0 & 0 & 0 & 0 & 250 & 2 & 3 & 0 & 2 & 2 & 0\end{array}$

$\begin{array}{rrrrrrrrrrr}1 . E-8 & & & & & & & & & & \\ -2 & 0 & 1 & 1 & 1 & 0 & 0 & & & \\ -2 & 5 & 01 & 103 & 0 & 02 & 0 & 2 & 0 & 2 & 1\end{array}$

$\begin{array}{lllll}.00000 \mathrm{E}+02 & 0.00000 \mathrm{E}+02 & 0.00000 \mathrm{E}+00 & 0.00000 \mathrm{E}+00\end{array}$

$0 \quad 0$

$\star * 5-B L O C K$ SYSTEM MODEL

50

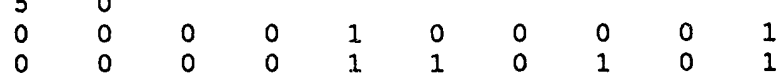

$\begin{array}{ccccc}0 & 0 & 0 & 0 & 1\end{array}$

$-0.10000000 \mathrm{E}+00 \quad 3.19775200 \mathrm{E}+01-0.50000000 \mathrm{E}-012.52661900 \mathrm{E}+01 \quad 1.00000000 \mathrm{E}+00$ *

$-0.50000000 \mathrm{E}-018.88264400 \mathrm{E}+0.1-0.50000000 \mathrm{E}-01 \quad 3.94784200 \mathrm{E}+011.00000000 \mathrm{E}+00$ *

$0.00000000 \mathrm{E}+00 \quad 2.80000000 \mathrm{E}+01 \quad 1.00000000 \mathrm{E}+00 \quad 1.25664000 \mathrm{E}+01 \quad 0.00000000 \mathrm{E}+00 *$

$-2.51330000 \mathrm{E}+00 \quad 6.31650000 \mathrm{E}+00-0.25000000 \mathrm{E}+00 \quad 8.05690000 \mathrm{E}+00 \quad 1.00000000 \mathrm{E}+00 *$

END

$-10$

END SEARCH

\section{Example 11:}

\section{A. 11}


C EXSYS920525b.FIT, USE EXSYSm920522b.DAT C A 9th ORDER FIT TO THE DATA.

C Fit to folding DFT of impulse response.

C Fitting to gain only.

C 000000011111111112222222222333333333344444444445555555555666666666677777777778 C 345678901234567890123456789012345678901234567890123456789012345678901234567890

$\star \star$ LOGICAL UNITS:

C

$\begin{array}{lllllllllllllllllll}0 & 0 & 0 & 0 & -2 & 3 & 0 & -8 & 9 & 10 & 11 & 00 & 00 & 00 & 00 & 00 & 00 & 00 & 00\end{array}$

C ** CONTROL DATA:

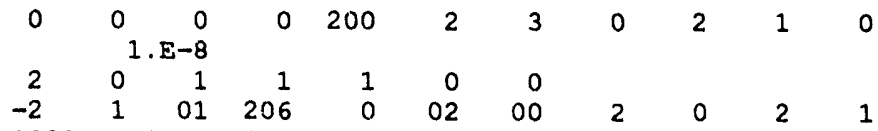

$\begin{array}{llll}1.00000 E+02 & 0.00000 E+02 & 0.00000 E+00 & 0.00000 E+00\end{array}$

$$
00
$$

* 5-BLOCK SYSTEM MODEL

$\begin{array}{llllllllll}5 & 0 & & & & & & & & \\ 0 & 0 & 0 & 0 & 1 & 0 & 0 & 0 & 0 & 1 \\ 0 & 0 & 0 & 0 & 1 & 1 & 0 & 1 & 0 & 1 \\ 0 & 0 & 0 & 0 & 1 & & & & \end{array}$

$-0.10000000 \mathrm{E}+00 \quad 1.66796300 \mathrm{E}+01-0.20000000 \mathrm{E}+00 \quad 4.83610600 \mathrm{E}+00 \quad 1.00000000 \mathrm{E}+00=2$ $-0.10000000 \mathrm{E}+00 \quad 3.19775200 \mathrm{E}+01-0.50000000 \mathrm{E}-012.52661900 \mathrm{E}+01 \quad 1.00000000 \mathrm{E}+00 * 2$ $\begin{array}{llllll}-0.50000000 \mathrm{E}-01 & 8.88264400 \mathrm{E}+01-0.50000000 \mathrm{E}-01 & 3.94784200 \mathrm{E}+01 & 1.00000000 \mathrm{E}+00 * & 2\end{array}$ $0.00000000 \mathrm{E}+00 \quad 2.80000000 \mathrm{E}+01 \quad 1.00000000 \mathrm{E}+00 \quad 1.25664000 \mathrm{E}+01 \quad 0.00000000 \mathrm{E}+00 * \quad 6$ $-2.51330000 \mathrm{E}+00 \quad 6.31650000 \mathrm{E}+00-0.25000000 \mathrm{E}+00 \quad 8.05690000 \mathrm{E}+00 \quad 1.00000000 \mathrm{E}+00$ * END

$-10$

END SEARCH

C EXSYS920319.FIT, USE EXSYS920319.DAT

C A 9th ORDER FIT TO THE DATA.

C Fit to BPADET of impulse response.

C Fitting to gain only.

C 000000011111111112222222222333333333344444444445555555555666666666677777777778 C 345678901234567890123456789012345678901234567890123456789012345678901234567890 C ** LOGICAL UNITS:

$\begin{array}{lllllllllllllllllll}0 & 0 & 0 & 0 & -2 & 3 & 0 & -8 & 9 & 10 & 11 & 00 & 00 & 00 & 00 & 00 & 00 & 00 & 00\end{array}$

$C \star \star$ CONTROL DATA:

$\begin{array}{llclllllll}0 & 0 & 0 & 0 & 250 & 2 & 3 & 0 & 2 & 0\end{array}$

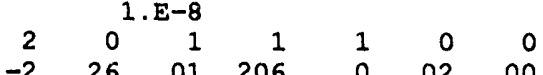

$1.00000 \mathrm{E}+02 \quad 0.00000 \mathrm{E}+02 \quad 0.00000 \mathrm{E}+00 \quad 0.00000 \mathrm{E}+00$

00

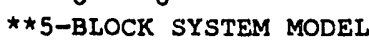

50

$\begin{array}{llllllllll}0 & 0 & 0 & 0 & 1 & 0 & 0 & 0 & 0 & 1 \\ 0 & 0 & 0 & 0 & 1 & 1 & 0 & 1 & 0 & 1\end{array}$

$-0.10000000 \mathrm{E}+00 \quad 1.66796300 \mathrm{E}+01-0.20000000 \mathrm{E}+00 \quad 4.83610600 \mathrm{E}+00 \quad 1.00000000 \mathrm{E}+00=2$

$-0.10000000 \mathrm{E}+00 \quad 3.19775200 \mathrm{E}+01-0.50000000 \mathrm{E}-01 \quad 2.52661900 \mathrm{E}+01 \quad 1.00000000 \mathrm{E}+00 *$

$\begin{array}{llllll}-0.50000000 \mathrm{E}-01 & 8.88264400 \mathrm{E}+01-0.50000000 \mathrm{E}-01 & 3.94784200 \mathrm{E}+01 & 1.00000000 \mathrm{E}+00 * & 2\end{array}$

$\begin{array}{lllllll}0.00000000 E+00 & 2.80000000 E+01 & 1.00000000 E+00 & 1.25664000 E+01 & 0.00000000 E+00 * & 6\end{array}$

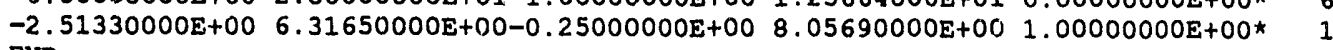
END

$-10$

END SEARCH 
C

C EXSYS920409b2.FIT, USE EXSYS920409.DAT

C A 9 th ORDER EIT TO THE DATA.

C Fit to BPADFT of nolsy impulse response. Nolse=1/f with var=1

C Fitting to gain only.

C 000000011111111112222222222333333333344444444445555555555666666666677777777778

C 345678901234567890123456789012345678901234567890123456789012345678901234567890

C

$C \star \star$ LOGICAL UNITS:

C
$\begin{array}{lllllllllllllllllll}0 & 0 & 0 & 0 & -2 & 3 & 0 & -8 & 9 & 10 & 1.1 & 00 & 00 & 00 & 00 & 00 & 00 & 00 & 00\end{array}$

C * CONTROL DATA:

$\begin{array}{llllllllll}0 & 0 & 0 & 0 & 250 & 2 & 3 & 0 & 2 & 2\end{array}$

$\begin{array}{rrrrrrrrrr}2 & 0 & 1 & 1 & 1 & 0 & 0 & & & \\ -2 & 6 & 01 & 206 & 0 & 02 & 00 & 2 & 0 & 2\end{array}$

$\begin{array}{llll}1.00000 \mathrm{E}+02 & 0.00000 \mathrm{E}+02 & 0.00000 \mathrm{E}+00 & 0.00000 \mathrm{E}+00\end{array}$

00

**5-BLOCK SYSTEM MODEL

$\begin{array}{llllllllll}5 & 0 & & 0 & 1 & 0 & 0 & 0 & 0 & 1 \\ 0 & 0 & 0 & 0 & 1 & 1 & 0 & 1 & 0 & 1 \\ 0 & 0 & 0 & 0 & 1 & \end{array}$

$-0.10000000 E+001.66796300 E+01-0.20000000 E+00 \quad 4.83610600 E+00 \quad 1.00000000 E+00=$

$-0.10000000 \mathrm{E}+00 \quad 3.19775200 \mathrm{E}+01-0.50000000 \mathrm{E}-012.52661900 \mathrm{E}+01 \quad 1.00000000 \mathrm{E}+00$ *

$-0.50000000 \mathrm{E}-018.88264400 \mathrm{E}+01-0.50000000 \mathrm{E}-013.94784200 \mathrm{E}+011.00000000 \mathrm{E}+00 *$

$0.00000000 E+00 \quad 2.80000000 E+01 \quad 1.00000000 E+00 \quad 1.25664000 E+010.00000000 E+00 *$

$-2.51330000 \mathrm{E}+00 \quad 6.31650000 \mathrm{E}+00-0.25000000 \mathrm{E}+00 \quad 8.05690000 \mathrm{E}+00 \quad 1.00000000 \mathrm{E}+00$ *

END

$-10$

END SEARCH

C

EXSYS920525a.FIT, USE EXSYSm920522a.DAT

C

C A 9 th ORDER FIT TO THE DATA.

C

C Fit to folding DFT of nolsy impulse response. No1se=1/f with var=1.

C Fitting to gain only.

C 000000011111111112222222222333333333344444444445555555555666666666677777777778

C 345678901234567890123456789012345678901234567890123456789012345678901234567890

C

$C \star *$ LOGICAL UNITS:

$\begin{array}{lllllllllllllllllll}0 & 0 & 0 & 0 & -2 & 3 & 0 & -8 & 9 & 10 & 11 & 00 & 00 & 00 & 00 & 00 & 00 & 00 & 00\end{array}$

C $\star *$ CONTROL DATA:

$\begin{array}{lcccccccccc}0 & 0 & 0 & 0 & 200 & 2 & 3 & 0 & 2 & 1 & 0\end{array}$

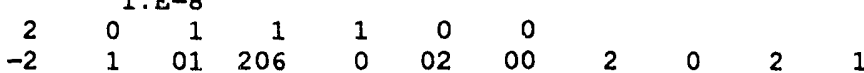

$\begin{array}{llll}1.00000 \mathrm{E}+02 & 0.00000 \mathrm{E}+02 & 0.00000 \mathrm{E}+00 & 0.00000 \mathrm{E}+00\end{array}$

$0 \quad 0$

$\star \star 5-B L O C K$ SYSTEM MODEL

$\begin{array}{llllllllll}5 & 0 & & & & & 0 & 0 & 0 & 1 \\ 0 & 0 & 0 & 0 & 1 & 0 & 0 & 1 & 0 & 1 \\ 0 & 0 & 0 & 0 & 1 & 1 & 0 & 1\end{array}$

$-0.10000000 \mathrm{E}+001.66796300 \mathrm{E}+01-0.20000000 \mathrm{E}+00 \quad 4.83610600 \mathrm{E}+00 \quad 1.00000000 \mathrm{E}+00=$ $-0.10000000 \mathrm{E}+00 \quad 3.19775200 \mathrm{E}+01-0.50000000 \mathrm{E}-01 \quad 2.52661900 \mathrm{E}+01 \quad 1.00000000 \mathrm{E}+00 *$ $-0.50000000 \mathrm{E}-01 \quad 8.88264400 \mathrm{E}+01-0.50000000 \mathrm{E}-01 \quad 3.94784200 \mathrm{E}+01 \quad 1.00000000 \mathrm{E}+00 *$

$0.00000000 \mathrm{E}+00 \quad 2.80000000 \mathrm{E}+01 \quad 1.00000000 \mathrm{E}+00 \quad 1.25664000 \mathrm{E}+010.00000000 \mathrm{E}+00 *$ $-2.51330000 E+00 \quad 6.31650000 E+00-0.25000000 E+00 \quad 8.05690000 E+001.00000000 E+00 \star$ END

$-10$

END SEARCB 


\section{Example 12:}

c

C EXSYS920409b1.FIT, USE EXSYS920409.DAT

C

C A 9th ORDER FIT TO THE DATA.

C

C Fit to fft of noisy 1mpulse response. Noise=white with var=1.

C Fitting to gain only.

C

c 000000011111111112222222222333333333344444444445555555555666666666677777777778 c 345678901234567890123456789012345678901234567890123456789012345678901234567890 C

$C \star \star$ LOGICAL UNITS:

C $\star \star$ CONTROL DATA:

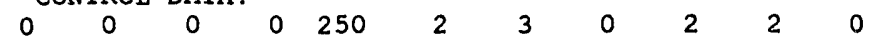

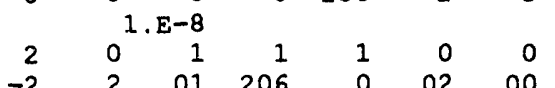

$\begin{array}{lllll}0 & 2 & 0 & 2 & 1\end{array}$

$\begin{array}{llll}1.00000 E+02 & 0.00000 E+02 & 0.00000 E+00 & 0.00000 E+00\end{array}$

$$
00
$$

**5-BLOCK SYSTEM MODEL

$$
\begin{array}{ccc}
0 & 0 \\
2 & 0
\end{array}
$$

$\begin{array}{llllllllll}5 & 0 & & & & & & & & \\ 0 & 0 & 0 & 0 & 1 & 0 & 0 & 0 & 0 & 1\end{array}$

$\begin{array}{llllllllll}0 & 0 & 0 & 0 & 1 & 1 & 0 & 1 & 0 & 1\end{array}$

$-0.10000000 \mathrm{E}+00 \quad 1.66796300 \mathrm{E}+01-0.20000000 \mathrm{E}+00 \quad 4.83610600 \mathrm{E}+00 \quad 1.00000000 \mathrm{E}+00 \mathrm{E}$ $-0.10000000 \mathrm{E}+00 \quad 3.19775200 \mathrm{E}+01-0.50000000 \mathrm{E}-012.52661900 \mathrm{E}+01 \quad 1.00000000 \mathrm{E}+00 *$

$-0.50000000 \mathrm{E}-01 \quad 8.88264400 \mathrm{E}+01-0.50000000 \mathrm{E}-01 \quad 3.94784200 \mathrm{E}+01 \quad 1.00000000 \mathrm{E}+00 *$

$0.00000000 \mathrm{E}+00 \quad 2.80000000 \mathrm{E}+01 \quad 1.00000000 \mathrm{E}+00 \quad 1.25664000 \mathrm{E}+01 \quad 0.00000000 \mathrm{E}+00$ * $-2.51330000 E+00 \quad 6.31650000 E+00-0.25000000 E+00 \quad 8.05690000 E+00 \quad 1.00000000 E+00 *$ END

$-10$

END SEARCH

C

C EXSYS920409d1.FIT, USE EXSYS920409.DAT

C

C A 9th ORDER FIT TO THE DATA.

C F1t to fft of nolsy impulse response. No1semwite with var $=10$.

C Fitting to gain only.

c 000000011111111112222222222333333333344444444445555555555666566666677777777778

C 345678901234567890123456789012345678901234567890123456789012345678901234567890

$C \star \star$ LOGICAL UNITS:

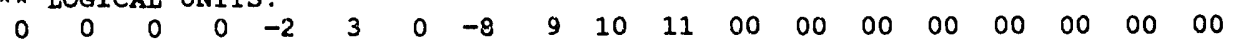

$C \star \star$ CONTROL DATA:

$\begin{array}{lcccccccccc}0 & 0 & 0 & 0 & 250 & 2 & 3 & 0 & 2 & 2 & 0\end{array}$

$\begin{array}{rrrrrrrrrrr}2 & 0 & 1 & 1 & 1 & 0 & 0 & & & \\ -2 & 4 & 01 & 206 & 0 & 02 & 00 & 2 & 0 & 2 & 1\end{array}$

$\begin{array}{lll}1.00000 \mathrm{E}+02 & 0.00000 \mathrm{E}+02 \quad 0.00000 \mathrm{E}+00 \quad 0.00000 \mathrm{E}+00\end{array}$

S-BLOCK SYSTEM MODEL

**5-BLOCK

$\begin{array}{llllllllll}5 & 0 & & & 1 & 0 & 0 & 0 & 0 & 1 \\ 0 & 0 & 0 & 0 & 1 & 1 & 0 & 1 & 0 & 1 \\ 0 & 0 & 0 & 0 & 1 & 1\end{array}$

$-0.10000000 \mathrm{E}+00 \quad 1.66796300 \mathrm{E}+01-0.20000000 \mathrm{E}+00 \quad 4.83610600 \mathrm{E}+00 \quad 1.00000000 \mathrm{E}+00 \mathrm{E}$

$-0.10000000 \mathrm{E}+00 \quad 3.19775200 \mathrm{E}+01-0.50000000 \mathrm{E}-012.52661900 \mathrm{E}+01 \quad 1.00000000 \mathrm{E}+00$ *

$-0.50000000 \mathrm{E}-01 \quad 8.88264400 \mathrm{E}+01-0.50000000 \mathrm{E}-01 \quad 3.94784200 \mathrm{E}+01 \quad 1.00000000 \mathrm{E}+00$ *

$0.00000000 \mathrm{E}+00 \quad 2.80000000 \mathrm{E}+01 \quad 1.00000000 \mathrm{E}+001.25664000 \mathrm{E}+01 \quad 0.00000000 \mathrm{E}+00$ * 
$-2.51333000 \mathrm{E}+00 \quad 6.31650000 \mathrm{E}+00-0.25000000 \mathrm{E}+00 \quad 8.05690000 \mathrm{E}+001.00000000 \mathrm{E}+00 *$ END

$-10$

END SEARCH

\section{Example 13:}

C EXSYS920409C1.FIT, USE EXSYS920409.DAT

C A 9th ORDER FIT TO THE DATA.

C Fit to fft of nolsy impulse response. No1semwite with var=5.

C Fitting to gain only.

000000011111111112222222222333333333344444444445555555555666666666677777777778 C 345678901234567890123456789012345678901234567890123456789012345678901234567890

C $\star \star$ LOGICAL UNITS:

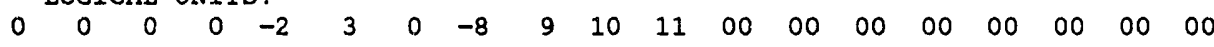

C $\star *$ CONTROL DATA:

$\begin{array}{llcllllllll}0 & 0 & 0 & 0 & 250 & 2 & 3 & 0 & 2 & 2 & 0\end{array}$

$2 \quad 1 . \mathrm{E}-8$

$\begin{array}{lllllllllllll}-2 & 3 & 01 & 206 & 0 & 02 & 00 & 2 & 0 & 2 & 1\end{array}$

$\begin{array}{llll}1.00000 \mathrm{E}+02 & 0.00000 \mathrm{E}+02 \quad 0.00000 \mathrm{E}+00 \quad 0.00000 \mathrm{E}+00\end{array}$

00

**5-BLOCK SYSTEM MODEI

$\begin{array}{llllllllll}5 & 0 & & & & & & & \\ 0 & 0 & 0 & 0 & 1 & 0 & 0 & 0 & 0 & 1 \\ 0 & 0 & 0 & 0 & 1 & 1 & 0 & 1 & 0 & 1 \\ 0 & 0 & 0 & 0 & 1 & \end{array}$

$-0.10000000 \mathrm{E}+00 \quad 1.66796300 \mathrm{E}+01-0.20000000 \mathrm{E}+00 \quad 4.83610600 \mathrm{E}+00 \quad 1.00000000 \mathrm{E}+00 \mathrm{E}$ $-0.10000000 \mathrm{E}+00 \quad 3.19775200 \mathrm{E}+01-0.50000000 \mathrm{E}-01 \quad 2.52661900 \mathrm{E}+01 \quad 1.00000000 \mathrm{E}+00$ * $\begin{array}{llllll}-0.50000000 E-01 & 8.88264400 E+01-0.50000000 E-01 & 3.94784200 E+01 & 1.00000000 E+00 *\end{array}$

$0.00000000 \mathrm{E}+00 \quad 2.80000000 \mathrm{E}+01 \quad 1.00000000 \mathrm{E}+00 \quad 1.25664000 \mathrm{E}+010.00000000 \mathrm{E}+00 *$ $-2.51330000 \mathrm{E}+006.31650000 \mathrm{E}+00-0.25000000 \mathrm{E}+00 \quad 8.05690000 \mathrm{E}+00 \quad 1.00000000 \mathrm{E}+00$ * END

$-10$

END SEARCH

C

C EXSYS920409C2.FIT, USE EXSYS920409.DAT

C

C A 9th ORDER EIT TO THE DATA.

C Fit to fft of noisy impulse response. Nolse=1/f with var=5

C Fitting to gain only.

C 000000011111111112222222222333333333344444444445555555555666666666677777777778

C 345678901234567890123456789012345678901234567890123456789012345678901234567890 C

C $\star \star$ IOGICAL UNITS:

C

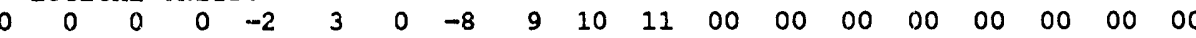

C $\star \star$ CONTROL DATA:

$\begin{array}{llllllllll}0 & 0 & 0 & 0 & 250 & 2 & 3 & 0 & 2 & 2\end{array}$

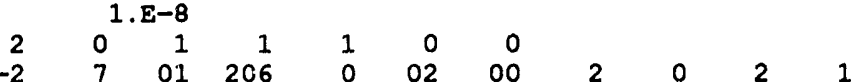

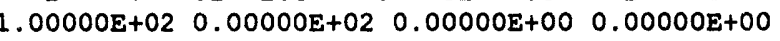

00

**5-BLOIK SYSTEM MODEL

50

(0)

0

0

A.15 


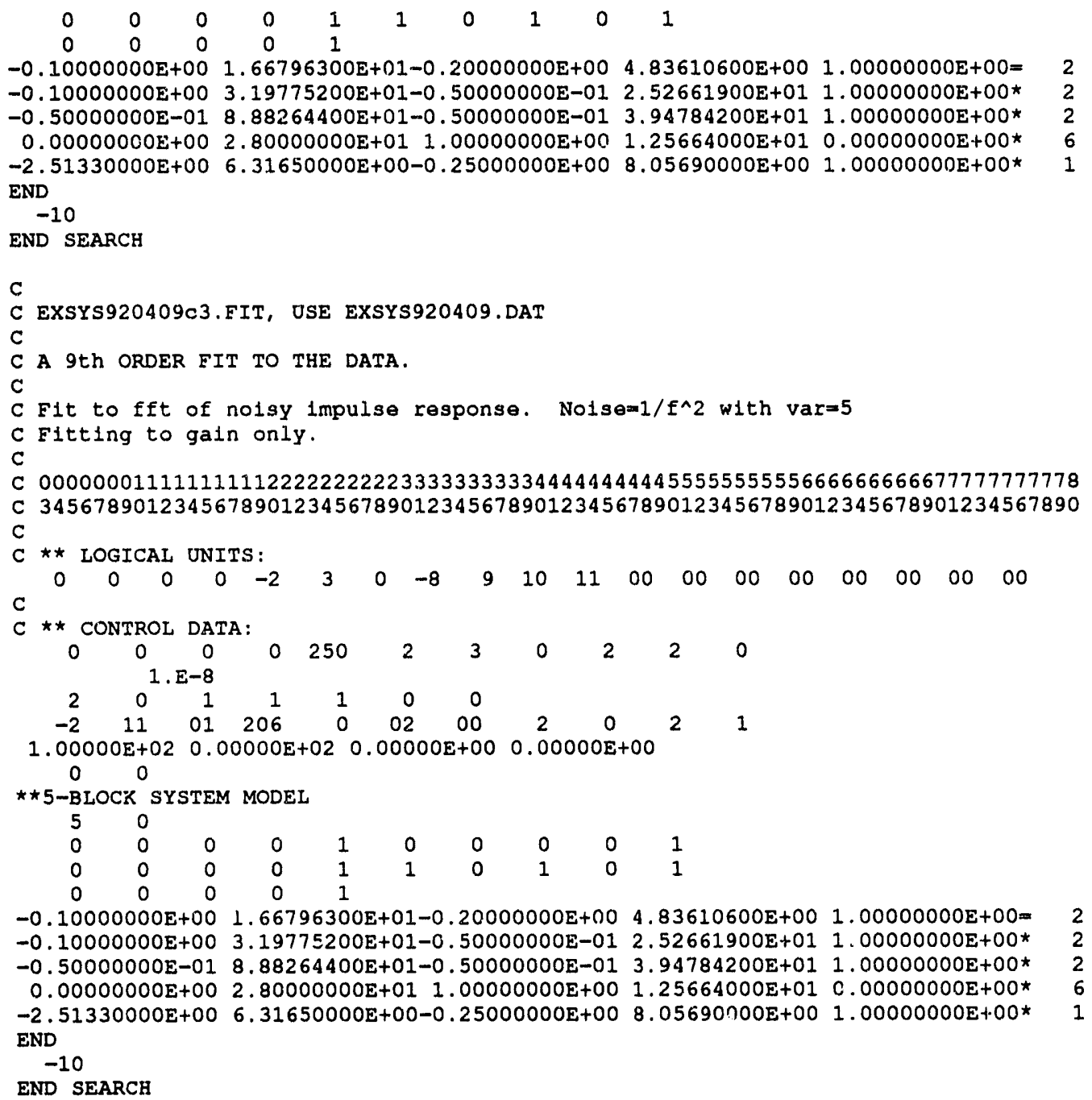

\section{Example 14:}

C

C EXSYS920409C4.FIT, OSE EXSYS920409.DAT

C

C A 9th ORDFR FIT TO THE DATA.

C

C F1t to fft of nolsy impulse response. Molse=colored with varm 5

C Fitting to gain only.

C

C $0000000111111111122222222 ? 2333333333344444444445555555555666666666677777777778$

C 345678901234567890123456789012345678901234567890123456789012345678901234567890 C

C $\star \star$ LOGICAL ONITS :

C

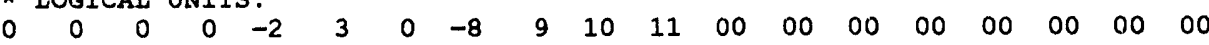

C ** CONTROL DATA:

$\begin{array}{lcrrrrrrrrr}0 & 0 & 0 & 0 & 250 & 2 & 3 & 0 & 2 & 2 & 0 \\ & 0 & 0 & 1 . E-8 & 1 & 1 & 0 & 0 & & & \end{array}$


$\begin{array}{lllllllllll}-2 & 15 & 01 & 206 & 0 & 02 & 00 & 2 & 0 & 2 & 1\end{array}$

1. $.00000 \mathrm{E}+02 \quad 0.00000 \mathrm{E}+02 \quad 0.00000 \mathrm{E}+00 \quad 0.00000 \mathrm{E}+00$

$$
00
$$

**5-BLOCK SYSTEM MODEL

$$
\begin{array}{llllllllll}
5 & 0 & & & & 0 & 0 & 0 & 0 & 1 \\
0 & 0 & 0 & 0 & 1 & 0 & 0 & 1 & 0 & 1 \\
0 & 0 & 0 & 0 & 1 & 1 & 0 & 1 & &
\end{array}
$$

$-0.10000000 E+00 \quad 1.66796300 E+01-0.20000000 E+00 \quad 4.83610600 E+00 \quad 1.00000000 E+00=$ $-0.10000000 E+00 \quad 3.19775200 E+01-0.50000000 E-01 \quad 2.52661900 E+01 \quad 1.00000000 E+00 *$ $-0.50000000 \mathrm{E}-01$ 8.88264400E+01-0.50000000E-01 3.94784200E+01 $1.00000000 \mathrm{E}+00 *$ $0.00000000 \mathrm{E}+002.80000000 \mathrm{E}+011.00000000 \mathrm{E}+001.25664000 \mathrm{E}+010.00000000 \mathrm{E}+00 *$ $-2.51330000 \mathrm{E}+00 \quad 6.31650000 \mathrm{E}+00-0.25000000 \mathrm{E}+00 \quad 8.05690000 \mathrm{E}+00 \quad 1.00000000 \mathrm{E}+00 *$ END

$-10$

END SEARCH

\section{Example 15:}

C EXSYS920622b_4.FIT, USE EXSYS920517.DAT

C Fitting to PNLSYS3 (SIMO) system. Exact frequency response.

C Poles are fit to both paths.

C Gain fit to output 2 only.

C 000000011111111112222222222333333333344444444445555555555666666666677777777778 C 345678901234567890123456789012345678901234567890123456789012345678901234567890 C

$C \star \star$ LOGICAL UNITS:

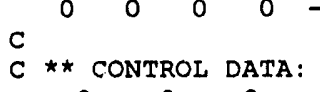

$$
\begin{array}{rrrrrrrrrrr}
0 & 0 & 0 & 0 & 550 & 2 & 3 & 0 & 2 & 0 & 0 \\
& \multicolumn{1}{c}{1 . \mathrm{E}-8} & & & & & & & & \\
2 & 0 & 1 & 1 & 1 & 0 & 0 & & & & \\
-2 & 2 & 01 & 103 & 0 & 02 & 00 & 2 & 0 & 2 & 1
\end{array}
$$

$\begin{array}{llll}1.00000 E+02 & 0.00000 E+02 & 0.00000 E+00 & 0.00000 E+00\end{array}$

00

C $\star \star$ PATH $2,4-B L O C K$ SYSTEM MODEL

40

$\begin{array}{llllllllll}0 & 0 & 0 & 0 & 1 & 0 & 0 & 0 & 0 & 1 \\ 0 & 0 & 0 & 0 & 0 & 0 & 0 & 0 & 0 & 1\end{array}$

$2.82743340 \mathrm{E}+00-3.94784200 \mathrm{E}+00-0.20000000 \mathrm{E}+00 \quad 4.87610600 \mathrm{E}+00 \quad 1.00000000 \mathrm{E}+00=$ $-1.00000000 \mathrm{E}+00 \quad 2.91075500 \mathrm{E}+00-0.25000000 \mathrm{E}+00 \quad 8.05690000 \mathrm{E}+00 \quad 1.00000000 \mathrm{E}+00 *$ $-0.25000000 \mathrm{E}+002.52661 .900 \mathrm{E}+01-0.05000000 \mathrm{E}+00 \quad 2.52661900 \mathrm{E}+01 \quad 1.00000000 \mathrm{E}-02 \star$ $-1.00000000 \mathrm{E}+001.57913700 \mathrm{E}+02-0.05000000 \mathrm{E}+00 \quad 3.94784200 \mathrm{E}+011.00000000 \mathrm{E}+00 *$ END

$-10$

END SEARCH

C EXSYS920622C_7.FIT, USE EXSYS920517.DAT

C Fitting to R.iLSYS3 (SIMO) system. Exact frequency response.

C Poles are fit to output 1.

C Gain fit to both outputs.

C 000000011111111112222222222333333333344444444445555555555666666666677777777778 C 345678901234567890123456789012345678901234567890123456789012345678901234567890 C

$C \star \star$ LOGICAL UNITS:

c

C $\star \star$ CONTROL DATA:

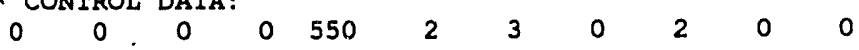




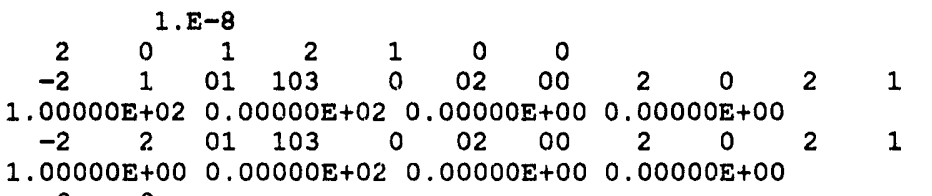

$1.00000 \mathrm{E}+00 \quad 0.00000 \mathrm{E}+02 \quad 0.00000 \mathrm{E}+00 \quad 0.00000 \mathrm{E}+00$

C*PATH $1,5-B L O C K$ SYSTEM MODEL

$\begin{array}{llllll}5 & 0 & & & \\ 0 & 0 & 0 & 0 & 1 & 0\end{array}$

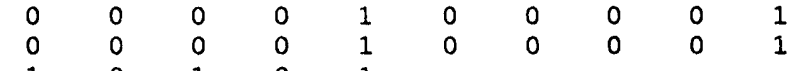

$-0.10000000 \mathrm{E}+00 \quad 1.66896300 \mathrm{E}+01-0.20000000 \mathrm{E}+00 \quad 4.87610600 \mathrm{E}+00 \quad 1.00000000 \mathrm{E}+00 \mathrm{E}$ $-2.51330000 \mathrm{E}+00 \quad 6.31650000 \mathrm{E}+00-0.25000000 \mathrm{E}+00 \quad 8.05690000 \mathrm{E}+00 \quad 1.00000000 \mathrm{E}+00 *$ $-0.10000000 \mathrm{E}+00 \quad 3.19775200 \mathrm{E}+01-0.50000000 \mathrm{E}-012.52661900 \mathrm{E}+01 \quad 1.00000000 \mathrm{E}+00 *$

$-0.50000000 \mathrm{E}-01 \quad 8.88264400 \mathrm{E}+01-0.50000000 \mathrm{E}-01 \quad 3.94784200 \mathrm{E}+01 \quad 1.00000000 \mathrm{E}+00 *$ $0.00000000 \mathrm{E}+00 \quad 2.80000000 \mathrm{E}+01 \quad 1.00000000 \mathrm{E}+00 \quad 1.25664000 \mathrm{E}+01 \quad 0.00000000 \mathrm{E}+00$ * $C \star \star \mathrm{PATH} 2,4-\mathrm{BLOCK}$ SYSTEM MODEL

40

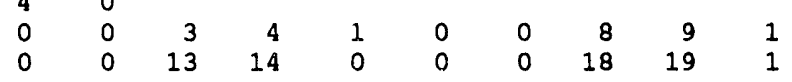

$2.82743340 \mathrm{E}+00-3.94784200 \mathrm{E}+00-0.20000000 \mathrm{E}+00 \quad 4.87610600 \mathrm{E}+00 \quad 1.00000000 \mathrm{E}+00=$ $-1.00000000 E+002.91075500 E+00-0.25000000 E+00 \quad 8.05690000 E+001.00000000 E+00 \star$ $-0.25000000 \mathrm{E}+00 \quad 2.52661900 \mathrm{E}+01-0.05000000 \mathrm{E}+00 \quad 2.52661900 \mathrm{E}+01 \quad 1.00000000 \mathrm{E}-02 \star$ $-1.00000000 \mathrm{E}+001.57913700 \mathrm{E}+02-0.05000000 \mathrm{E}+003.94784200 \mathrm{E}+011.00000000 \mathrm{E}+00$ * END

$-10$

END SEARCH 


\section{Distribution}

No. of

Copies

Offsite

12

DOE/Office of Scientific and Technical Information

2 J. F. Hauer, EOH

Bonneville Power Administration

P.O. Box 3621

Portland, OR 97208

L. L. Scharf

Department of Electrical and Computer Engineering

Engineering Center OT 3-12

University of Colorado at Boulder

Boulder, CO 80309-0425

\section{J. Agee}

M.S. D-3772

U.S. Bureau of Reclamation

P.O. Box 25007

Denver, CO 80225

D. A. Pierre

Electrical Engineering Department

Montana State University

Bozeman, MT 59717
No. of

Copies

Onsite

Department of Energy Richland Field Office

D. R. Segna

19

Pacific Northwest Laboratory

M. K. Donnelly

D. M. Elwood

L. D. Kannberg

D. J. Trudnowski (10)

Publishing Coordination

Technical Report Files (5) 


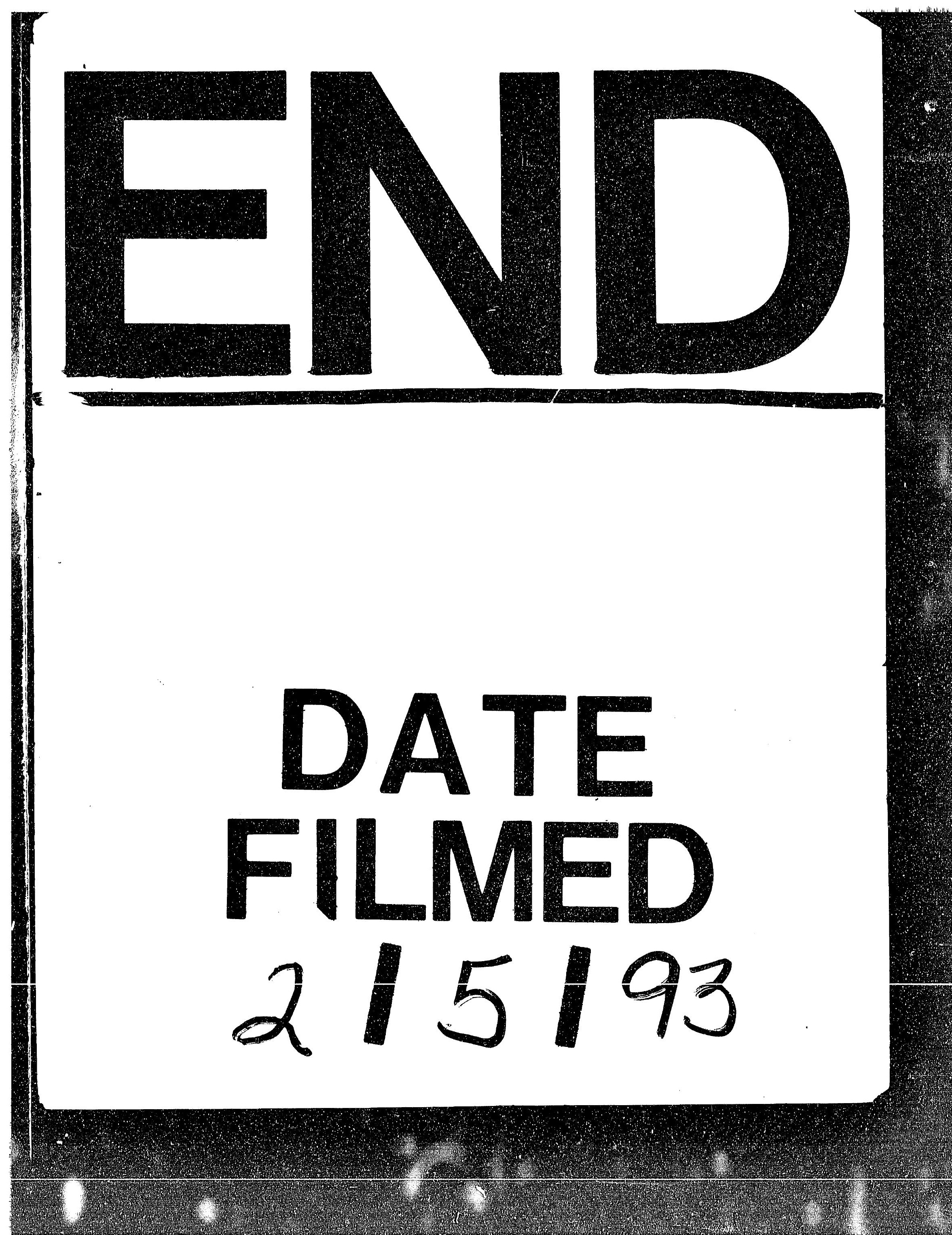


